San Jose State University

SJSU ScholarWorks

Master's Theses

Master's Theses and Graduate Research

Spring 2017

\title{
Temporal and Spatial Impacts of Water Control Structures on the Benthic Infaunal Community of a Tidally Restricted Wetland in Elkhorn Slough, CA
}

Christine Marie Mann

San Jose State University

Follow this and additional works at: https://scholarworks.sjsu.edu/etd_theses

\section{Recommended Citation}

Mann, Christine Marie, "Temporal and Spatial Impacts of Water Control Structures on the Benthic Infaunal Community of a Tidally Restricted Wetland in Elkhorn Slough, CA" (2017). Master's Theses. 4810. DOI: https://doi.org/10.31979/etd.5ga5-7vxc

https://scholarworks.sjsu.edu/etd_theses/4810

This Thesis is brought to you for free and open access by the Master's Theses and Graduate Research at SJSU ScholarWorks. It has been accepted for inclusion in Master's Theses by an authorized administrator of SJSU ScholarWorks. For more information, please contact scholarworks@sjsu.edu. 
TEMPORAL AND SPATIAL IMPACTS OF WATER CONTROL STRUCTURES ON THE BENTHIC INFAUNAL COMMUNITY OF A TIDALLY RESTRICTED WETLAND IN ELKHORN SLOUGH, CA

\author{
A Thesis \\ Presented to \\ The Faculty of the Moss Landing Marine Laboratories \\ San José State University
}

\author{
In Partial Fulfillment \\ of the Requirements for the Degree \\ Master of Science
}

by

Christine Marie Mann

June 2017 
(C) 2017

Christine M. Mann

ALL RIGHTS RESERVED 
The Designated Thesis Committee Approves the Thesis Titled

TEMPORAL AND SPATIAL IMPACTS OF WATER CONTROL STRUCTURES ON THE BENTHIC INFAUNAL COMMUNITY OF A TIDALLY RESTRICTED WETLAND IN ELKHORN SLOUGH, CA

by

Christine Marie Mann

APPROVED FOR THE DEPARTMENT OF MARINE SCIENCE

SAN JOSÉ STATE UNIVERSITY

May 2017

Dr. Ivano Aiello

Moss Landing Marine Laboratories

Dr. John Oliver

Moss Landing Marine Laboratories

Dr. Kenneth Coale

Moss Landing Marine Laboratories 


\section{ABSTRACT \\ TEMPORAL AND SPATIAL IMPACTS OF WATER CONTROL STRUCTURES ON THE BENTHIC INFAUNAL COMMUNITY OF A TIDALLY RESTRICTED WETLAND IN ELKHORN SLOUGH, CA \\ by Christine Marie Mann}

North Azevedo Pond in Elkhorn Slough, CA is a partially tidally restricted wetland that underwent an experimental ponding manipulation which increased inundation and tidal mixing within the system. This wetland has two spatially significant infaunal microsystems, south and north. Benthic cores taken before and after the manipulation showed that both the south and north infaunal communities remained dominated by the same major taxa, respectively. Both systems, however, experienced species shifts following the ponding manipulation. In the South, thenon-native bivalve, Gemma gemma, declined from an average of 19,103 to 385 individuals $\left(\mathrm{m}^{2}\right)^{-1}$ whereas the native clam, Nutricola tantilla, increased from an average of 128 to 26,154 individuals $\left(\mathrm{m}^{2}\right)^{-1}$. In the north, Capitella teleta declined from an average of 15,256 to 1,667 individuals $\left(\mathrm{m}^{2}\right)^{-1}$, while Pseudopolydora kempi, increased from a mean of 7,436 to 38,077 individuals $\left(\mathrm{m}^{2}\right)^{-1}$. Overall, the hydrographic manipulations were successful in improving water quality by increasing ponding and creating more complex infaunal communities than those present prior to the ponding manipulation. 


\section{ACKNOWLEDGMENTS}

I want to thank the Benthic Lab for sharing their data sets to supplement my own data collection. I want to thank all the taxonomists whom enabled me to power through identifying all of my critters. Thank you to my two interns, Imani and Enio, for their hard work ethic and taxonomic prowess. Lastly, thank you to all the folks at ESNERR and ESF for helping me carry out my thesis project with data, background information, and access to my study site. Crucial funding for this thesis came from San Jose State University, CCR, and Myers Ocean Trust.

Thank you to my committee members especially John Oliver for his refreshingly unconventional style of advising. I am inspired by his vast knowledge of the natural world, and I hope to know even a little bit of what he knows by the end of my lifetime. This thesis would not have been possible without my unofficial advisor, Kamille Hammerstrom. I will never forget her kindness, patience, and willingness always to set aside time to help me with any aspect of my thesis.

Most importantly, I'd like to thank my family. Mom, it means so much to me that you have always shown me unwavering love and support towards me. Katherine, Carolyn, and Evelyn, you are all so dear to me, and I am grateful for the love and respect you give me. Lastly, thank you Corey, for being there for me through the last haul of my thesis, and for keeping me focused at the task at hand. 


\section{TABLE OF CONTENTS}

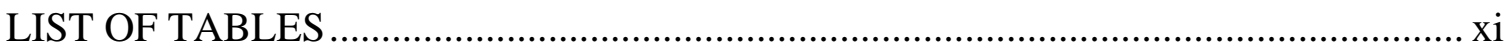

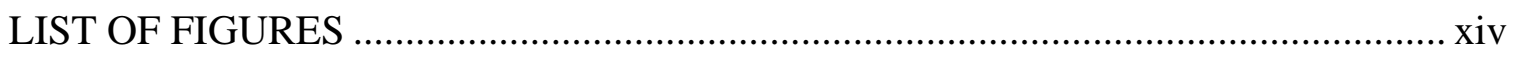

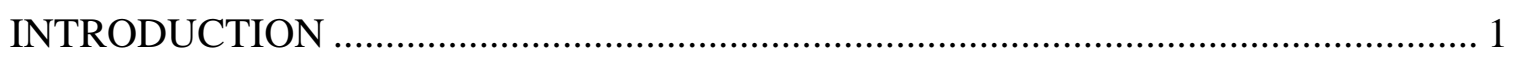

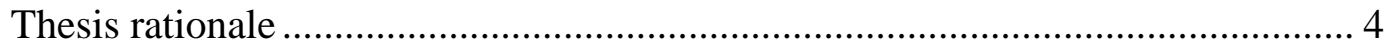

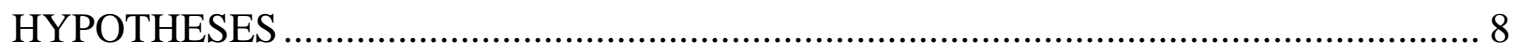

MATERIALS AND METHODS....................................................................... 9

Study area and study system ………………………….................................... 9

Pre-manipulation system............................................................................... 9

Post-manipulation system ............................................................................. 11

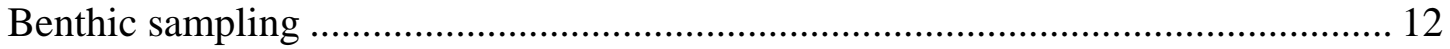



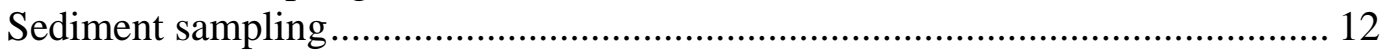

Environmental sampling ...................................................................................... 15

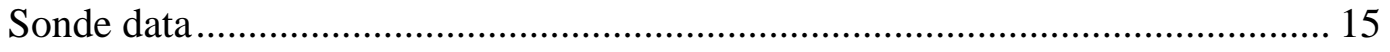

Spatial environmental description................................................................ 16

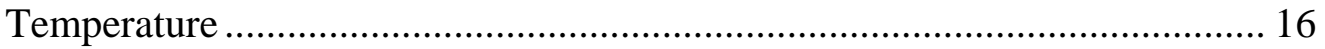

YSI discrete water quality points.................................................................. 17

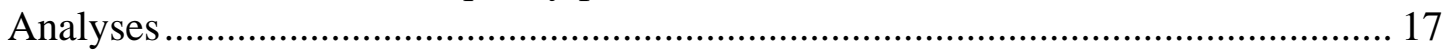

Spatial and temporal categorization........................................................... 18

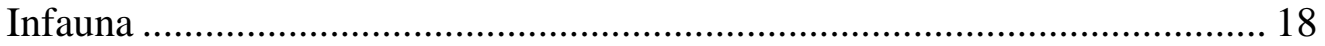

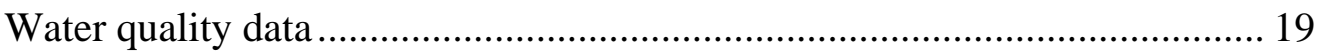

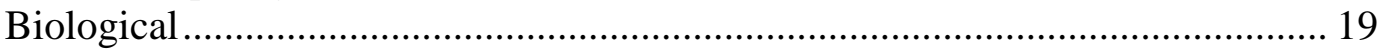

Univariate descriptive analyses.................................................................... 19

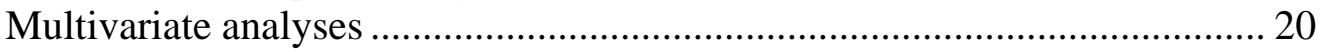



Environmental data analyses ............................................................................ 21

Water quality data ...................................................................................... 21

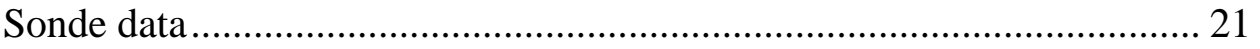

Grain size data..................................................................................... 22

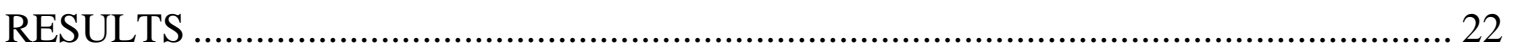

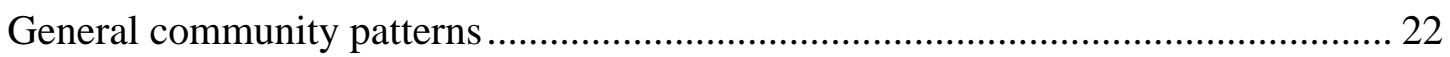

Abundance and diversity tests ............................................................................ 24

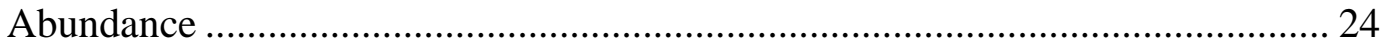

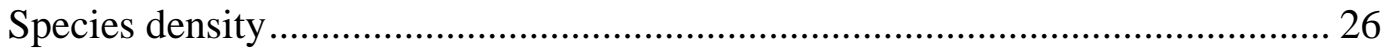

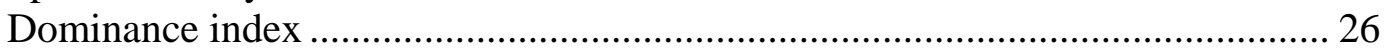




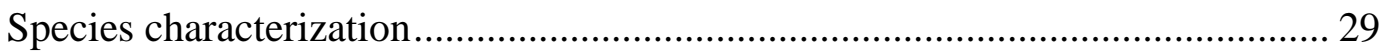

Infaunal Community Drivers ............................................................................... 29

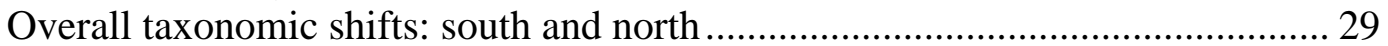

Before South and After South......................................................................... 31

Before North and After North.............................................................................. 36

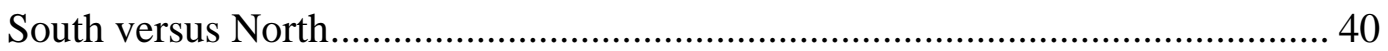



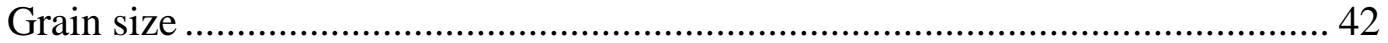

Mean, mode, and standard deviation ........................................................... 42

Percent class grain size .............................................................................. 48

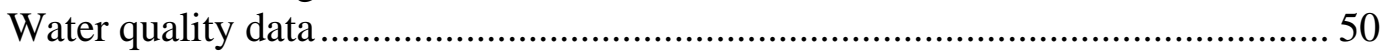

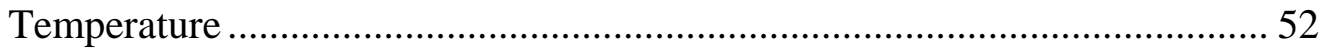

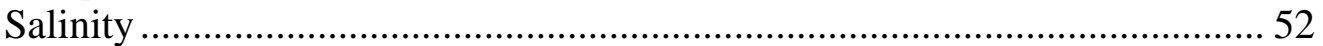

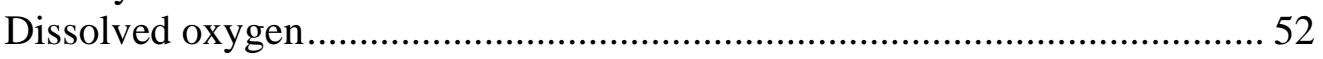

Duration of water quality events.................................................................... 53

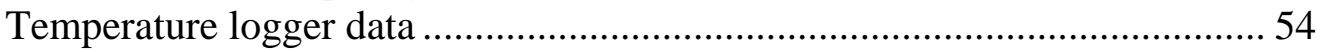

YSI data .............................................................................................. 58

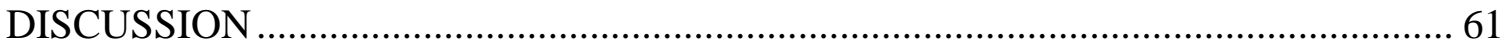

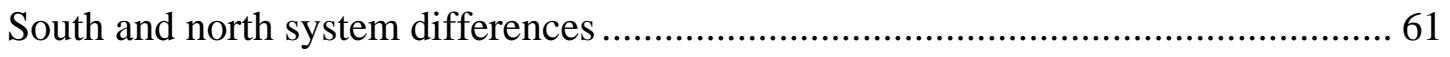

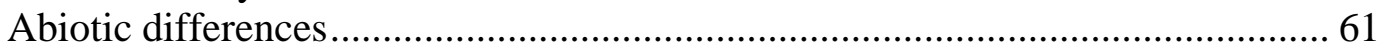

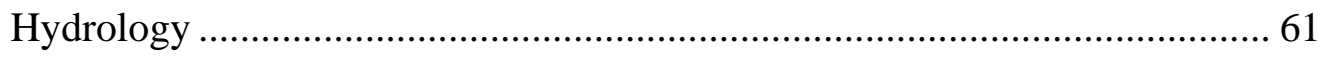

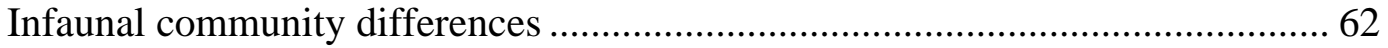

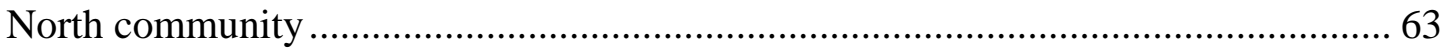



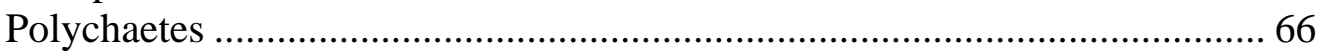

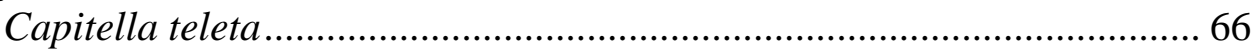

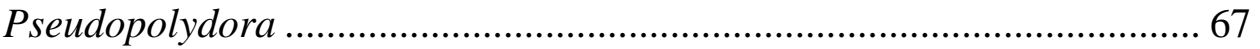

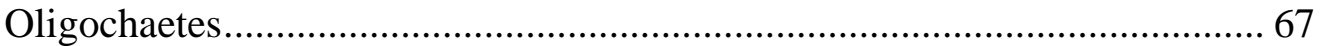

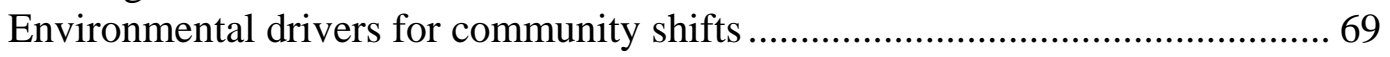

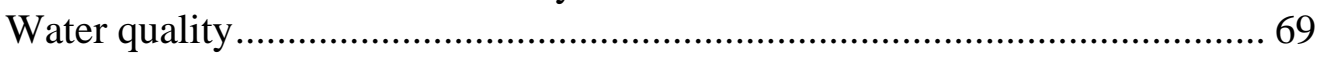

South community ………………………………………………………....... 70

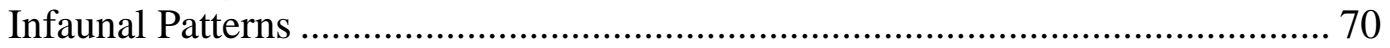

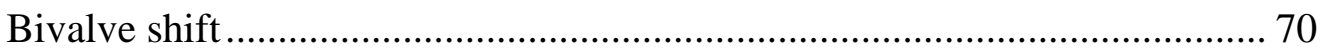

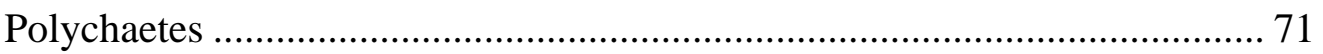

Batillaria refuge...................................................................................... 72

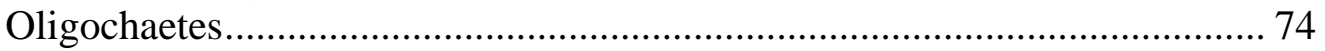

Environmental drivers for community shifts .................................................... 74



North Azevedo versus other Elkhorn Slough wetlands ........................................... 74

Estuarine habitat loss indicators......................................................................... 75

Globally similar tidally restored wetland systems ...................................................... 75

Adaptive management implications........................................................................... 76 


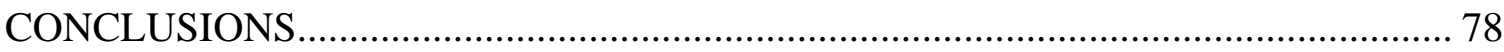

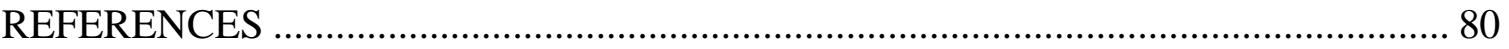



Appendix A: Timeline of relevant historical and ecological events for North

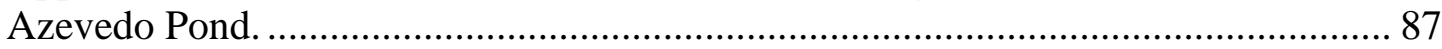

Appendix B: Dendrogram of cluster analysis of Benthic infaunal communities ....... 88

Appendix C: Benthic invertebrates per $.0078 \mathrm{~m}^{2}$ in the south region of North Azevedo Pond, $\uparrow$ denotes non-native taxa.

Appendix D: Benthic invertebrates per $.0078 \mathrm{~m}^{2}$ in the north region of North Azevedo Pond, $\uparrow$ denotes non-native taxa.

Appendix E: Site names with corresponding latitude and longitude ........................ 91

Appendix F: Basal grain size data for sediment core samples............................... 92

Appendix G: MDS plot of peripheral wetland report data and North Azevedo data; A= After Impact, B=Before Impact. 


\section{LIST OF TABLES}

Table 1. Summary of benthic infaunal and sediment sampling; " $n$ " is total samples collected........................................... 15

Table 2. List of water quality instruments and parameters used for this study; $\mathrm{DO}=$ dissolved oxygen $(\mu \mathrm{M}), \mathrm{T}=$ temperature $\left(\mathrm{C}^{\circ}\right)$; $\mathrm{Sal}=$ salinity (ppt); $\mathrm{S}=$ south; $\mathrm{N}=$ north.......................... 17

Table 3. PERMANOVA and SIMPER results for benthic infaunal communities, * indicates significant p-value $(\leq .05)$

Table 4. Two-way ANOVA statistical outputs for abundance (a), species density (b), and diversity (c); $\mathrm{df}=$ degrees of freedom; $\mathrm{MS}=$ mean square; $\mathrm{f}=$ fratio; $\mathrm{p}=\mathrm{p}$ value; * denotes statistically significant $(\mathrm{p}$ $\leq .05)$.

Table 5. Percent number of species that are native, non-native, unresolved, or cryptogenic by impact and location regime based on number of categorized species per total number of species.................. 29

Table 6. List of average individuals per core $\left(.0078 \mathrm{~m}^{2}\right)$ for each major taxonomic group for the South samples with an emphasis on subgroups for both Crustacea and Mollusca. $\mathrm{N}=$ number of sample sites; $s=$ number of sample periods; $\mu=$ average number of individuals falling under the indicated major taxonomic group; $\mathrm{SE}=$ standard error of the average values found; Freq= frequency of occurrence.

Table 7. List of average individuals per core $\left(.0078 \mathrm{~m}^{2}\right)$ for each major taxonomic group for the North samples with an emphasis on subgroups for both Crustacea and Mollusca. $N=$ number of sample sites; $s=$ number of sample periods; $\mu=$ average number of individuals falling under the indicated major taxonomic group; $\mathrm{SE}=$ standard error of the average values found; Freq= frequency of occurrence

Table 8. The top 20 most abundant species per core $\left(.0078 \mathrm{~m}^{2}\right)$ for before (a) and after (b) the water control structures were installed at the south region of North Azevedo Pond; $n=$ number of sample sites; 
$s=$ number of sampling periods; group=major taxonomic group; $\mu=$ average abundance per core; $\mathrm{SE}=$ standard error of the average abundance; \%=percent average species abundance over total abundance; Freq= frequency of occurrence of a species across all sample sites.

Table 9. The top 20 most abundant species per core $(.0078 \mathrm{~m} 2)$ for before (a) and after (b) the water control structures were installed at the no region of North Azevedo Pond; $n=$ number of sample sites; $s=$ number of sampling periods; group=major taxonomic group; $\mu=$ average abundance per core; $\mathrm{SE}=$ standard error of the average abundance; \%=percent average species abundance over total abundance; Freq= frequency of occurrence of a species across all sample sites.

Table 10. Summary of surface grain size measurement by impact and location.....

Table 11. Two-way ANOVA grain size analyses of square root transformed mean grain size, log transformed mode grain size, and square root transformed grain size by impact and location; $\mathrm{df}=$ degrees of freedom; $\mathrm{MS}=$ mean square; $\mathrm{f}=\mathrm{f}$ ratio, $\mathrm{p}=\mathrm{p}$ value; $*$ denotes a significant $\mathrm{p}$-value $(\mathrm{p}<.05)$.

Table 12. Percent grain size class 2-way ANOVA statistics summary.........

Table 13. Average water quality conditions in the south region of North Azevedo Pond. Means were calculated from monthly averages. Ranges were determined from individual data points (every 15 minutes; Before= January 2007- December 2009; After= January 2009-January 2015; \pm SD = mean \pm standard deviation; Rainy =rainy season: November-March; Dry = dry season: AprilOctober; $\mathrm{n}=$ number of sample mean months used for each water number of sample mean months used for each water quality factor; "—" = missing water quality data.

Table 14. Average water quality conditions in the north region of North Azevedo Pond. Means were calculated from monthly averages. Ranges were determined from individual data points (every 15 minutes); Before =January 2007- December 2008; After=April 2010-September 2015; $\mu \pm \mathrm{SD}=$ mean \pm standard deviation; Rainy =rainy season: November-March; Dry = dry season: April- 
October; $\mathrm{n}=$ number of sample mean months used for each water number of sample mean months used for each water quality factor; " - " = missing water quality data........................ 51

Table 15. Multiple t-tests between October 2015 daily water quality averages and the south and north regions of North Azevedo Pond

Table 16. Percent of time that extreme water quality occurred................ 53

Table 17. Sublethal water quality events by duration...................... 54

Table 18. Average YSI data points versus average temporally corresponding sondes' measurements; - indicates missing data for that time period; a) DO (dissolved oxygen), b) temperature, c)

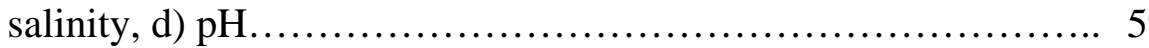

Table 19. One-way ANOVAs comparing three water quality instruments (north sonde, south sonde, and handheld YSI) for each water quality measurement: a) DO (dissolved oxygen), b) temperature, c) salinity, and d) $\mathrm{pH}$; Post-hoc Tukey HSD test results are included where there was significance. $\mathrm{df}=$ degrees of freedom, error; $\mathrm{MS}=$ mean square, $\mathrm{MS}$ error $=$ Mean square of error; $\mathrm{f}=\mathrm{f}$ ratio, $\mathrm{p}=\mathrm{p}$-value, “*”=significant $\mathrm{p}$-value $(\mathrm{p}<.05)$, posthoc=significant pairwise comparisons; $\mathrm{S}=$ south sonde; $\mathrm{N}=$ north sonde; Y=handheld YSI; “-”" = no significant pairwise comparisons. 


\section{LIST OF FIGURES}

Fig. 1. Overview map of North Azevedo Pond, Elkhorn Slough, CA..... 6

Fig. 2. South water control structure completed December 2009............ 7

Fig. 3. North water control structure completed in December 2008...... 8

Fig. 4. Map of North Azevedo's south and north sample sites............ 14

Fig. 5. Increase in number of individuals per core for both south and north regions of North Azevedo Pond........................ 25

Fig. 6. South and north differences in average number of species per core................................................... 26

Fig. 7. Mean dominance index values and standard errors by impact and location................................................. 27

Fig. 8. Changes in abundance of non-native snail, Batillaria attramentaria by impact and location........................ 34

Fig. 9. Two most abundant bivalves, Gemma gemma (a) and Nutricola tantilla (b), showing a replacement of Gemma with Nutricola in the south and a spike in appearance for both populations in the north .................................................... 35

Fig. 10. Pseudopolydora kempi abundances by impact and location........ 39

Fig. 11. Capitella teleta abundances by impact and location............. 40

Fig. 12. Monocorophium insidiosum abundances by impact and location... 41

Fig. 13. Edwardsiidae abundances by impact and location............... 42

Fig. 14. Mode grain size by impact and location...................... 44

Fig. 15. Mean grain size by impact and location...................... 45

Fig. 16. Standard deviation grain size for impact and location............. 46 
Fig. 17. Principle Component 1 values reflected onto a bar graph by impact and location........................................ 50

Fig. 18. Daily variations in temperature from temperature logger and South sonde only data..................................... 55

Fig. 19. Daily variations in temperature from temperature loggers, south sonde, and north sonde................................. 56

Fig. 20. Variations in temperature within a single day, 9/08/2015......... 57 


\section{INTRODUCTION}

Anthropogenic manipulations have altered the tidal exchange in the majority of estuarine systems, oftentimes transforming well-flushed systems into restricted ones (Portnoy 1991, Portnoy and Giblin 1997, Portnoy 1999, Vose and Bell 1994, Roman et al. 1995, Burdick et al. 1997, Eertman et al. 2002, Kennish 2002, Roman et al. 2002). Many anthropogenic manipulations, such as logging, agriculture, and urban development can fundamentally alter tidal systems. Among these, construction of roads and railways produce some of the most severe alterations to tidal regimes, both in total area affected and degree of change to hydrologic processes. Tidal flushing and tidal mixing are key determinants of estuarine structure, function, and stability (Schelske and Odum 1962, Steever et al. 1976, Odum 1980, Odum et al. 1995, Callaway 2001, Pennings and Bertness 2001). Water control structures such as culverts, dikes, and berms associated with the construction of roads and railways interfere with and drastically alter hydrological processes (Roman et al.1995). Historically, the structure and function of the wetlands behind these roads were seldom an important design component, whereas transportation requirements, road stability, and watershed flooding all were heavily taken into consideration in construction plans. These modified ecosystems are inadvertent large-scale experiments on tidal exchange alterations. By studying them, lessons can be learned to improve the design and construction of future roads and railways and to understand tidal alterations' impacts on wetlands.

Tidally restricted wetlands are generally shallow and have limited flushing, making 
them particularly sensitive to anthropogenic manipulations. This limited flushing results in increased frequency and duration of events such as water temperature, low dissolved oxygen, high pH, and, at times, hypersalinity (Beck and Bruland 2000, Beck et al. 2001, Nezlin et al. 2006, Hughes et al. 2011,). All of these extreme conditions have been shown to negatively affect overall vegetation (Ward et al.1986), fish (Weaver and Holloway 1974, Gilmore et al. 1982), plankton, and benthic infaunal community richness and abundance (Copeland 1974, Rey et al. 1991, Ritter et al. 2008).

Benthic infaunal communities are invertebrate assemblages that reside within the sediment of aquatic ecosystems such as tidally restricted wetlands. These communities are often taxonomically diverse, including annelids, crustaceans, and mollusks, amongst many other phyla. Their wide range of physiological tolerances, feeding modes, trophic interactions, and overall limited mobility make them responsive, as a group, to environmental stressors (Bilyard 1987, Diaz et al. 2004).). Thus, benthic macroinfaunal communities (invertebrates $\geq 0.5 \mathrm{~mm}$ ) are often used to assess changes in their environment, because their habitat exposes them directly to anthropogenic influences such as eutrophication and tidal flushing manipulations (Vose and Bell 1994, Stocks and Grassle 2003, Oliver et al. 2009). In wetland sites with either upland agriculture and/or high nutrient upwelling water from offshore, eutrophication occurs and can cause green algal blooms (Paerl 1997, Anderson et al. 2002). Seasonal die-offs and decomposition of these algae blooms further contributes to the lowering of dissolved oxygen (Jewell and McCarty 1971) and to the deposition of organic material to the sediment (Schaadt 2005). 
This, along with tidal flushing, also influences sediment processes including movementaccretion and subsidence, and sorting. All of these conditions create a unique habitat, which influences the development and persistence of the benthic community that characterizes restricted wetlands.

Changes to the benthic habitat have been shown to change the richness, abundance, and distribution of benthic infaunal communities (Eriksen 1968, Aldridge et al. 1987, Erman and Ligon 1988, Richards and Bacon 1994). One study in a South Carolina wetland compared benthic infaunal communities between an open marsh, tidal creek, and two impounded (tidally restricted) marsh systems over two years. They found that the open marsh site and tidal creek had a higher total number of taxa and density of invertebrates than the two impounded sites (Wenner and Beatty 1988). Another study in Hood Canal, WA found that benthic infaunal communities were significantly influenced by changes in dissolved oxygen (DO) levels and grain size. At $188 \mu \mathrm{M}$ or lower, total abundance, taxa richness, and arthropod, mollusk, and other taxa abundance decreased significantly. At $31 \mu \mathrm{M}$ or less, total abundance, taxa richness, and annelid, arthropod, and mollusk abundance all decreased significantly. Also, they found that a positive correlation existed between coarser sediments and infaunal diversity and abundance (Long et al. 2007).

Inundation time also greatly affects benthic infaunal density and diversity. Low intertidal communities are known to be higher in density than upper intertidal and marsh communities because they are less impacted by physiological stressors such as 
desiccation. Higher habitat communities are affected by both terrestrial and aquatic conditions and thus must be highly adapted to deal with these daily tidal dynamic changes in their habitat (Kneib 1984). Due to marked response to changes in water quality and sediment processes, along with being secondary producers, benthic invertebrates are some of the best environmental indicators of changes to a marsh's ecosystem and overall marsh health (Pearson and Rosenberg 1978, Richards 1996, Hawkins et al. 2000).

\section{Thesis rationale}

Elkhorn Slough, historically an estuary, is a coastal embayment located on the central coast of California at the vertex of Monterey Bay. The construction of a railroad across Elkhorn Slough in the 1870s created a multitude of tidally restricted wetlands. Tidal influence for many of these wetlands is restricted to one or two culverts under the railway levee. North Azevedo Pond (4.2 ha) is one such tidally restricted wetland curtailed from the main channel by a railroad trestle with two culverts under the railroad allowing limited tidal exchange (Fig. 1). These culverts are located at the south and north ends of the wetland. The north end is at a higher elevation $(1.332 \mathrm{~m})$ than the south end (1.009 $\mathrm{m})$. The north end was fairly shallow and only a small portion of its area ( 5\%) was consistently inundated. However, the south end was regularly ponded with water ( $\sim 15 \%$ of the area) at relatively deeper depths. These differences in hydrology were noted in selecting where benthic sampling occurred for Oliver et al. 2009, where sampling was restricted to the south end due to consistently little inundation in the north end. 
Two ponding water control structures were added to this system adjacent to the two existing culverts in an attempt to increase tidal flooding and improve water quality without decreasing marsh acreage by drowning marsh vegetation (North Azevedo Adaptive Management Plan) (see Appendix A, Fig. 2, Fig. 3). The south water control structure was completed in December 2009, and the north water control structure in December 2008. These ponding manipulations created a unique experiment and an opportunity to study how ponding infrastructures contribute to biogeochemical changes in tidally restricted wetlands. Both insufficient (due to restriction) and excessive (due to land subsidence and sea level rise) tidal flooding can lead salt marsh loss (Boumans et al. 2002). This tidally restricted wetland and others in Elkhorn Slough are some of the best experimental models for predicting the fate of coastal wetlands if relative sea level continues to rise and seawater intrudes further inland. Using benthic invertebrate communities as a baseline for studying changes in this system, I monitored and assessed this experimental ponding manipulation. I drew upon and analyzed a comprehensive data set that included monitoring data from before and after water control structure construction. This was done in order to record and document ecological changes in the marsh, to synthesize a work that will inform future management decisions, to suggest future changes (if any) to the experiment, and to consider what can be done in other locations. 


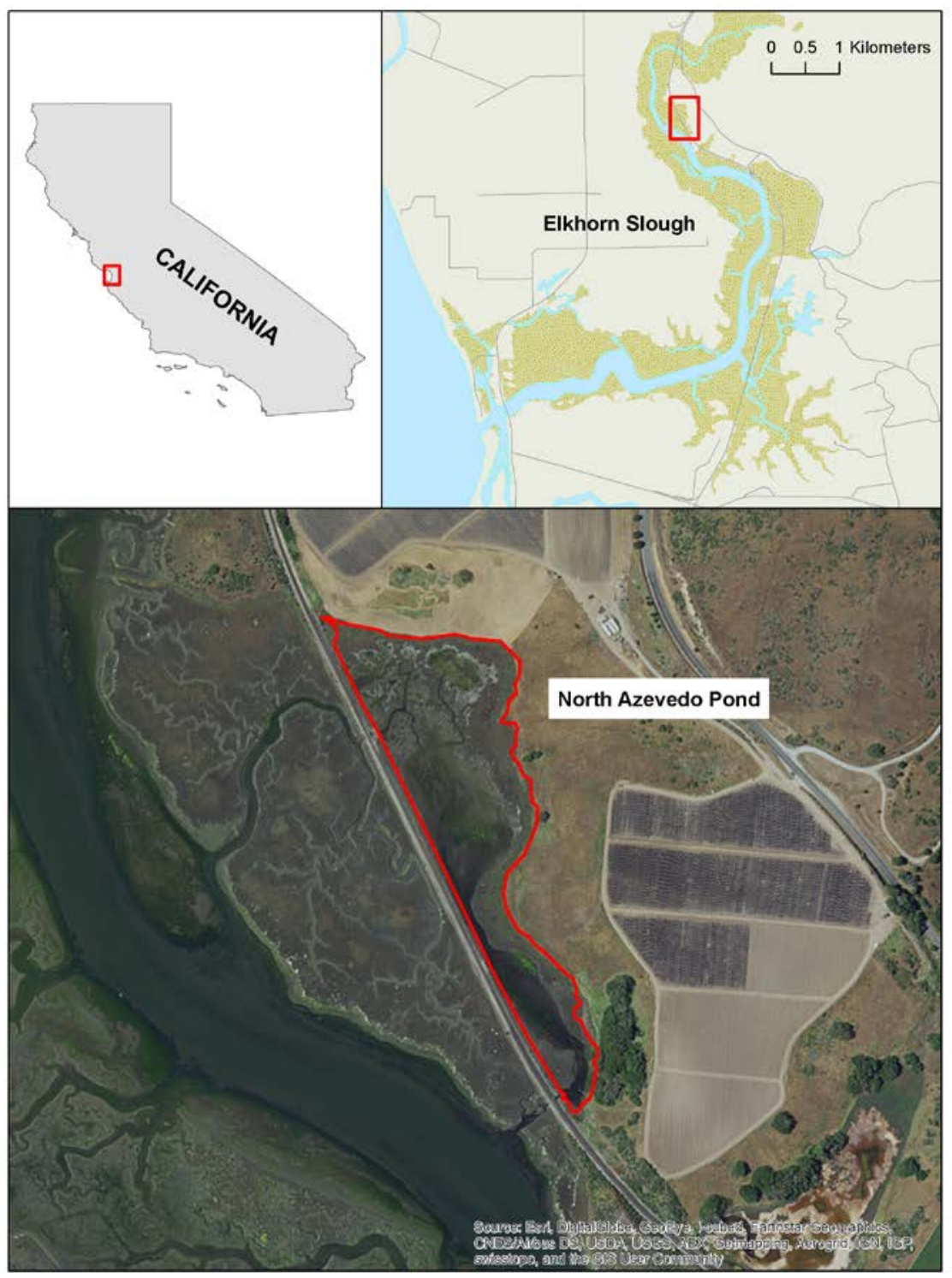

Fig. 1. Overview map of North Azevedo Pond, Elkhorn Slough, CA 


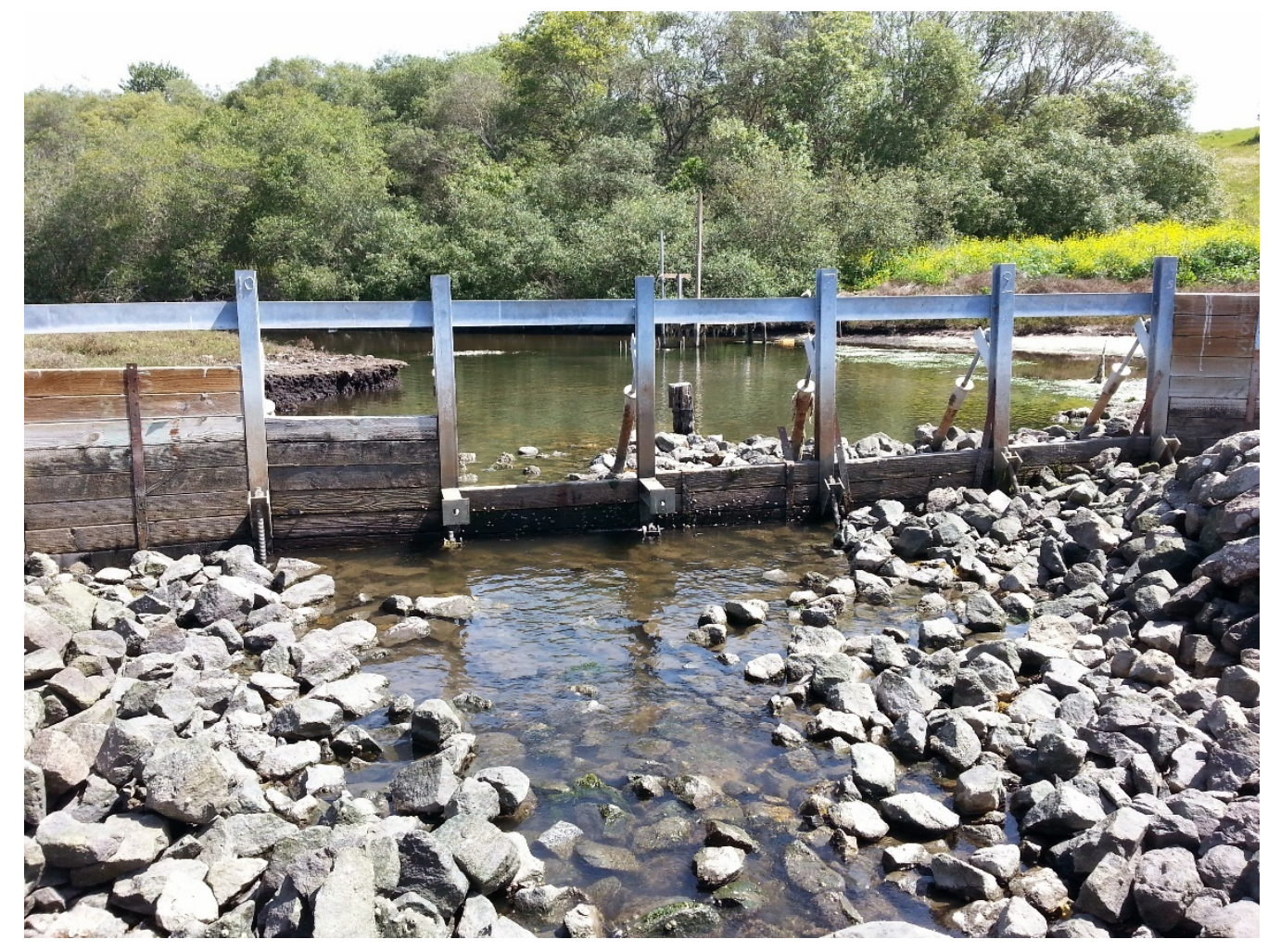

Fig. 2. South water control structure completed December 2009. Facing east looking into North Azevedo Pond from the main channel 


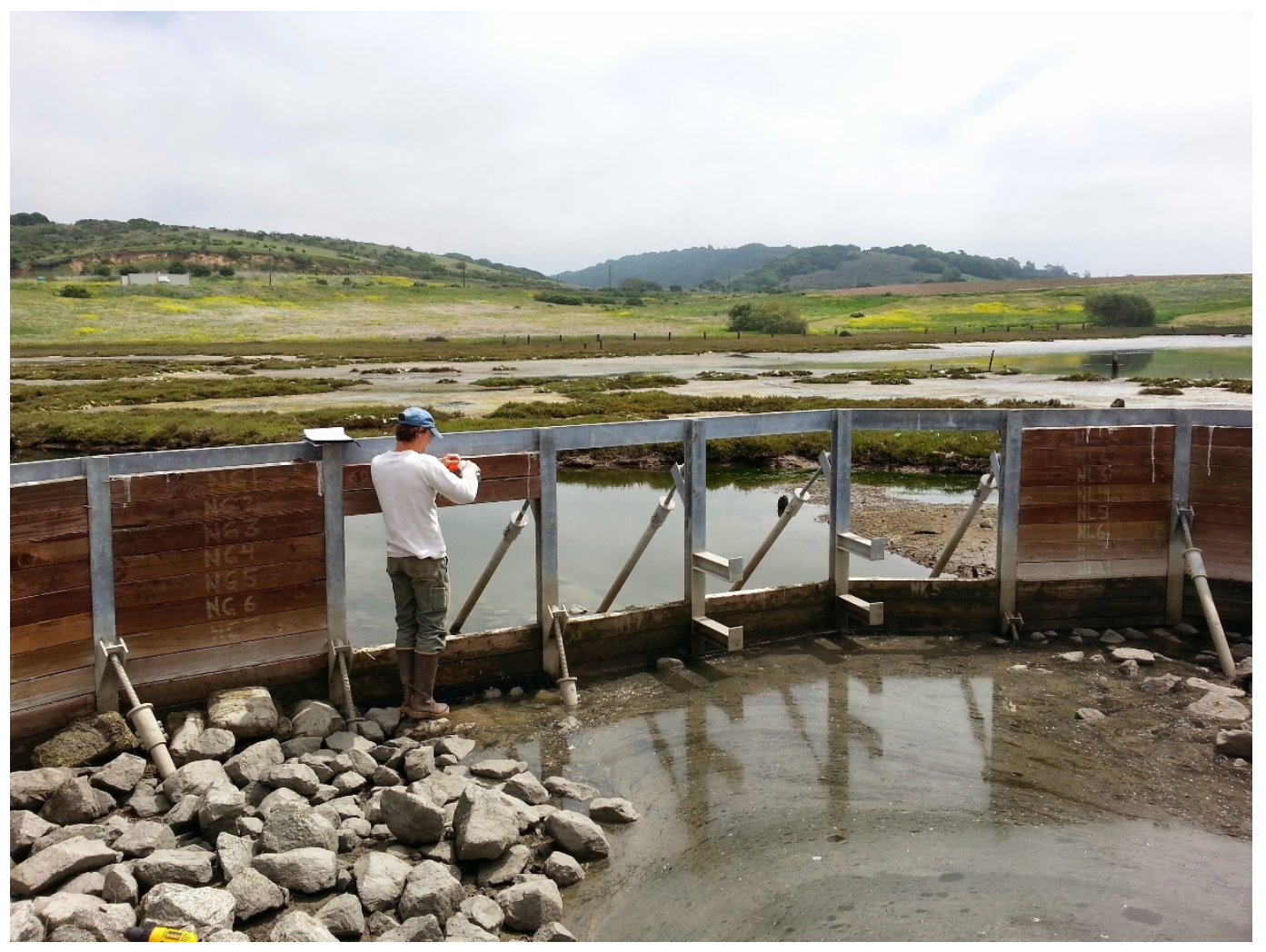

Fig. 3. North water control structure completed in December 2008. View is facing east looking into North Azevedo Pond.

\section{HYPOTHESES}

In my study, I pose the following question: Did benthic infaunal community composition and relative species abundance significantly change and how, before and after construction of the ponding manipulations? My hypotheses to address this question:

$\mathrm{H}_{1}$ : Benthic infaunal community assemblages will be different between pre-water control construction and post-water control construction.

$\mathrm{H}_{2}$ : Benthic infaunal community assemblages will be different between the south region of North Azevedo Pond and the north region of North Azevedo Pond. 
$\mathrm{H}_{3}$ : Benthic infaunal communities will be higher in abundance and species density in post-water control construction than pre-water control construction

$\mathrm{H}_{4}$ : Benthic infaunal communities in the south will have a higher abundance and species density than communities in the north in both pre- and post-water control structure.

\section{MATERIALS AND METHODS}

\section{Study area and study system}

North Azevedo Pond is located in Elkhorn Slough, CA northeast of the main channel

(Fig. 1). In the 1870s, this wetland was curtailed from the main channel by railroad tracks, and only received tidal exchange through two culverts: one located on the south end of the wetland and the other on the north. Subsequent to railroad construction, North Azevedo Pond existed under a tidally restricted hydrological regime. When water control structures were built adjacent to these two culverts, this changed the wetland's hydrology by increasing the water level and inundation time.

Pre-manipulation system. North Azevedo experienced daily dramatic changes to water quality conditions prior to water control construction. The highly elevated north flat was only covered at high tides and the south mudflat had relatively stagnant water with significant periods of anoxia (Oliver et al. 2009). In 1997, the south culvert broke 
open and resulted in an increase in tidal range. The Elkhorn Slough National Estuarine Research Reserve (ESNERR) found a significant decrease in nitrate (NO3) within the system (samples were taken in the middle of the wetland) from before and after this accidental restoration took place (Gee et al. 2010). This change in hydrology decreased nutrients in the system due to greater tidal exchange, and created a 100' vegetated buffer between adjacent agricultural fields and the high-water edge of the wetland.

However, the wetland persisted in a highly dynamic and unstable hydro-chemical state despite the unintended increase in flushing to the system. In 2000, a nutrient study described North Azevedo Pond's water quality as hyperventilated (Chapin et al. 2004). A hyperventilated wetland system is defined as one in which the wetland experiences both rapid and dramatic supersaturation and depletion in diel oxygen levels in response to nutrients, sunlight, and tidal cycles (Beck and Bruland 2000, Beck et al. 2001). Oxygen supersaturation occurred when high incoming tides brought high nitrate and oxygen into the system, and diel oxygen production further increased from higher macroalgal photosynthetic rates due to high nutrient inputs from freshwater sources. At night, oxygen levels at times decreased to as low as $10 \mu \mathrm{M}$, but then incoming high tides and light (daytime) restored healthy oxygen levels to the system. During neap tides, lower high tides were not high enough to significantly flood Azevedo Pond and the resulting water quality was hypoxic past nightfall, extending more than six hours. From 2007 to 2008, the south end experienced hypoxia $(\leq 63 \mu \mathrm{M}) 1.47 \%$ of the time and hypersalinity ( $>50$ 
ppt) $0.65 \%$ of the time-both of these calculated from monthly averages from the Elkhorn Slough National Estuarine Research Reserve (ESNERR) database (Oliver et al. 2009).

Post-manipulation system. As previously mentioned, from 2008 to 2009, tidal flashboard control structures were built behind the two existing culverts in order to retain more tidal water in the isolated wetland. Moderate structural modifications were made on the south structure from the initial construction, but none were made on the north structure. These modifications were too difficult to track due to a lack of documentation. So, for the purpose of this study, only the initial hydrological changes marked by the completion of tidal flashboard construction were used as the benchmark for experimental restoration. The general goal of the manipulation was to improve water quality by increasing inundation to the system. The new control structures ponded water in the high marsh at approximately 4 feet above MLLW (Mean Lower Low Water)- the elevation of the levee spillway (Elkhorn Slough Foundation records), converting a high and often dry mudflat, especially in the north region, to a high salt marsh pond. Sampling before and after these ponding manipulations allowed ecosystem changes to be documented.

This project focused on using benthic infaunal communities as measurements of change in the North Azevedo Pond wetland system, before and after water control construction. Thus, data analysis and sampling were divided into both temporal and spatial categories. Temporally, the data set was divided into two separate groups- before the water control structures were built and after they were constructed. For spatial organization, data were classified by splitting them into two distinct regions-South and 
north. Water quality data, sediment grain size analysis, and census of benthic infaunal organisms were used to elucidate any of significant temporal and spatial patterns in the benthic infaunal communities.

\section{Benthic sampling}

Sampling bouts occurred in August 2007, April 2008 (Oliver et al. 2009), October 2008, September 2009, and July 2014 (Table 1). For the purpose of this thesis, site names were simplified to "S\#" and they increased in number the further they were from each respective culvert. Overall, there were ten sites that were used for this study that were subsampled from a larger set of sample sites. There was some replication between years but no overall consistent replication of sample location and number from each sampling period to period (Table 1, Fig. 4).

Macrofauna sampling. All benthic infaunal cores were collected by using hand-held cores (0.0078 m2, $0.1 \mathrm{~m}$ diameter x $0.1 \mathrm{~m}$ depth), which were then washed over a $0.5 \mathrm{~mm}$ screen. Animals were first relaxed with magnesium chloride, and samples were subsequently fixed in $4 \%$ buffered formaldehyde for 48 hours. These samples were then transferred to $70 \%$ ethanol for processing. All benthic organisms were sorted and identified to lowest possible taxon, usually species.

Sediment sampling. Sediment push cores $\left(0.0007 \mathrm{~m}^{2}, 0.03 \mathrm{~m}\right.$ diameter x $0.1 \mathrm{~m}$ depth) were collected immediately adjacent to each benthic infaunal core and stored upright during transport to avoid mixing. Cores for grain size analysis were refrigerated at the laboratory. The particle size analyses were carried out with a Beckman-Coulter LS 
13320 laser particle size analyzer (Beckman Coulter Inc. 2003) using the aqueous module of the machine. Cores were measured to the tenth of a centimeter. Analyses were done on both the surface and basal layer of each core. Coulter statistical software was used to calculate mean, mode, median, standard deviation, utilizing the arithmetic method (Coulter Corporation, 1992). This software also calculated each sample’s percent by size classes: $4 \mu \mathrm{m}, 10 \mu \mathrm{m}, 63 \mu \mathrm{m}, 125 \mu \mathrm{m}$, and $250 \mu \mathrm{m}$. These percentages were then used to interpolate \% silt, \% clay, and \% sand. 


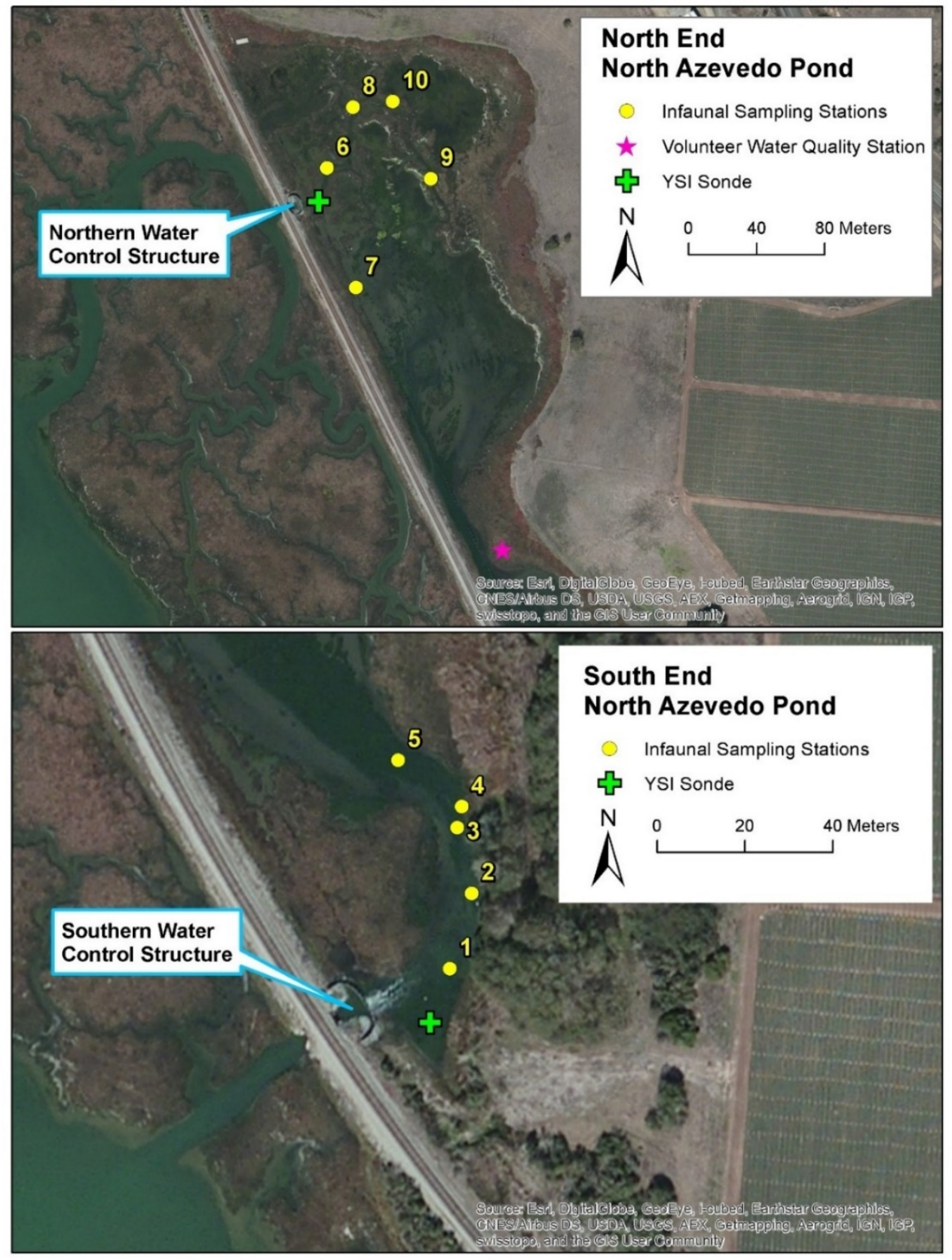

Fig. 4. Map of North Azevedo’s south and north sample sites. Sample sites numbered according to distance from each respective culvert 
Table 1. Summary table of benthic infaunal and sediment sampling; " $n$ ” is total samples collected

\begin{tabular}{c|ccc}
\multicolumn{1}{c}{ Sampling type } & Date & Region & $\mathrm{n}$ \\
\hline \hline \multirow{5}{*}{ Benthic cores } & August 2007 & $\mathrm{S}$ & 4 \\
& April 2008 & $\mathrm{S}$ & 4 \\
& October 2008 & $\mathrm{N}$ & 5 \\
& September 2009 & $\mathrm{N}$ & 5 \\
& July 2014 & $\mathrm{N}, \mathrm{S}$ & 10 \\
\hline \multirow{5}{*}{ Sediment cores } & August 2007 & $\mathrm{S}$ & 3 \\
& April 2008 & $\mathrm{S}$ & 1 \\
& October 2008 & $\mathrm{N}$ & 3 \\
& September 2009 & $\mathrm{N}$ & 3 \\
& July 2014 & $\mathrm{N}, \mathrm{S}$ & 10 \\
\hline
\end{tabular}

\section{Environmental sampling}

Sonde data. Continuous dissolved oxygen, $\mathrm{pH}$, salinity, and temperature measurements at 15 minute intervals were attained from two YSI 6600 V2 multiprobe sondes-one was in the south end and the other in the north end of North Azevedo Pond. The south sonde was deployed during the entirety of the study. The north sonde was intermittently deployed adjacent to the north water control structure at two time intervals: from April 2010 to August 2010 and then again from September 2014 to September 2015. Water quality data for the south sonde from 2007-2010 and 2014-2015 were acquired from the NERRS’' (National Estuarine Research Reserve System) website (http://cdmo.baruch.sc.edu/). These data omitted any "flagged" data (data values that were unusual or suspicious) and corrected drift 
data to adhere to CDMO (Centralized Data Management Office) standards.

Therefore, this south sonde data set did have some noticeable gaps in recorded values, at times, spanning a month. North sonde data were acquired from ESNERR directly. For the north sonde, any missing and flagged values from this dataset were either lost or deemed as bad data, and corrected drift data were included in this data set.

\section{Spatial environmental description.}

Temperature. During 2014 field sampling, the north region of the wetland was observed to experience less tidal exchange and lower inundation than the south region where the fixed sonde was located. Thus, in an effort to consider any potential spatial temperature variation not captured by the south sonde, nine $\underline{\mathrm{HOBO}} 64 \mathrm{~K}$ pendant temperature loggers (Onset Computers) were deployed in the north end. These temperature logger readings were used as a proxy for water flow. Higher temperatures indicated an area with lower tidal flow and higher stagnation. Temperature loggers were deployed from May 5th to June 6th 2015 and July 14th to September 18th 2015. Each temperature logger was located closely above the soil surface and affixed with cable ties to a PVC pipe which was planted in the sediment where water was present. Every temperature logger site was selected within a few meters of each infaunal sampling site in order to capture temperature readings that reflected the sampled benthic infaunal conditions. The loggers were set to measure every fifteen minutes to match the frequency of the sonde readings. 
Ysi discrete water quality points. In addition to deploying temperature loggers, discrete water quality measurements were taken on several dates with a handheld YSI (model 556 MPS) at each temperature logger site, haphazardly throughout the wetland, and adjacent to the south sonde. South sonde data were corrected using the handheld YSI data, given the handheld YSI was calibrated the day of data collection and the sonde was calibrated monthly. Temperature logger values were also corrected with handheld YSI data collected at each respective logger. For a complete list of all water quality parameters used for this study see Table 2 .

Table 2. List of water quality instruments and parameters used for this study; $\mathrm{DO}=$ dissolved oxygen $(\mu \mathrm{M}), \mathrm{T}=$ temperature $\left(\mathrm{C}^{\circ}\right)$; Sal= salinity (ppt); $\mathrm{S}=$ south; $\mathrm{N}=$ north

\begin{tabular}{ccccc} 
Instrument & Time Period & Region & WQ Parameter & Freq \\
\hline \hline WQ YSI Sonde & 1995 - present & S & DO, pH, T, Sal & 15 min \\
& $\begin{array}{c}\text { Apr 2010-Aug 2010; } \\
\text { Jan 2014-Sept 2015 }\end{array}$ & N & DO, pH, T, Sal & 15 min \\
Handheld YSI & $\begin{array}{c}\text { Mar 16, May 6, June } \\
\text { 15, July 14, Sept 18 } \\
\text { 2015 }\end{array}$ & N & DO, pH, T, Sal & N/A \\
\hline
\end{tabular}

Temperature Loggers

May 8-June 15 2015, July 14-Sept 182015

$\mathrm{N}$

$15 \min$

\section{Analyses}




\section{Spatial and temporal categorization.}

Infauna. All the infaunal data were grouped into spatial and temporal categorizations. Infaunal sampling that preceded water control structure construction was named "Before Impact” or “Before”. This included three sampling periods- August 2007, April 2008, and October 2008. Infaunal sampling data that occurred post-water control structure construction were named “After Impact” or “After”. These “After Impact” years included both September 2009 and July 2014. Additionally, all infaunal samples were subcategorized by their sampling location. Samples from the south end were labelled "South" and samples from the north end were labelled "North”. Thus, any future referral to these different spatial and temporal sampling regimes will be also be cited as four distinct sampling groups: “ Before South”, “After South”, “Before North” and “After North".

Sampling years within each pooled impact and location group were tested using the ANOSIM (Analysis of Similarity) multivariate statistical test for differences in order to support the justification of pooling them together (Primer 6). Only sampling years within the same spatial and temporal category were compared. Both After South and Before North only had one sampling year, so it was only possible to compare Before South and After North sampling periods, each of these having two sampling years. After North samples were slightly significantly different (One-way ANOSIM, R= 0.208, $\mathrm{p}=.048$ ). After examining the SIMPER analysis, the overall community structure did not differ ecologically between each sampling year. Both communities were dominated by 
polychaetes and oligochaetes. The five-year gap between After years probably drove these differences in community that were present in the One-way ANOSIM. However, these community differences were expected given the natural ecological succession and continuous changes that benthic communities normally experience over time. Overall, it still made sense to proceed with this grouping of After samples given their shared location and environmental conditions.

Water quality data. All water quality data were similarly organized spatially and temporally but also seasonally. Data from the north sonde were labelled "North”, and data from the south sonde were labelled "South". Any water quality data prior to December 1 $1^{\text {st }}, 2008$ in the north end were considered "Before" and water quality data prior to December $1^{\text {st }}, 2009$ in the South end were considered "Before”. Any data past these two dates for the respective locations were considered "After”. Water quality data were also further organized by “dry season” (April to September) versus "rainy season” (November to March) given all infaunal sampling occurred during the "dry season”.

\section{Biological.}

Univariate descriptive analyses. Means and standard errors for abundance, species density, and Simpson's dominance index $(\lambda)$ were calculated and plotted by location and then by impact. Residuals were checked for normal distribution, and homogeneity of variances was tested for abundance, species density, and dominance. Two-way ANOVA (Analysis of Variance) tests were run to analyze the effects of impact and location on abundance, species density, and dominance. 
Multivariate analyses. All multivariate analyses were carried out in Primer 6 (PERMANOVA+ package). Infaunal data were fourth root transformed and then used to create a Bray-Curtis similarity matrix. This matrix was examined by cluster analysis to identify community patterns within and between all sampling periods. A dendrogram and a multi-dimensional scaling (MDS) plot were both created to visualize patterns between categorical regimes. Individual species contributions to the separation of the different temporal/spatial regimes were examined using the SIMPER (Similarity Percentages) procedure. A significant interaction was identified between impact and location after running a 2-way PERMANOVA (Permutational Multivariate Analysis of Variance). Because these two factors could not be analyzed independently of each other given this significant interaction, a pairwise PERMANOVA test was run to analyze spatial and temporal differences within and between community assemblages.

A cluster analysis and MDS plot were also created for North Azevedo versus all of the other wetlands from the Oliver et al. 2009 report to see if the After Impact samples for both south and north ends of the pond changed in terms of flushing and infauna community composition.

Species characterization. All species in samples were assigned an introduction status label (native, non-native, cryptogenic, and unresolved). These species characterizations were then used to calculate percent number of species that fell under each of the four categories aforementioned. 


\section{Environmental data analyses.}

\section{Water quality data.}

Sonde Data. Dissolved oxygen, $\mathrm{pH}$, salinity, and temperature measurements from both sondes were calculated into monthly means and daily means. Means and standard deviations of monthly means were calculated according to the impact and location by Dry/Rainy Season Regime.

Due to the extreme unevenness of sample sizes between south and north and before and after for water quality data, it was not possible to run comprehensive statistical analyses for monthly or daily average water quality points. However, a t-test was conducted on south and north October 2014 sonde daily averages to capture a snapshot of how they statistically compared to each other.

Percent occurrence of extreme water quality over both time periods (Before and After) measurements were calculated from individual data points of dissolved oxygen, salinity, and temperature. In addition to calculating percent of occurrence over whole time period, the percent and number of occurrences by duration of event were also calculated. Extreme water quality events were deemed any water quality conditions that proved stressful or lethal to biota, in this case, benthic infauna. Anything less than or equal $63 \mu \mathrm{M}$ was considered a hypoxic event (Diaz and Rosenberg 1995, Rabalais et al. 1999). A dissolved oxygen reading between $94-188 \mu \mathrm{M}$ was considered an initial critical threshold in dissolved oxygen for mollusks, amphipods, and ostracods (Dutch et al. 2005, Long et al. 2007) Anything greater than or equal to 20 degrees Celsius was considered a 
critical temperature threshold for benthic invertebrates ( Bryant et al. 1985). Lastly, hypersaline water conditions were considered anything equal to or above $35 \mathrm{ppt}$ (parts per thousand), the average standard salinity of seawater (Teske and Wooldridge 2002, Hastie and Smith 2006).

One-way ANOVAs with pertinent post-hoc tests were run between each water quality parameter and the three water quality instruments-YSI, South sonde, and North sonde.

Plots and tables were created in Microsoft Excel and SigmaPlot. Water quality data were analyzed in Excel and SAS (SAS 9.3).

Grain Size Data. Means and standard deviations of all cores (surface and basal ends) were plotted against each other to distinguish any patterns. Means of standard deviation and mean were plotted with the impact and location regime. Principal Component Analysis (PCA) was used to examine \% class size trends between impact and location. The effects of impact and location of grain size measurements were tested using two-way ANOVAs.

\section{RESULTS}

\section{General community patterns}

The cluster analysis and the MDS plot both showed distinct clustering between Before South and After South infaunal communities and between South and North communities (see Appendix B, Figure 5). There was no obvious pattern between Before and After North samples. This is because the After North samples showed high variability with outliers and dispersed clustering. These differences seemed to be driven 
by two particular sites, S7_2009 and S6_2014 (see Appendix D). Both of these samples had high numbers of Paranais litoralis $c f$ whereas other After North samples did not. However, there were distinct South and North sample community differences. All means stated are per core $\left(0.0078\left(\mathrm{~m}^{2}\right)^{-1}, 0.1 \mathrm{~m}\right.$ diameter x $0.1 \mathrm{~m}$ depth).

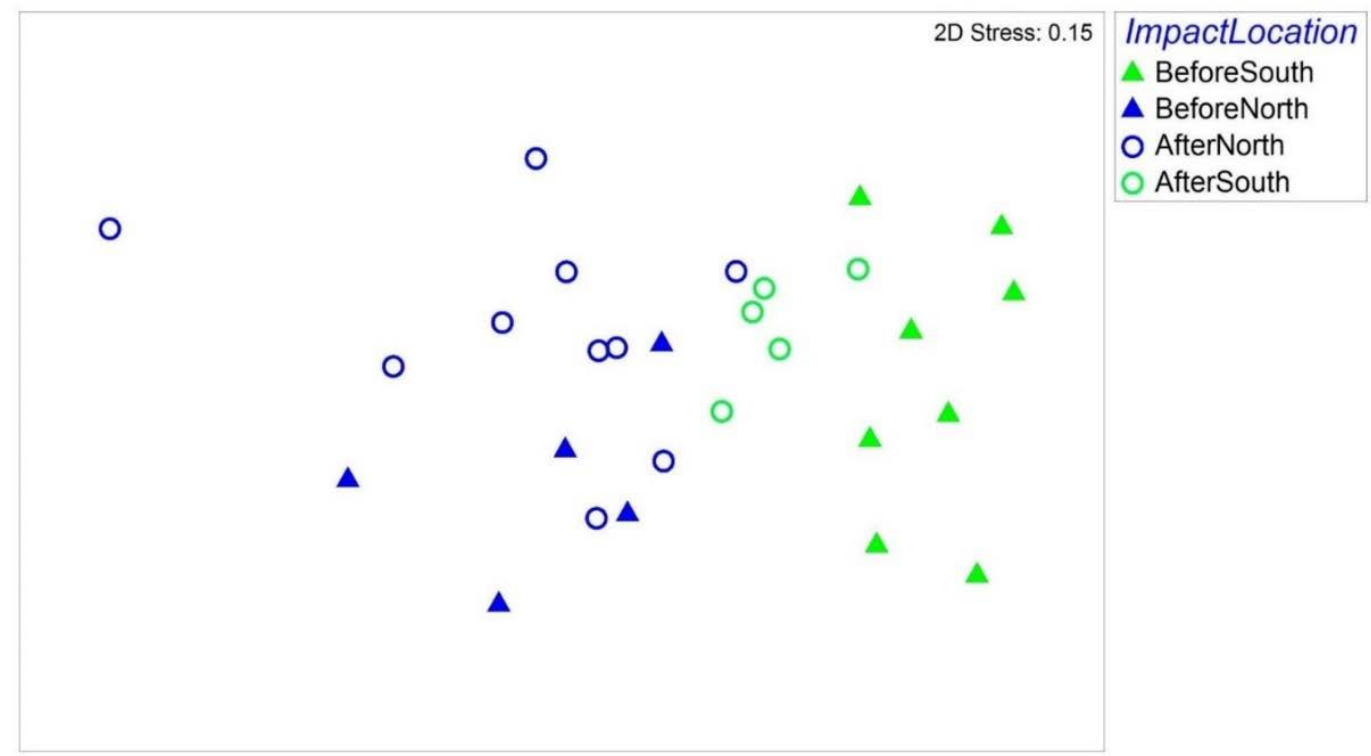

Fig. 5. MDS ordination of all infaunal sample sites showing distinct clustering patterns between South and North, and also Before South and After South

samples

The PERMANOVA pairwise comparisons tests supported evidence for significant differences between Before South and After South (Table 3). Also, there was a consistent significant difference between South and North infaunal communities before and after manipulation.

The SIMPER analyses between groups (impact and location) were useful in identifying which species were driving differences between groups and similarly 
contributing to the similarities within a group. These certain species were not necessarily the most abundant but had a strong influence on differences given their frequency of occurrence. The percent dissimilarity was also useful in further describing differences between groups (Table 3).

Table 3. PERMANOVA and SIMPER results for benthic infaunal communities, * indicates significant $\mathrm{p}$-value $(\leq .05)$

\begin{tabular}{|l|c|c|c|}
\hline \multicolumn{3}{|c|}{ PERMANOVA outputs } & SIMPER \\
\hline & test statistic & P-value & \% dissimilarity \\
\hline Pairwise comparisons & 2.4958 & $0.001^{*}$ & 76.06 \\
\hline Before South* Before North & 2.0639 & $0.002^{*}$ & 62.57 \\
After South*After North & 1.9122 & $0.001^{*}$ & 59.35 \\
Before South*After South & 1.0727 & 0.319 & 56.88 \\
Before North* After North
\end{tabular}

\section{Abundance and diversity tests}

Abundance. The two-way ANOVA test showed no significant effects of impact and location on average abundance (Table 4). There was a trend toward increased abundance for both locations after manipulation (Fig. 5). 


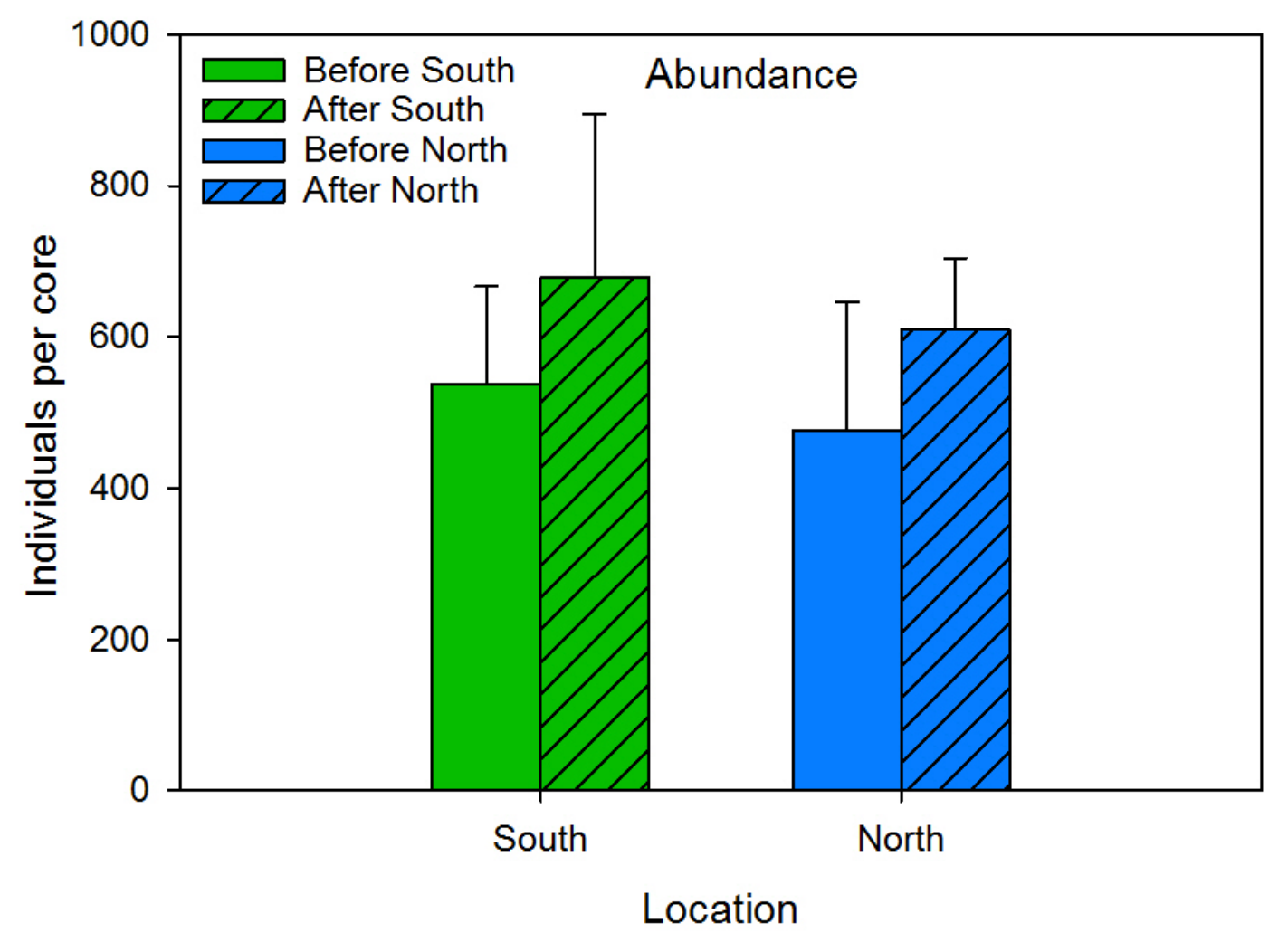

Fig. 5. Increase in number of individuals per core for both south and north regions of North Azevedo Pond. Means and standard errors 
Species density. There was no significant effect of impact on species density (Table 4). However, there was a significant effect of location on species density and $\left(F_{1,24}=\right.$ 6.65, $p=0.017$ ). Plotting these two regimes revealed that there was a higher species density in the south then the north (Fig. 6).

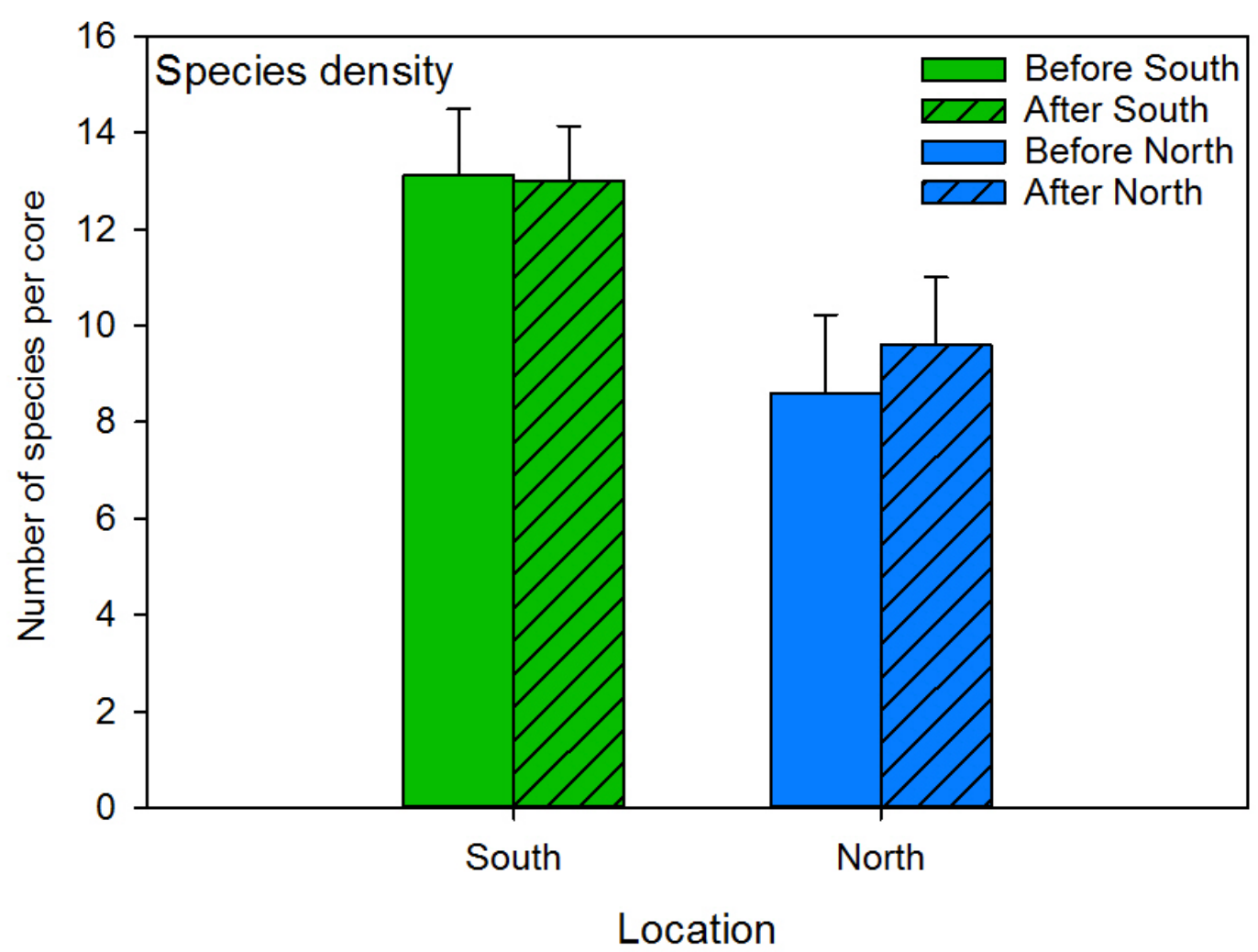

Fig. 6. South and north differences in average number of species per core. Means and standard errors

Dominance index. There was no significant effect of impact and location on individual sample dominance index values (Table 4). Dominance temporally increased in the north end, whereas it decreased in the south end of the wetland (Fig. 7). 


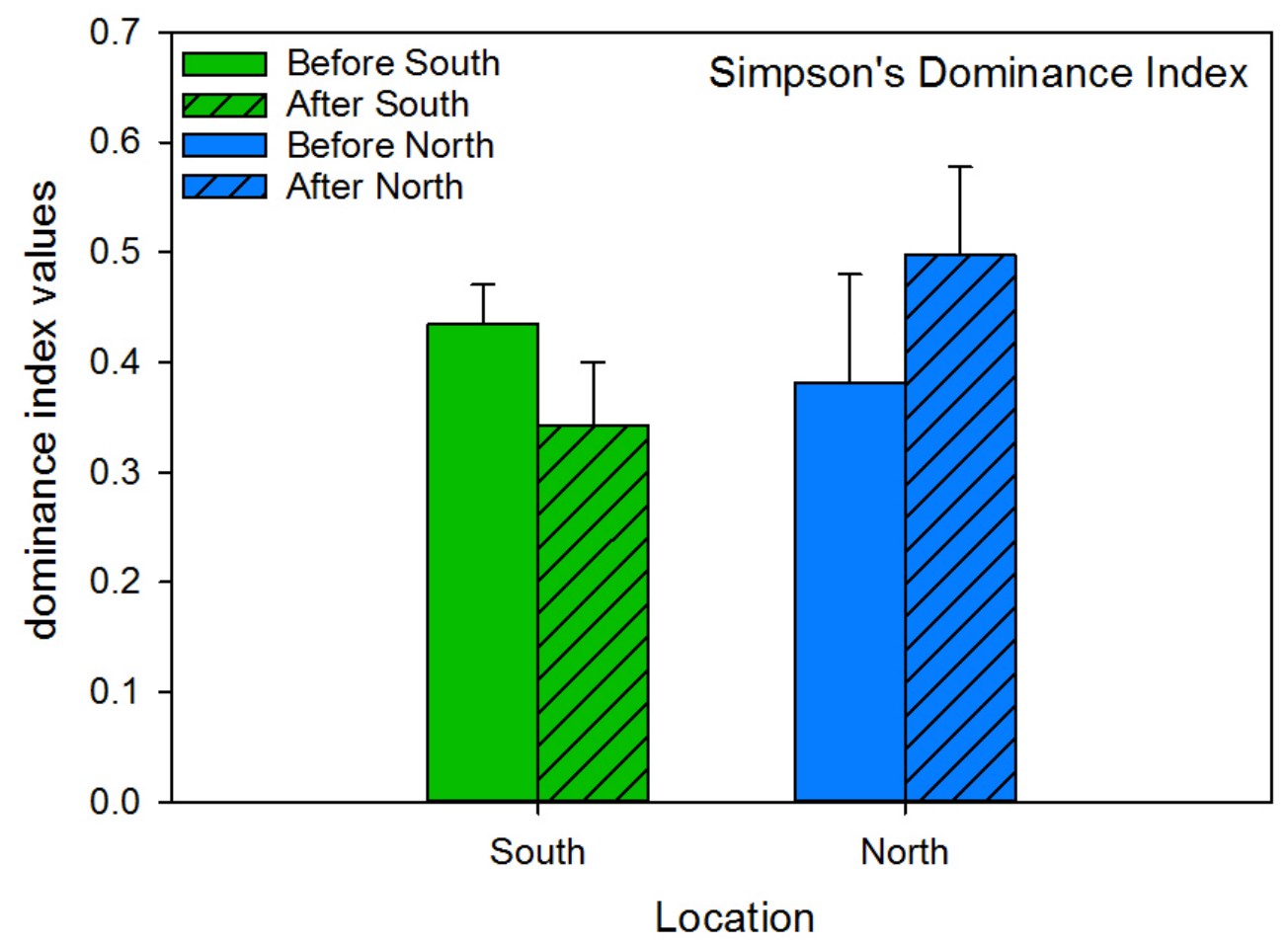

Fig. 7. Mean dominance index values and standard errors by impact and location 
Table 4. Two-way ANOVA statistical outputs for abundance (a), species density (b), and diversity $(\mathrm{c}) ; \mathrm{df}=$ degrees of freedom; $\mathrm{MS}=$ mean square; $\mathrm{f}=$ fratio; $\mathrm{p}=\mathrm{p}$ value; * denotes statistically significant $(\mathrm{p} \leq .05)$

a) Abundance

\begin{tabular}{lcccc} 
& $\mathrm{df}$ & $\mathrm{MS}$ & $\mathrm{f}$ & $\mathrm{p}$ \\
\hline \hline Impact & 1 & $1.21 \mathrm{E}+05$ & 0.896 & 0.353 \\
Location & 1 & $2.71 \mathrm{E}+04$ & 0.201 & 0.658 \\
Impact*Location & 1 & $5.24 \mathrm{E}+01$ & 0.000 & 0.984 \\
Error & 24 & $1.35 \mathrm{E}+05$ & & \\
\hline
\end{tabular}

b) Species Density

\begin{tabular}{lcccc} 
& df & MS & $\mathrm{f}$ & $\mathrm{p}$ \\
\hline \hline Impact & 1 & 1.225 & 0.081 & 0.778 \\
Location & 1 & 100.489 & 6.654 & $0.0165^{*}$ \\
Impact*Location & 1 & 2.025 & 0.134 & 0.717 \\
Error & 24 & 15.103 & & \\
\hline
\end{tabular}

c) Dominance

\begin{tabular}{lcccc} 
& $\mathrm{df}$ & $\mathrm{MS}$ & $\mathrm{f}$ & $\mathrm{p}$ \\
\hline \hline Impact & 1 & $6.81 \mathrm{E}-03$ & 0.166 & 0.688 \\
Location & 1 & $1.21 \mathrm{E}-02$ & 0.294 & 0.592 \\
Impact*Location & 1 & $6.85 \mathrm{E}-04$ & 0.017 & 0.898 \\
Error & 24 & $4.11 \mathrm{E}-02$ & & \\
\hline
\end{tabular}


Species characterization. There were no noticeable or significant differences between the temporal spatial regime and the percentage of introduced and native species (Table 5).

Table 5. Percent number of species that are native, non-native, unresolved, or cryptogenic by impact and location regime based on number of categorized species per total number of species. Numbers in parentheses are percentages based on abundance per species.

\begin{tabular}{|c|c|c|c|c|}
\hline \multirow[b]{2}{*}{ \% Species Categorization } & \multicolumn{2}{|c|}{ South } & \multicolumn{2}{|c|}{ North } \\
\hline & Before & After & Before & After \\
\hline$\%$ Native & $34.4(4.1)$ & $38.1(31.6)$ & $10.5(1.6)$ & $24(1.5)$ \\
\hline \% Non-native & 25 (65.5) & $28.6(46.5)$ & $26.3(24.9)$ & $28(57.5)$ \\
\hline \% Unresolved & 34.4 (16.9) & $33.3(21.9)$ & $63.2(73.6)$ & $48(41.3)$ \\
\hline \% Cryptogenic & $6.3(13.4)$ & $0(0)$ & $0(0)$ & $0(0)$ \\
\hline
\end{tabular}

\section{Infaunal community drivers}

Overall taxonomic shifts: south and north. The two major groups, Crustacea and Mollusca, exhibited the biggest shifts in the south region (Table 6). Crustaceans decreased from a mean of 37,949 ( $\mathrm{SE}=34.1)$ to $19,744(\mathrm{SE}=25.2)$ individuals $\left(\mathrm{m}^{2}\right)^{-1}$, and mollusks increased from an average of 19,102 (SE=44.2) to 26,538 (SE=8.3) individuals $\left(\mathrm{m}^{2}\right)^{-1}$. Amphipods were the biggest subgroup that impacted changes in crustacean abundance; bivalves and gastropods were the two main subgroups that contributed to changes in the mollusks. 
Table 6. List of average individuals per core $\left(.0078 \mathrm{~m}^{2}\right)$ for each major taxonomic group for the South samples with an emphasis on subgroups for both Crustacea and Mollusca. $\mathrm{N}=$ number of sample sites; $\mathrm{s}=$ number of sample periods; $\mu=$ average number of individuals falling under the indicated major taxonomic group; $\mathrm{SE}=$ standard error of the average values found; Freq= frequency of occurrence. Crustacea subgroups are all Order taxa and the Mollusca subgroups are all Class taxa.



However, in the north, the benthic infaunal community was heavily influenced by shifts in oligochaetes and polychaetes. Polychaetes increased from 23,974 (SE=24.5) to 42,821 $(\mathrm{SE}=40.0)$ individuals $\left(\mathrm{m}^{2}\right)^{-1}$, but oligochaetes decreased from a mean of 24,487 ( $\mathrm{SE}=28.8)$ to 17,051 individuals $\left(\mathrm{m}^{2}\right)^{-1}(\mathrm{SE}=15.4)$ (Table 7). 
Table 7. List of average individuals per core $\left(.0078 \mathrm{~m}^{2}\right)$ for each major taxonomic group for the North samples with an emphasis on subgroups for both Crustacea and Mollusca. $\mathrm{N}=$ number of sample sites; $\mathrm{s}=$ number of sample periods; $\mu=$ average number of individuals falling under the indicated major taxonomic group; $\mathrm{SE}=$ standard error of the average values found; Freq= frequency of occurrence occurrence of a species across all sample sites . Crustacea subgroups are all Order taxa and the Mollusca subgroups are all Class taxa

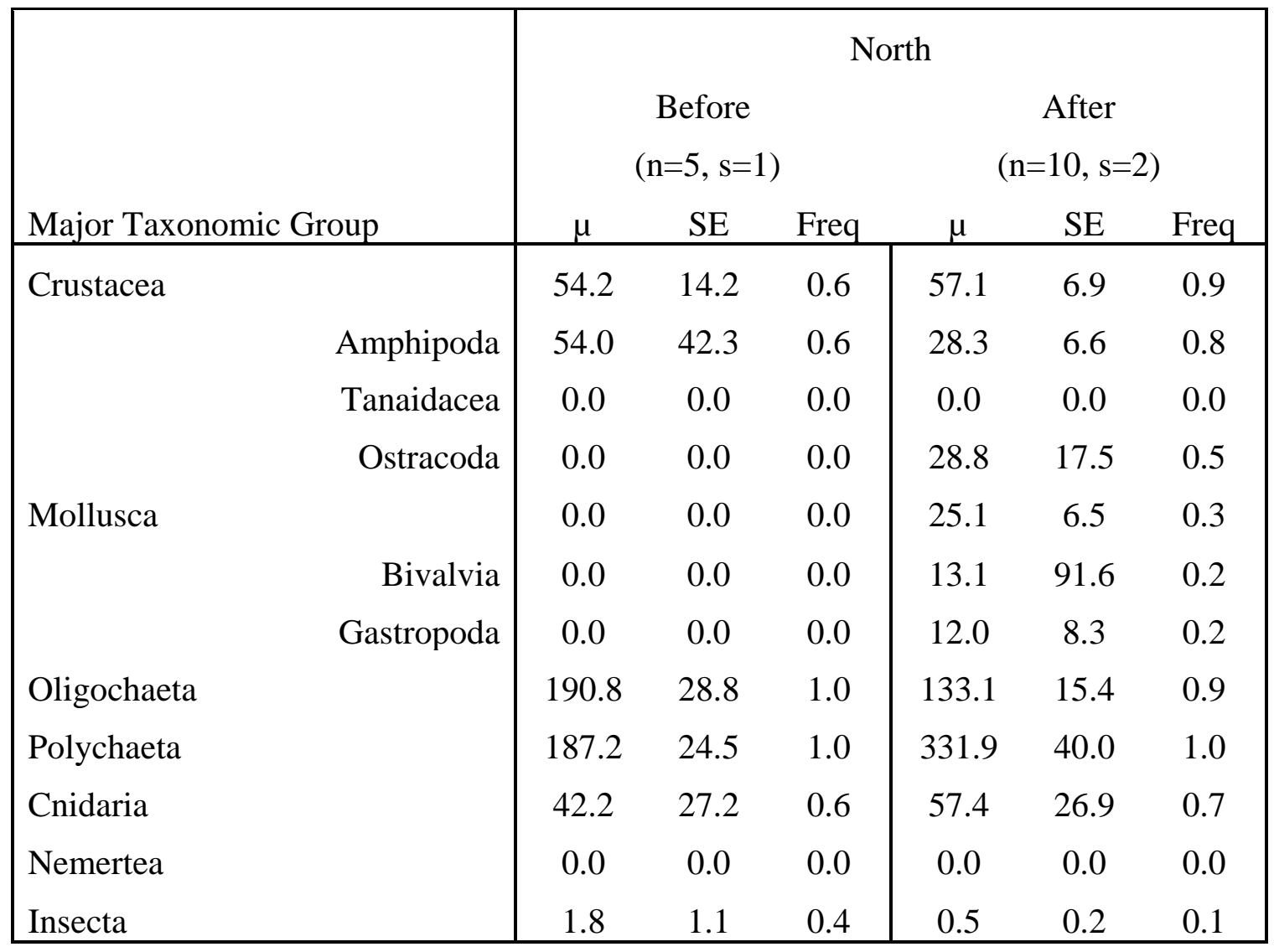

Before South and After South. As mentioned earlier, the south infaunal community was dominated by crustaceans and mollusks. Moreover, certain individual species of these groups were responsible for influencing the community composition. Batillaria attramentaria, a non-native gastropod, increased from a mean abundance of 526 $(\mathrm{SE}=3.9)$ to 16,436 individuals $\left(\mathrm{m}^{2}\right)^{-1}(\mathrm{SE}=56.1)$ (Fig. 9, Table 8). The SIMPER analysis further supported this species as the top driver of temporal differences. 
Table 8 . The top 20 most abundant species per core $\left(.0078 \mathrm{~m}^{2}\right)$ for before (a) and after (b) the water control structures were installed at the south region of North Azevedo Pond; $\mathrm{n}=$ number of sample sites; $\mathrm{s}=$ number of sampling periods; group=major taxonomic group; $\mu$ =average abundance per core; $\mathrm{SE}=$ standard error of the average abundance; $\%=$ percent average species abundance over total abundance; Freq= frequency of occurrence of a species across all sample sites. * denotes a species that significantly contributed to similarities within a group; $†$ species are non-native

\begin{tabular}{llllll|} 
a) Before South region of North Azevedo Pond (n=8, s=2) & & & & \\
Species & \multicolumn{1}{c}{ Group } & $\mu$ & SE & $\%$ & Freq \\
\hline Monocorophium insidiosum $\dagger$ & Ampipoda & $174.3^{*}$ & 75.9 & 32.4 & 1.0 \\
Gemma gemma $\dagger$ & Bivalvia & $148.8^{*}$ & 61.5 & 27.6 & 1.0 \\
Zeuxo normani & Tanaidacea & 72.3 & 64.9 & 13.4 & 0.6 \\
Tubificoides spp. & Oligochaeta & 34.8 & 11.5 & 6.5 & 0.8 \\
Paranais littoralis cf & Oligochaeta & 22.8 & 21.0 & 4.2 & 0.3 \\
Limnodriloides spp. & Oligochaeta & 18.9 & 12.4 & 3.5 & 0.6 \\
Streblospio benedicti & Polychaeta & 9.6 & 5.9 & 1.8 & 0.8 \\
Grandidierella japonica $\dagger$ & Amphipoda & 7.0 & 5.4 & 1.3 & 0.6 \\
Lineus rubescens & Nemertea & 6.1 & 3.2 & 1.1 & 0.5 \\
Diadumenidae $\dagger$ & Cnidaria & 5.8 & 3.7 & 1.1 & 0.4 \\
Nutricola tantilla & Bivalvia & 0.6 & 0.5 & 0.1 & 0.3 \\
Battillaria attramentaria $\dagger$ & Gastropoda & 4.1 & 3.9 & 0.8 & 0.1 \\
Capitella teleta $\dagger$ & Polychaeta & 1.3 & 0.7 & 0.2 & 0.4 \\
Bathydrilus spp. & Oligochaeta & 0.0 & 0.0 & 0.0 & 0.0 \\
Pseudopolydora kempi $\dagger$ & Polychaeta & 0.0 & 0.0 & 0.0 & 0.0 \\
Edwardsiidae & Cnidaria & 1.0 & 0.4 & 0.2 & 0.6 \\
Pseudopolydora spp. & Polychaeta & 0.0 & 0.0 & 0.0 & 0.0 \\
Podocopida & Ostracoda & 0.0 & 0.0 & 0.0 & 0.0 \\
Tryonia imitator & Gastropoda & 0.0 & 0.0 & 0.0 & 0.0 \\
Tubificadae & Oligochaeta & 0.0 & 0.0 & 0.0 & 0.0 \\
\hline
\end{tabular}




\begin{tabular}{|c|c|c|c|c|c|}
\hline Species & Group & $\mu$ & SE & $\%$ & Freq \\
\hline Monocorophium insidiosum $†$ & Ampipoda & $150.8 *$ & 31.6 & 22.2 & 1.0 \\
\hline Gemma gemma $\dagger$ & Bivalvia & 3.0 & 1.6 & 0.4 & 0.6 \\
\hline Zeuxo normani & Tanaidacea & 0.0 & 0.0 & 0.0 & 0.0 \\
\hline Tubificoides spp. & Oligochaeta & $74.2^{*}$ & 45.9 & 10.9 & 1.0 \\
\hline Paranais littoralis cf & Oligochaeta & 1.8 & 1.6 & 0.3 & 0.2 \\
\hline Limnodriloides spp. & Oligochaeta & 29.0 & 16.9 & 4.3 & 0.8 \\
\hline Streblospio benedicti & Polychaeta & $26^{*}$ & 18.7 & 3.8 & 1.0 \\
\hline Grandidierella japonica $†$ & Amphipoda & 2.2 & 1.2 & 0.3 & 0.4 \\
\hline Lineus rubescens & Nemertea & 0.0 & 0.0 & 0.0 & 0.0 \\
\hline Diadumenidae $\dagger$ & Cnidaria & 0.0 & 0.0 & 0.0 & 0.0 \\
\hline Nutricola tantilla & Bivalvia & 204.2 & 134.3 & 30.1 & 0.8 \\
\hline Battillaria attramentaria $\dagger$ & Gastropoda & $128.2^{*}$ & 56.1 & 18.9 & 1.0 \\
\hline Capitella teleta $\dagger$ & Polychaeta & 26.6 & 11.4 & 3.9 & 0.8 \\
\hline Bathydrilus spp. & Oligochaeta & 15.6 & 8.1 & 2.3 & 0.8 \\
\hline Pseudopolydora kempi $\dagger$ & Polychaeta & 5.2 & 1.4 & 0.8 & 0.8 \\
\hline Edwardsiidae & Cnidaria & 1.0 & 0.5 & 0.1 & 0.6 \\
\hline Pseudopolydora spp. & Polychaeta & 0.4 & 0.4 & 0.1 & 0.2 \\
\hline Podocopida & Ostracoda & 0.0 & 0.0 & 0.8 & 0.0 \\
\hline Tryonia imitator & Gastropoda & 0.0 & 0.0 & 0.0 & 0.0 \\
\hline Tubificadae & Oligochaeta & 0.0 & 0.0 & 0.0 & 0.0 \\
\hline
\end{tabular}




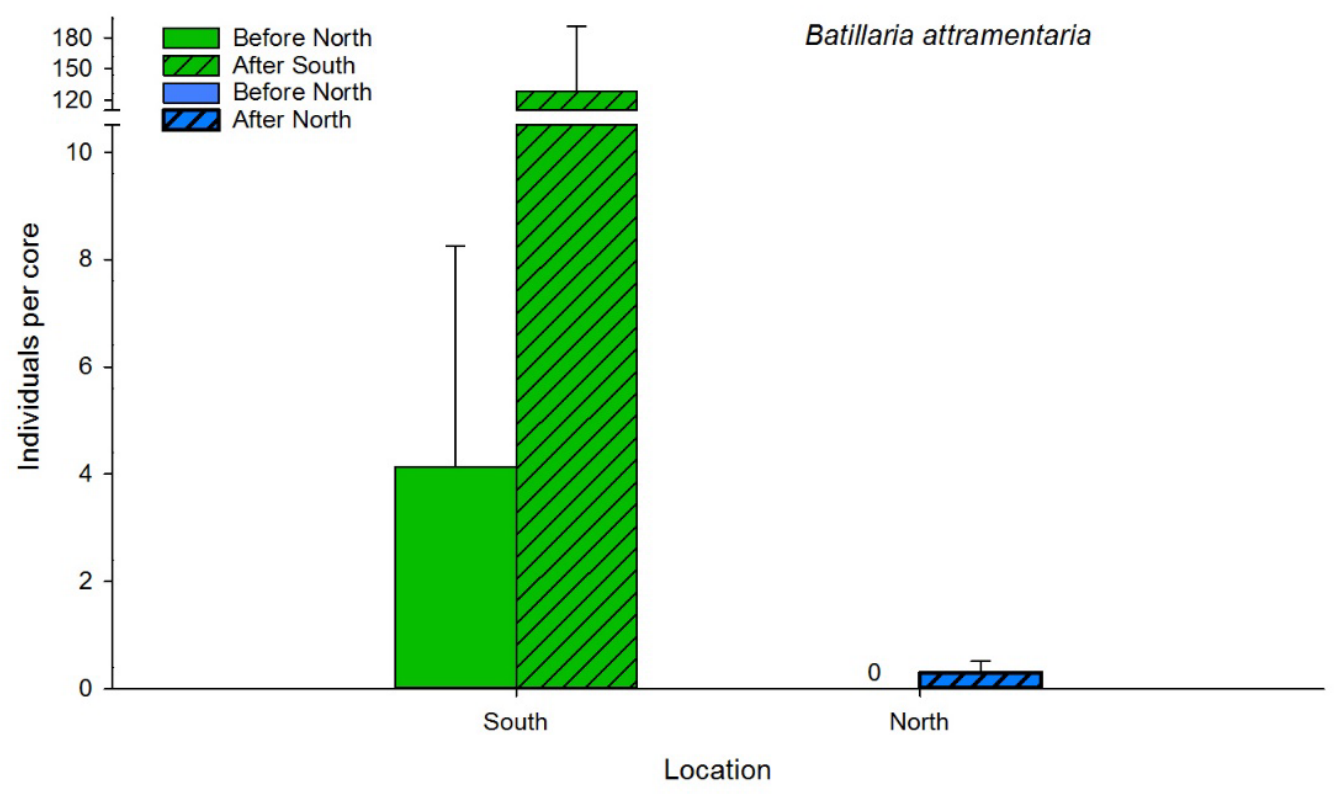

Fig. 8. Changes in abundance of non-native snail, Batillaria attramentaria by impact and location. Means and standard errors

In the south region, where there was an increase of Batillaria over time, there was a distinct drop in average abundance of Gemma gemma, a non-native bivalve. Overall, Gemma average abundance dropped from 19,077 (SE=61.5) to 385 individuals $\left(\mathrm{m}^{2}\right)^{-1}(\mathrm{SE}=1.6)$. Its drop in the community coincided with an increase in Nutricola tantilla, which spiked in three out of five stations (Table 8, Fig. 9, see Appendix C). 
a)

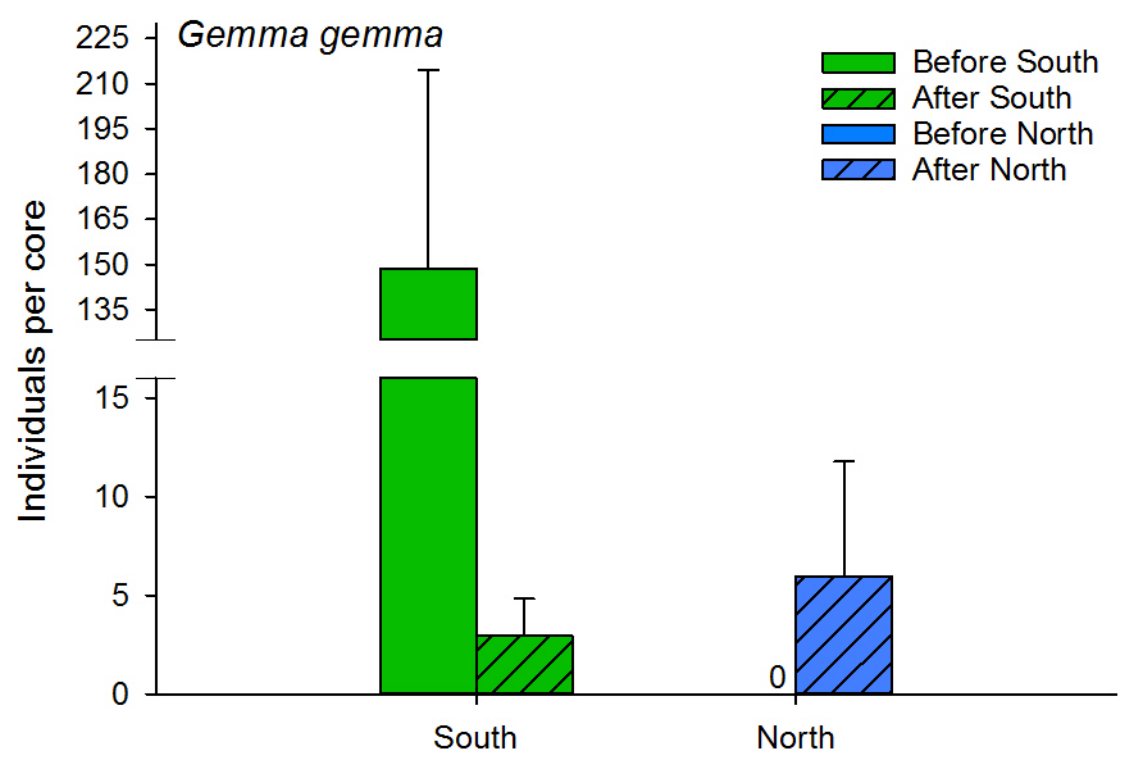

b)

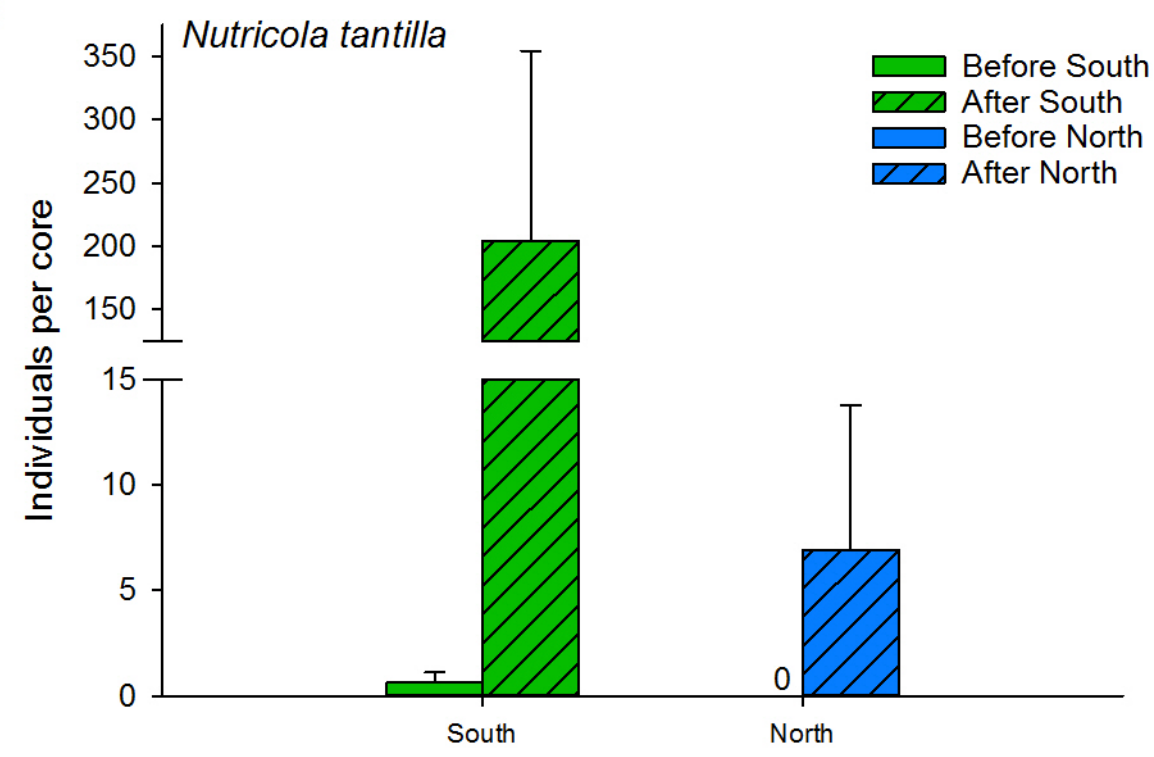

Fig. 9. Two most abundant bivalves, Gemma gemma (a) and Nutricola tantilla (b), showing a replacement of Gemma with Nutricola in the south and a spike in appearance for both populations in the north. Means and standard errors 
Before North and After North. Although there were no significant temporal differences found in the multivariate analyses for the communities in the north, there were a few noteworthy shifts in species abundances. The polychaete, Pseudopolydora kempi, increased from a mean of 7,462 (SE=16.4) to 38,103 individuals $\left(\mathrm{m}^{2}\right)^{-1}(\mathrm{SE}=96.5)$ (Fig. 10), and the polychaete, Capitella teleta, decreased from a mean of 15,231 ( $\mathrm{SE}=57.6)$ to 1,615 individuals $\left(\mathrm{m}^{2}\right)^{-1}(\mathrm{SE}=5.9)$ (Table 9, Fig. 11). On the other hand, both of these polychaete species increased in the south region; Capitella slightly increased from $167(\mathrm{SE}=.7)$ to 3,410 individuals $\left(\mathrm{m}^{2}\right)^{-1}(\mathrm{SE}=11.4)$, and Pseudopolydora increased in the south from 0 to 667 individuals $\left(\mathrm{m}^{2}\right)^{-1}(\mathrm{SE}=1.4)$. 
Table 9. The top 20 most abundant species per core $\left(.0078 \mathrm{~m}^{2}\right)$ for before (a) and after (b) the water control structures were installed at the no region of North Azevedo Pond; $\mathrm{n}=$ number of sample sites; $\mathrm{s}=$ number of sampling periods; group=major taxonomic group; $\mu=$ average abundance per core; $\mathrm{SE}=$ standard error of the average abundance; $\%=$ percent average species abundance over total abundance; Freq= frequency of occurrence of a species across all sample sites. * denotes a species that significantly contributed to similarities within a group; $†$ species are non-native

\begin{tabular}{|c|c|c|c|c|c|}
\hline Species & Group & $\mu$ & SE & $\%$ & Freg \\
\hline Capitella teleta† & Polychaeta & $118.8^{*}$ & 57.6 & 24.9 & 1.0 \\
\hline Paranais littoralis $c f$ & Oligochaeta & 93.4 & 55.8 & 19.6 & 0.6 \\
\hline Tubificoides spp. & Oligochaeta & $85.4^{*}$ & 42.1 & 17.9 & 1.0 \\
\hline Pseudopolydora kempi $\dagger$ & Polychaeta & $58.2 *$ & 16.4 & 12.2 & 1.0 \\
\hline Monocorophium insidiosum $†$ & Amphipoda & 53.8 & 43.1 & 11.3 & 0.6 \\
\hline Edwardsiidae & Cnidaria & 42.0 & 34.0 & 8.8 & 0.6 \\
\hline Streblospio benedicti $\dagger$ & Polychaeta & 5.8 & 5.0 & 1.2 & 0.4 \\
\hline Tubificadae & Oligochaeta & 5.4 & 4.8 & 1.1 & 0.2 \\
\hline Bathydrilus spp. & Oligochaeta & 3.0 & 1.6 & 0.6 & 0.4 \\
\hline Pseudopolydora spp. & Polychaeta & 2.4 & 1.7 & 0.5 & 0.4 \\
\hline Podocopida & Ostracoda & 0.0 & 0.0 & 0.0 & 0.0 \\
\hline Limnodriloides spp. & Oligochaeta & 1.4 & 1.3 & 0.3 & 0.2 \\
\hline Tryonia imitator & Gastropoda & 0.0 & 0.0 & 0.0 & 0.0 \\
\hline Grandidierella japonica $†$ & Crustacea & 0.0 & 0.0 & 0.0 & 0.0 \\
\hline Nutricola tantilla & Bivalvia & 0.0 & 0.0 & 0.0 & 0.0 \\
\hline Gemma gemma $†$ & Bivalvia & 0.0 & 0.0 & 0.0 & 0.0 \\
\hline Diadumenidae & Cnidaria & 0.2 & 0.2 & 0.0 & 0.2 \\
\hline Battillaria attramentaria $†$ & Mollusca & 0.0 & 0.0 & 0.0 & 0.0 \\
\hline Zeuxo normani & Tanaidacea & 0.0 & 0.0 & 0.0 & 0.0 \\
\hline Lineus rubescens & Nemertea & 0.0 & 0.0 & 0.0 & 0.0 \\
\hline
\end{tabular}




\begin{tabular}{|llcccc|}
\hline b) After North region of North Azevedo Pond (n=10, s=2) & & & & \\
Species & & & & & \\
Monocorophium insidiosum $\dagger$ & Group & $\mu$ & SE & $\%$ & Freq \\
Gemma gemma $\dagger$ & Ampipoda & 12.6 & 5.9 & 2.1 & 0.8 \\
Zeuxo normani & Bivalvia & 51.1 & 29.9 & 8.4 & 0.4 \\
Tubificoides spp. & Tanaidacea & 52.4 & 27.8 & 8.6 & 0.7 \\
Paranais littoralis cf & Oligochaeta & $297.2^{*}$ & 96.5 & 48.7 & 1.0 \\
Limnodriloides spp. & Oligochaeta & 18.2 & 10.1 & 3.0 & 0.8 \\
Streblospio benedicti & Oligochaeta & 62.5 & 34.4 & 10.2 & 0.7 \\
Grandidierella japonica $\dagger$ & Polychaeta & 17.1 & 12.9 & 2.8 & 0.5 \\
Lineus rubescens & Amphipoda & 0.0 & 0.0 & 0.0 & 0.0 \\
Diadumenidae $\dagger$ & Nemertea & 8.8 & 4.7 & 1.4 & 0.6 \\
Nutricola tantilla & Cnidaria & 3.2 & 1.8 & 0.5 & 0.4 \\
Battillaria attramentaria $\dagger$ & Bivalvia & 28.8 & 16.6 & 4.7 & 0.5 \\
Capitella teleta $\dagger$ & Gastropoda & 15.6 & 6.3 & 2.6 & 0.7 \\
Bathydrilus spp. & Polychaeta & 11.7 & 11.1 & 0.0 & 0.1 \\
Pseudopolydora kempi $\dagger$ & Oligochaeta & 10.1 & 9.2 & 0.1 & 0.2 \\
Edwardsiidae & Polychaeta & 6.9 & 6.5 & 0.0 & 0.1 \\
Pseudopolydora spp. & Cnidaria & 6.0 & 5.5 & 0.0 & 0.2 \\
Podocopida & Polychaeta & 0.5 & 0.3 & 0.0 & 0.2 \\
Tryonia imitator & Ostracoda & 0.3 & 0.2 & 0.0 & 0.2 \\
Tubificadae & Gastropoda & 0.0 & 0.0 & 0.0 & 0.0 \\
& Oligochaeta & 0.0 & 0.0 & 0.0 & 0.0 \\
\hline
\end{tabular}




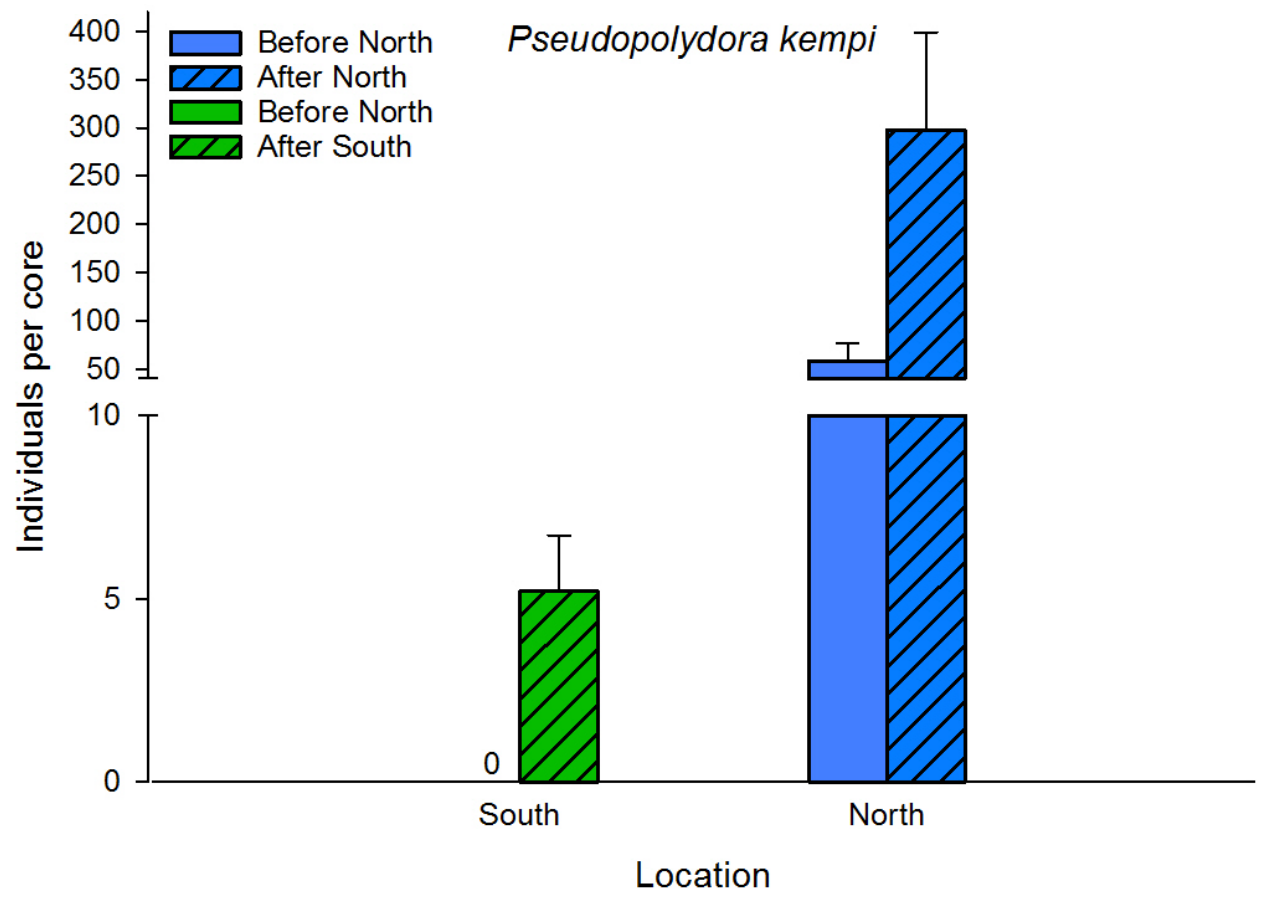

Fig. 10. Pseudopolydora kempi abundances by impact and location. Means and standard errors 




Fig. 11. Capitella teleta abundances by impact and location. Means and standard errors

South versus North. The benthic communities were significantly different between south and north regions of North Azevedo Pond (Table 3). The south end was dominated by high abundances of mollusks and crustaceans (Table 6, Table 8 ). Monocorophium insidiosum, a non-native amphipod, had the highest persistent abundance in both Before South (22,346 average individuals $\left.\left(\mathrm{m}^{2}\right)^{-1}, \mathrm{SE}=75.9\right)$ and After South samples $(19,333$ average individuals $\left.\left(\mathrm{m}^{2}\right)^{-1}, \mathrm{SE}=31.6\right)$, but was also present in the After North (Table 6, Table 7, Table 8, Table 9b, Fig. 12). As stated previously, the south had several high abundances of the following mollusk species: Batillaria attramentaria, Gemma gemma, Nutricola tantilla (Table 8). On the other hand, the north end was dominated by annelids 
and cnidarians (Table 7, Table 9). Capitella teleta and Pseudopolydora kempi were the two major annelids that greatly contributed to the dissimilarity between south and north (Table 7, Table 9, Fig. 10, Fig. 11). Edwardsiidae, a burrowing cnidarian, also drove differences between the two locations by having a much higher abundance in the north end both before and after construction (Fig. 13).

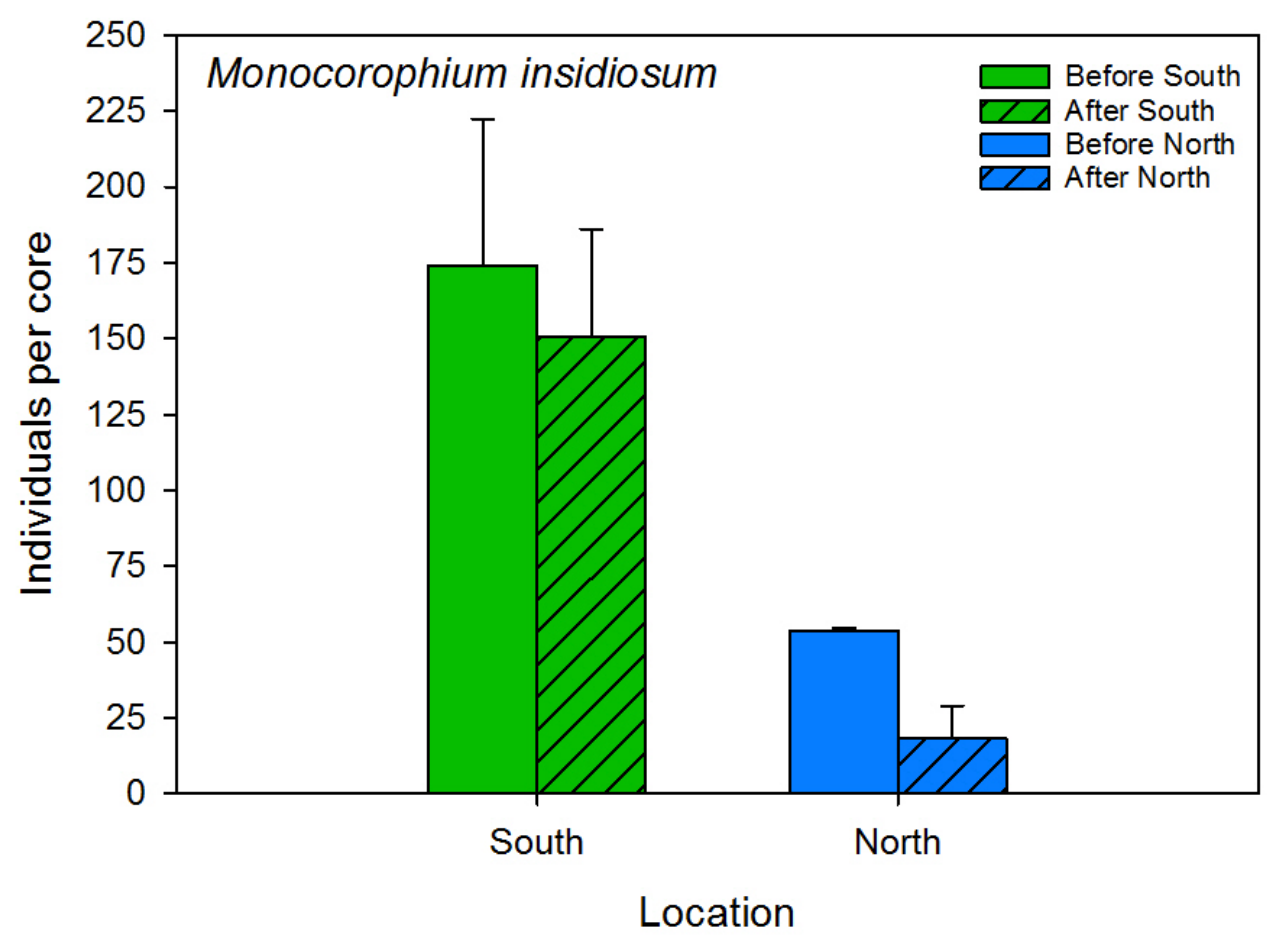

Fig. 12. Monocorophium insidiosum abundances by impact and location. Means and standard errors 


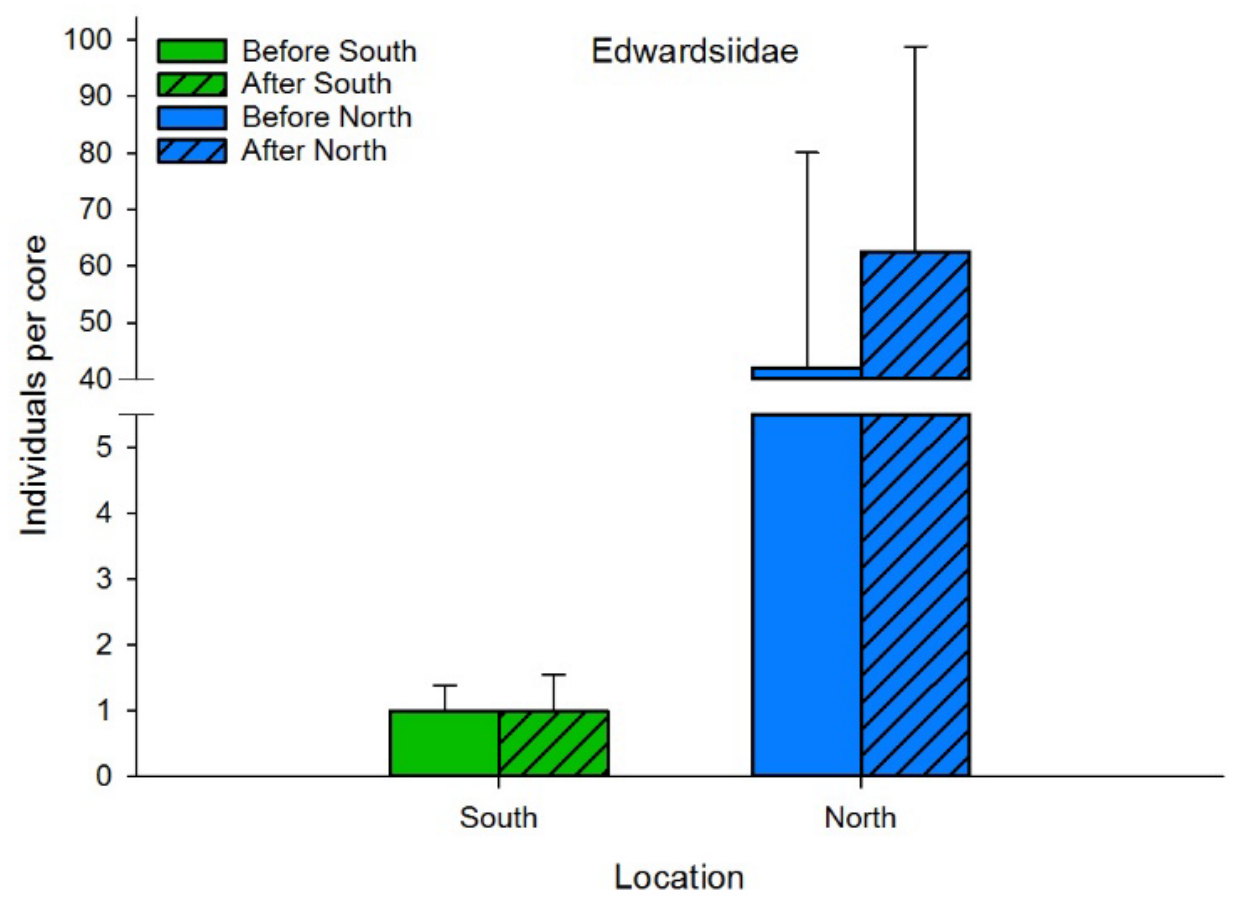

Fig. 13. Edwardsiidae abundances by impact and location. Means and standard errors

\section{Environmental Drivers}

\section{Grain size.}

Mean, mode, and standard deviation. Although I analyzed both basal (see Appendix G) and surface readings for the majority of my sediment samples, I decided to focus on surface samples given this was the layer representative of the benthic infaunal habitat (Table 10). 
Table 10. Summary table of surface grain size measurement by impact and location. All values not in parentheses are averages. Numbers in parentheses are standard error; $\mathrm{n}=$ number of sediment cores; $\mathrm{SD}=$ standard deviation. All values are in $\mu \mathrm{m}$ units

\begin{tabular}{r|c|c|c|c} 
& \multicolumn{2}{c}{ South } & \multicolumn{2}{c}{ North } \\
Before & After & Before & After \\
$(\mathrm{n}=3)$ & $(\mathrm{n}=8)$ \\
\hline Grain size factors & $(\mathrm{n}=4)$ & $173.68(48.91)$ & $23.67(2.46)$ & $22.12(1.73)$ \\
SD & $6.01(0.64)$ & $5.02(1.96)$ & $3.44(0.07)$ & $3.39(0.14)$ \\
Mode & $394.63(61.05)$ & $329.67(80.84)$ & $49.69(33.29)$ & $46.7(17.8)$ \\
Clay \% & $6.08(1.31)$ & $5.02(1.16)$ & $8.33(0.56)$ & $9.16(1.27)$ \\
Silt \% & $29.44(6.14)$ & $22.45(9.91)$ & $67.47(3.59)$ & $69.74(2.29)$ \\
Sand \% & $64.48(7.3)$ & $72.52(11.03)$ & $24.2(4.03)$ & $21.1(2.49)$
\end{tabular}

The mode grain size is defined as the most frequently occurring grain size (Fig.

14). Before South $(\mu=394.63, \mathrm{SE}=61.05)$ and After South $(\mu=329.67, \mathrm{SE}=80.84)$

both had mode values that fell under the categorical classification of medium size sand. The north had predominately much smaller modes. Before North $(\mu=46.69$, $\mathrm{SE}=33.29)$ and After North $(\mu=46.7, \mathrm{SE}=17.8)$ both fell under the silt classification. Mean grain size values for each regime were relatively smaller than the mode values but still showed distinct differences between the two locations (Fig. 15). 


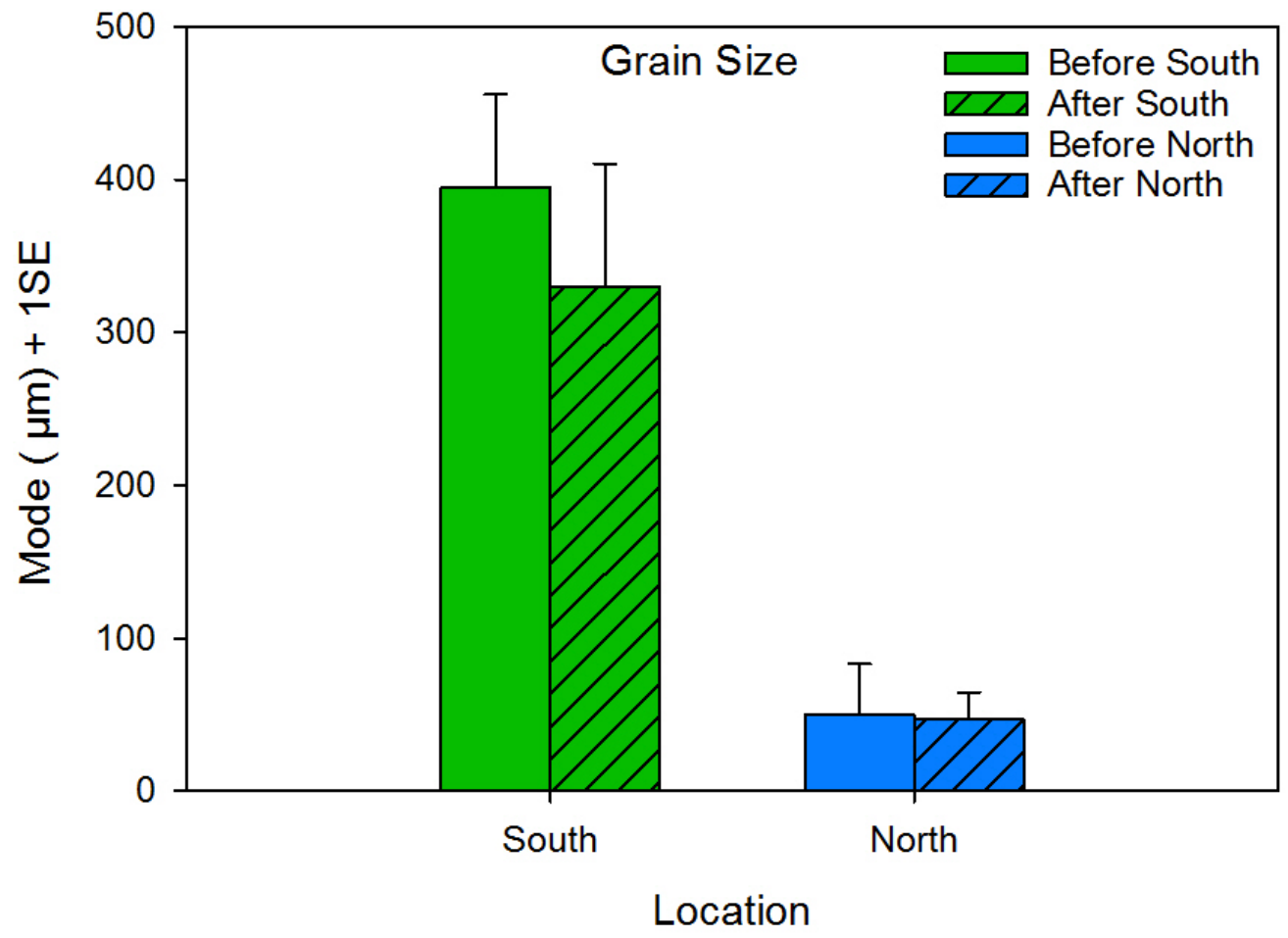

Fig. 14. Mode grain size by impact and location. Means and standard errors 


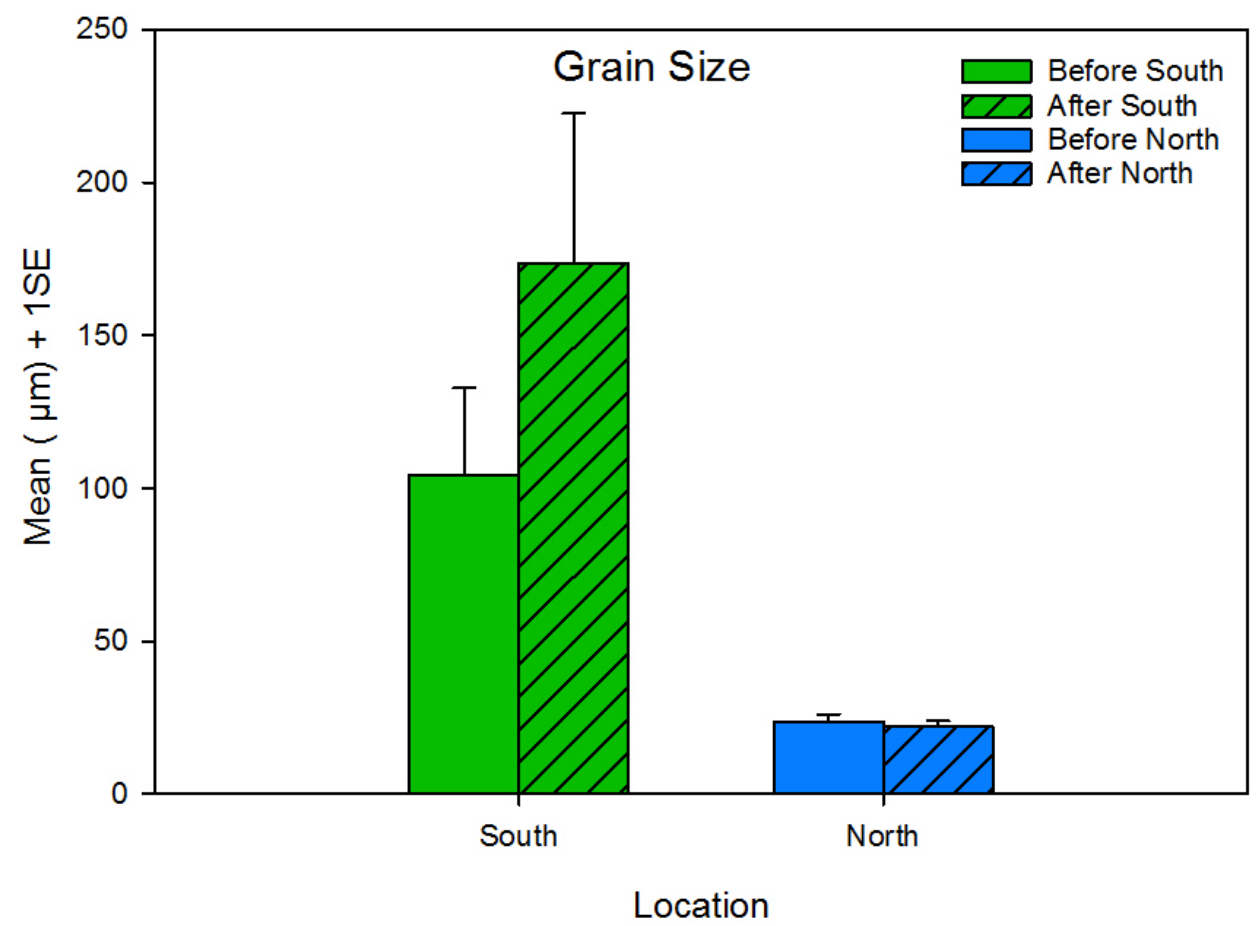

Fig. 15. Mean grain size by impact and location. Means and standard errors

Standard deviation (SD) was likewise higher in the south than in the north ( $\mathrm{S}=143, \mathrm{p}<.0001$ ). Both South SDs were greater than 4.00 classifying these sediment samples as "very poorly sorted "(Fork 1968). However, both Before and After North SDs were less than 4.00 and were classified as "poorly sorted” (Fig. 16). 


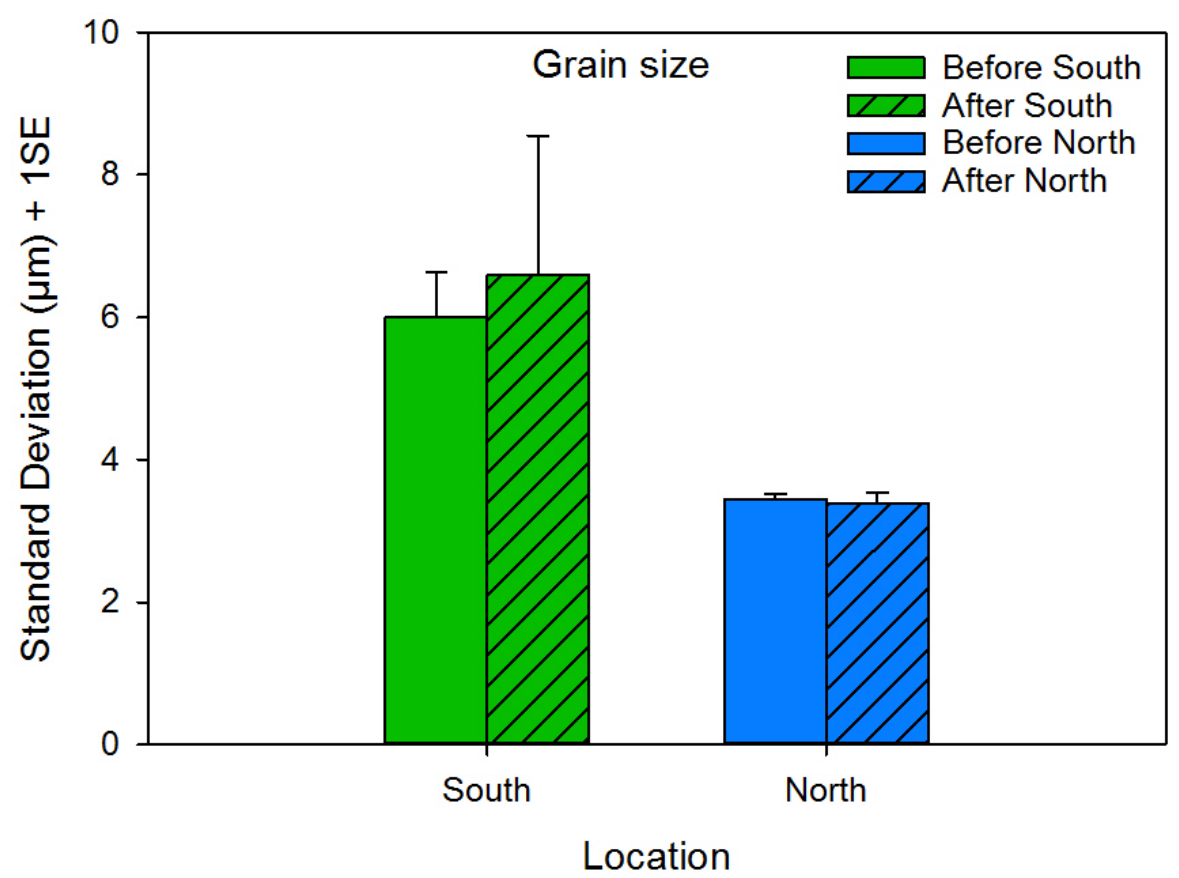

Fig. 16. Standard deviation grain size for impact and location. Means and standard errors

Two-way ANOVAs were run to test the effect of impact and location on each grain size measurement (mean, mode, and SD). Mean, mode, and SD were all transformed accordingly in order to correct for non-normal distribution. Mean, mode, and standard deviation for grain size were all found to be significantly different between locations (Table 11). 
Table 11. Two-way ANOVA grain size analyses of square root transformed mean grain size, log transformed mode grain size, and square root transformed grain size by impact and location; $\mathrm{df}=$ degrees of freedom; $\mathrm{MS}=$ mean square; $\mathrm{f}=\mathrm{f}$ ratio, $\mathrm{p}=\mathrm{p}$ value;

* denotes a significant $\mathrm{p}$-value $(\mathrm{p}<.05)$

a) $\sqrt{\text { Mean grain size }}$

\begin{tabular}{lcccc} 
& df & MS & f & p \\
\hline \hline Impact & 1 & 6.141 & 0.898 & 0.358 \\
Location & 1 & 184.408 & 26.955 & $<.0001^{*}$ \\
Impact*Location & 1 & 8.104 & 1.185 & 0.293 \\
Error & 16 & 6.841 & &
\end{tabular}

b) Log (Mode grain size)

\begin{tabular}{lcccc} 
& df & MS & f & p \\
\hline \hline Impact & 1 & 0.618 & 0.470 & 0.503 \\
Location & 1 & 20.456 & 15.529 & $0.0012^{*}$ \\
Impact*Location & 1 & 0.508 & 0.386 & 0.543 \\
Error & 16 & 1.317 & &
\end{tabular}

c) $\sqrt{\mathrm{SD}}$

\begin{tabular}{lcccc} 
& df & MS & f & p \\
\hline \hline Impact & 1 & 0.001 & 0.004 & 0.948 \\
Location & 1 & 1.656 & 10.654 & $0.0049 *$ \\
Impact*Location & 1 & 0.004 & 0.023 & 0.881 \\
Error & 16 & 0.155 & &
\end{tabular}


Percent class grain size. Percent grain size was calculated by consolidating class sizes. Clay was any grain size less than $4 \mu \mathrm{m}$. Silt was any grain size less than $63 \mu \mathrm{m}$ but greater than $4 \mu \mathrm{m}$. Sand was any grain size between $63 \mu \mathrm{m}$ and $250 \mu \mathrm{m}$.

Before South and After South were both significantly higher in \% sand than the North $\left(F_{1,16}=42.09, p<.0001\right)$. The $\%$ silt and $\%$ clay content in the north cores were both significantly higher than the south cores ( Table 12). A PCA was run on the \% grain size data in order to understand comprehensive trends between grain size and the two factors, impact and location (Fig. 17). 
Table 12. Percent grain size class 2-way ANOVA statistics summary table

a) \% clay

\begin{tabular}{lcccc} 
& df & MS & $\mathrm{f}$ & $\mathrm{p}$ \\
\hline \hline Impact & 1 & 0.0613 & 0.007 & 0.9341 \\
Location & 1 & 44.906 & 5.162 & $0.0372 *$ \\
Impact*Location & 1 & 3.9193 & 0.451 & 0.5117 \\
Error & 16 & 8.6993 & &
\end{tabular}

a) \% silt

\begin{tabular}{lcccc} 
& df & MS & $\mathrm{f}$ & $\mathrm{p}$ \\
\hline \hline Impact & 1 & 24.449 & 0.14 & 0.7129 \\
Location & 1 & 8012.8 & 46 & $<.0001^{*}$ \\
Impact*Location & 1 & 94.436 & 0.542 & 0.4722 \\
Error & 16 & 174.2 & &
\end{tabular}

a) \% sand

\begin{tabular}{lclll} 
& df & MS & $\mathrm{f}$ & $\mathrm{p}$ \\
\hline \hline Impact & 1 & 26.959 & 0.123 & 0.7308 \\
Location & 1 & 9257.4 & 42.09 & $<.0001^{*}$ \\
Impact*Location & 1 & 136.83 & 0.622 & 0.4418 \\
Error & 16 & 219.94 & &
\end{tabular}




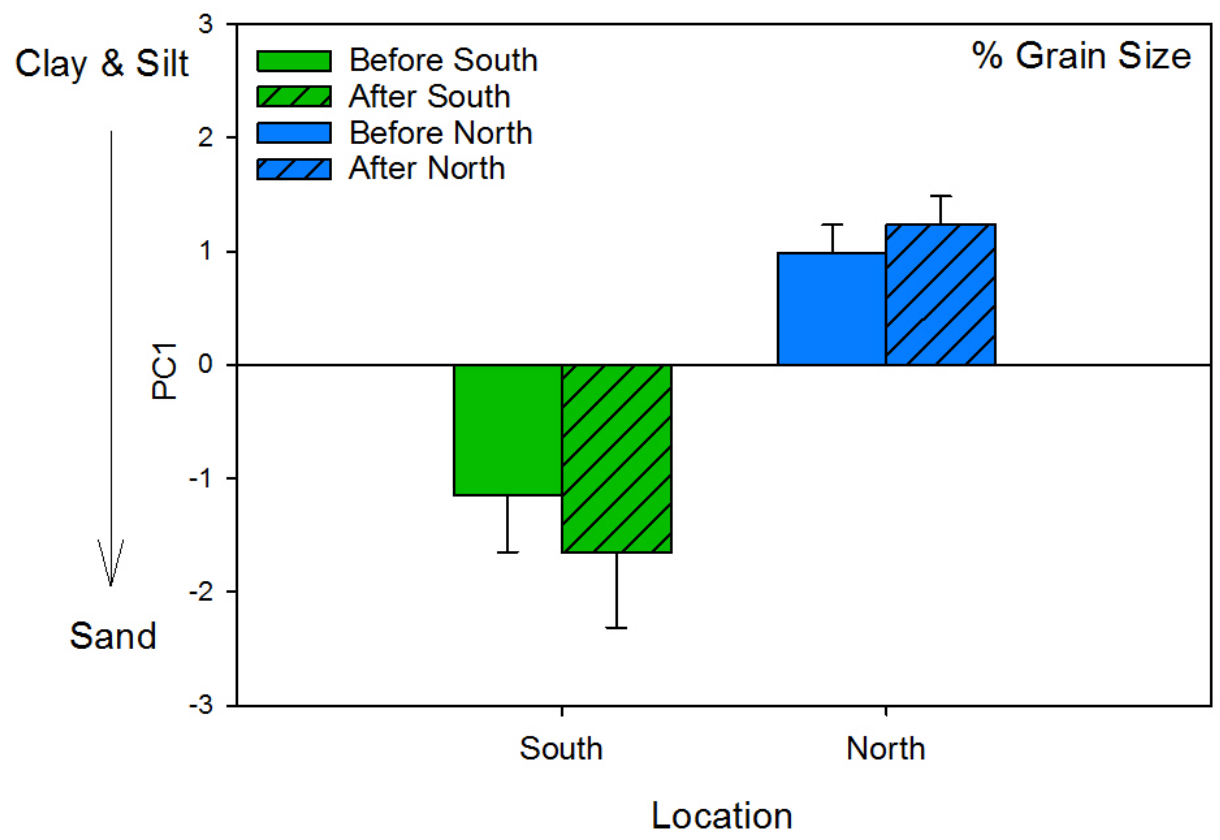

Fig. 17. Principle Component 1 values reflected onto a bar graph by impact and location. Means and standard errors

Water quality data. All means of monthly averages, standard deviations, and ranges (from individual data points) were summarized into two comprehensive tables separated by south (Table 13) and north (Table 14).

Multiple t-tests were used to compare south and north daily water quality averages for October 2014. Comparing these two locations, south had significantly higher DO than the north ( $p=0.0321)$. Also, the north had significantly higher salinities than the south ( $p$ $<.0001$ ) ( Table 15). Temperature and pH between the two locations for October 2014 were not significantly different. 
Table 13. Average water quality conditions in the south region of North Azevedo Pond. Means were calculated from monthly averages. Ranges were determined from individual data points (every 15 minutes; Before= January 2007- December 2009; After= January 2009-January 2015; \pm SD = mean \pm standard deviation; Rainy =rainy season: NovemberMarch; Dry = dry season: April-October; $n=$ number of sample mean months used for each water quality factor; “__” = missing water quality data

\begin{tabular}{|c|c|c|c|c|c|c|}
\hline \multicolumn{7}{|l|}{ South Water Quality } \\
\hline Factors & $\begin{array}{l}\text { Rainy } \\
(\mathrm{n}=16)\end{array}$ & $\begin{array}{c}\text { Dry } \\
(n=16)\end{array}$ & Range & $\begin{array}{l}\text { Rainy } \\
(\mathrm{n}=20)\end{array}$ & $\begin{array}{c}\text { Dry } \\
(\mathrm{n}=20)\end{array}$ & Range \\
\hline DO ( mg/L) & $254.6 \pm 40.4$ & $183.2 \pm 38.3$ & $0-709.4$ & $236 \pm 22$ & $189.6 \pm 30.5$ & $0-934.4$ \\
\hline Temperature $\left(\mathrm{C}^{\circ}\right)$ & $12.7 \pm 2.33$ & $18.9 \pm 1.6$ & $1.4-35.1$ & $13.9 \pm 2.2$ & $19.6 \pm 1.8$ & $1.7-35.1$ \\
\hline Salinity ( ppt) & $29.3 \pm 3.5$ & $33.4 \pm 1.8$ & $0-42.2$ & $29.8 \pm 2.3$ & $32.1 \pm 1.8$ & $0-44.8$ \\
\hline $\mathrm{pH}$ & $8.2 \pm 0.2$ & $8 \pm 0.2$ & $6.9-9.3$ & $8.1 \pm 0.3$ & $8.1 \pm 0.2$ & $6.2-10.8$ \\
\hline
\end{tabular}

Table 14. Average water quality conditions in the north region of North Azevedo Pond. Means were calculated from monthly averages. Ranges were determined from individual data points (every 15 minutes); Before =January 2007- December 2008; After=April 2010-September 2015; $\mu \pm \mathrm{SD}=$ mean \pm standard deviation; Rainy =rainy season:

November-March; Dry = dry season: April-October; $n=$ number of sample mean months used for each water quality factor; “_-” = missing water quality data

\begin{tabular}{|c|c|c|c|c|c|c|}
\hline \multicolumn{7}{|l|}{ North Water Quality } \\
\hline Factors & $\begin{array}{c}\text { Rainy } \\
(\mathrm{n}=0)\end{array}$ & $\begin{array}{c}\text { Dry } \\
(\mathrm{n}=0)\end{array}$ & Range & $\begin{array}{c}\text { Rainy } \\
(\mathrm{n}=6)\end{array}$ & $\begin{array}{l}\begin{array}{l}\text { Dry } \\
(\mathrm{n}=9)\end{array} \\
\end{array}$ & Range \\
\hline DO ( mg/L) & - & - & - & $218.4 \pm 32.4$ & $178.1 \pm 56.5$ & $0-1165.6$ \\
\hline Temperature $\left(\mathrm{C}^{\circ}\right)$ & - & - & - & $14.4 \pm 3.3$ & $23.5 \pm 7.1$ & $1.4-38.7$ \\
\hline Salinity ( ppt) & - & - & - & $32.7 \pm 2.3$ & $32.7 \pm 6.8$ & $0-52.0$ \\
\hline $\mathrm{pH}$ & - & - & - & $5.3 \pm 1.7$ & $8.2 \pm 0.2$ & $4.0-10.6$ \\
\hline
\end{tabular}


Table 15. Multiple t-tests between October 2015 daily water quality averages and the south and north regions of North Azevedo Pond

Location

\begin{tabular}{lcc} 
Factor & $\mathrm{t}_{1,60}$ & $\mathrm{p}$-value \\
\hline \hline $\mathrm{DO}(\mu \mathrm{M})$ & -2.19422 & $0.0321^{*}$ \\
Temperature $\left(\mathrm{C}^{\circ}\right)$ & 1.236884 & 0.2209 \\
Salinity $(\mathrm{ppt})$ & -5.92216 & $<.0001^{*}$ \\
$\mathrm{pH}$ & 1.236884 & 0.6717
\end{tabular}

Temperature. Means of monthly averages temporally increased in the south. Rainy season means increased from an average $12.74 \mathrm{C}^{\circ}(\mathrm{SD}=2.33)$ to an After Impact average of $13.92 \mathrm{C}^{\circ}(\mathrm{SD}=2.22)$. South dry season temperatures also increased from an average $18.85 \mathrm{C}^{\circ}(\mathrm{SD}=1.56)$ to an average $19.6 \mathrm{C}^{\circ}(\mathrm{SD}=1.83)$.

There were no reported "Before North” sonde data. However, the dry seasons for After North had a much higher mean temperature of 23.47 (SD=7.06) than After South dry seasons’ mean temperature of $19.6 \mathrm{C}^{\circ}(\mathrm{SD}=1.79)$. After North experienced extreme temperatures $\left(\geq 20 \mathrm{C}^{\circ}\right) 34.08 \%$ of the time which was higher than After South (24.23\%).

Salinity. Means of monthly salinity averages in the south remained consistent temporally throughout for both season regimes. After North experienced hypersalinity ( $\geq 35$ ppt) $25.99 \%$ of the time versus Before South (15.83\%) and After South (8.19\%) (Table 16).

Dissolved oxygen. Overall, dissolved oxygen means were higher during the rainy season versus the dry season for both locations. Dry season dissolved oxygen means marginally increased from $183.19 \mu \mathrm{M}(\mathrm{SD}=38.29)$ to $189.75(\mathrm{SD}=30.47)$ in the south. 
After North rainy season mean (218.45 $\mu \mathrm{M}, \mathrm{SD}=1.04)$ and dry season mean (178.14 $\mu \mathrm{M}, \mathrm{SD}=1.81$ ) were lower than the south seasonal regimes. After North experienced hypoxic events ( $\leq 63 \mu \mathrm{M})$ a higher percentage of the time (23.86\%) than Before South (14.97\%) and After South (13.04\%). After North was under critical DO conditions $25.75 \%$ versus After South (27.53\%) and Before South (22.6\%) (Table 16).

Table 16. Percent of time that extreme water quality occurred. Percentages are based on individual water quality data points (every 15 minutes) and not averages

\begin{tabular}{|lcc|cc|}
\hline & \multicolumn{2}{c}{ South } & \multicolumn{2}{c|}{ North } \\
Extreme water quality events & Before & After & Before & After \\
\hline \% Hypoxia events $(\leq 63 \mu \mathrm{M})$ & $14.97 \%$ & $13.04 \%$ & - & $23.86 \%$ \\
DO critical threshold $(94-188 \mu \mathrm{M})$ & $22.6 \%$ & $27.53 \%$ & - & $25.75 \%$ \\
\% Extreme temperature $\left(\geq 20 \mathrm{C}^{\circ}\right)$ & $23.64 \%$ & $24.23 \%$ & - & $34.08 \%$ \\
\% Hypersalinity $(\geq 35 \mathrm{ppt})$ & $15.83 \%$ & $8.19 \%$ & - & $25.99 \%$ \\
\hline
\end{tabular}

Duration of water quality events. Neither the south nor north experienced long term episodic extreme events (weeks to months), however both experienced shorter periodic events that were deemed as "sublethal” for infauna (Vaquer-Sunyer and Duarte 2008) (Table 17). South experienced higher occurrences of short sublethal episodic events in the After versus Before which were not reflected in the percent occurrence over the entire time period ( Table 16). The north also continued to have higher number of periodic sublethal events than the south. Also, north experienced a higher number of longer duration extreme temperatures and hypersalinities than the south as well. 
Table 17. Sublethal water quality events by duration. Number of occurrences and percent of time that those occurred for the designated duration in parentheses

a) South

\begin{tabular}{|c|c|c|c|c|c|c|}
\hline \multirow[b]{2}{*}{ Sublethal water quality events } & \multicolumn{6}{|c|}{ Before } \\
\hline & $\geq 12 \mathrm{~h}$ & $12-24 \mathrm{~h}$ & $1 \mathrm{~d}$ & $1-3 \mathrm{~d}$ & $4-7 \mathrm{~d}$ & $1 \mathrm{w}$ \\
\hline$\%$ Hypoxia $(\leq 63 \mu \mathrm{M})$ & $11679(15.3 \%)$ & $182(0.2 \%)$ & - & - & - & - \\
\hline DO critical threshold ( $94-188 \mu \mathrm{M})$ & $17814(23.3 \%)$ & $19(0 \%)$ & - & - & - & - \\
\hline$\%$ Extreme temperature $\left(\geq 20 \mathrm{C}^{\circ}\right)$ & 21254 (23\%) & $1335(1.4 \%)$ & - & - & - & - \\
\hline$\%$ Hypersalinity $(\geq 35 \mathrm{ppt})$ & 10050 (11.9\%) & $1810(2.1 \%)$ & $7(0 \%)$ & $912(1.1 \%)$ & $578(0.7 \%)$ & $2(0 \%)$ \\
\hline
\end{tabular}

\begin{tabular}{|c|c|c|c|c|c|c|}
\hline \multirow[b]{2}{*}{ Sublethal water quality events } & \multicolumn{6}{|c|}{ After } \\
\hline & $\geq 12 \mathrm{~h}$ & $12-24 \mathrm{~h}$ & $1 \mathrm{~d}$ & $1-3 d$ & $4-7 d$ & $1 \mathrm{w}$ \\
\hline \% Hypoxia $(\leq 63 \mu \mathrm{M})$ & $6829(21.7 \%)$ & $313(1 \%)$ & - & $45(0.1 \%)$ & - & - \\
\hline DO critical threshold ( $94-188 \mu \mathrm{M})$ & 8705 (27.7\%) & $29(0.1 \%)$ & - & - & - & - \\
\hline$\%$ Extreme temperature $\left(\geq 20 \mathrm{C}^{\circ}\right)$ & 8293 (25.4\%) & $1519(4.6 \%)$ & $8(0 \%)$ & $633(1.9 \%)$ & $363(1.1 \%)$ & - \\
\hline$\%$ Hypersalinity ( $\geq 35 \mathrm{ppt}$ ) & $4166(12.7 \%)$ & $1151(3.5 \%)$ & $5(0 \%)$ & $403(1.2 \%)$ & $103(0.3 \%)$ & - \\
\hline
\end{tabular}

b) North

After

\begin{tabular}{l|c|c|c|c|c|c} 
Sublethal water quality events & \multicolumn{2}{c}{$\geq 12 \mathrm{~h}$} & \multicolumn{1}{c}{$12-24 \mathrm{~h}$} & $1 \mathrm{~d}$ & $1-3 \mathrm{~d}$ & \multicolumn{2}{c}{$4-7 \mathrm{~d}$} & $1 \mathrm{w}$ \\
\hline \hline \% Hypoxia $(\leq 63 \mu \mathrm{M})$ & $9213(27.8 \%)$ & $1046(3.16 \%)$ & $2(0.01 \%)$ & $144(0.43 \%)$ & - & - \\
DO critical threshold $(94-188 \mu \mathrm{M})$ & $6210(18.74 \%)$ & - & - & - & - & - \\
\% Extreme temperature $\left(\geq 20 \mathrm{C}^{\circ}\right)$ & $9898(29.86 \%)$ & $1969(5.94 \%)$ & $12(0.04 \%)$ & $4706(14.2 \%)$ & $3926(11.85 \%)$ & $3346(10.1 \%)$ \\
\% Hypersalinity $(\geq 35 \mathrm{ppt})$ & $5303(16 \%)$ & $1856(5.6 \%)$ & $13(0.04 \%)$ & $2189(6.6 \%)$ & $1030(3.11 \%)$ & $3(0.01 \%)$
\end{tabular}

Temperature logger data. Temperature logger data were graphed temporally

alongside sonde data in two separate graphs in order to distinguish the two deployment periods: May-June 2015 and July-September 2015. There were no north sonde data for the first deployment period. The south sonde data reflected lower temperature readings than the temperature loggers in the north end and the north sonde data (Fig. 18, Fig. 19).

A day within this sampling period (September $18^{\text {th }}, 2015$ ) with the highest standard deviation was chosen to magnify the differences between temperature and location within the wetland system comparing temperature logger data and sonde data (Fig. 20). 


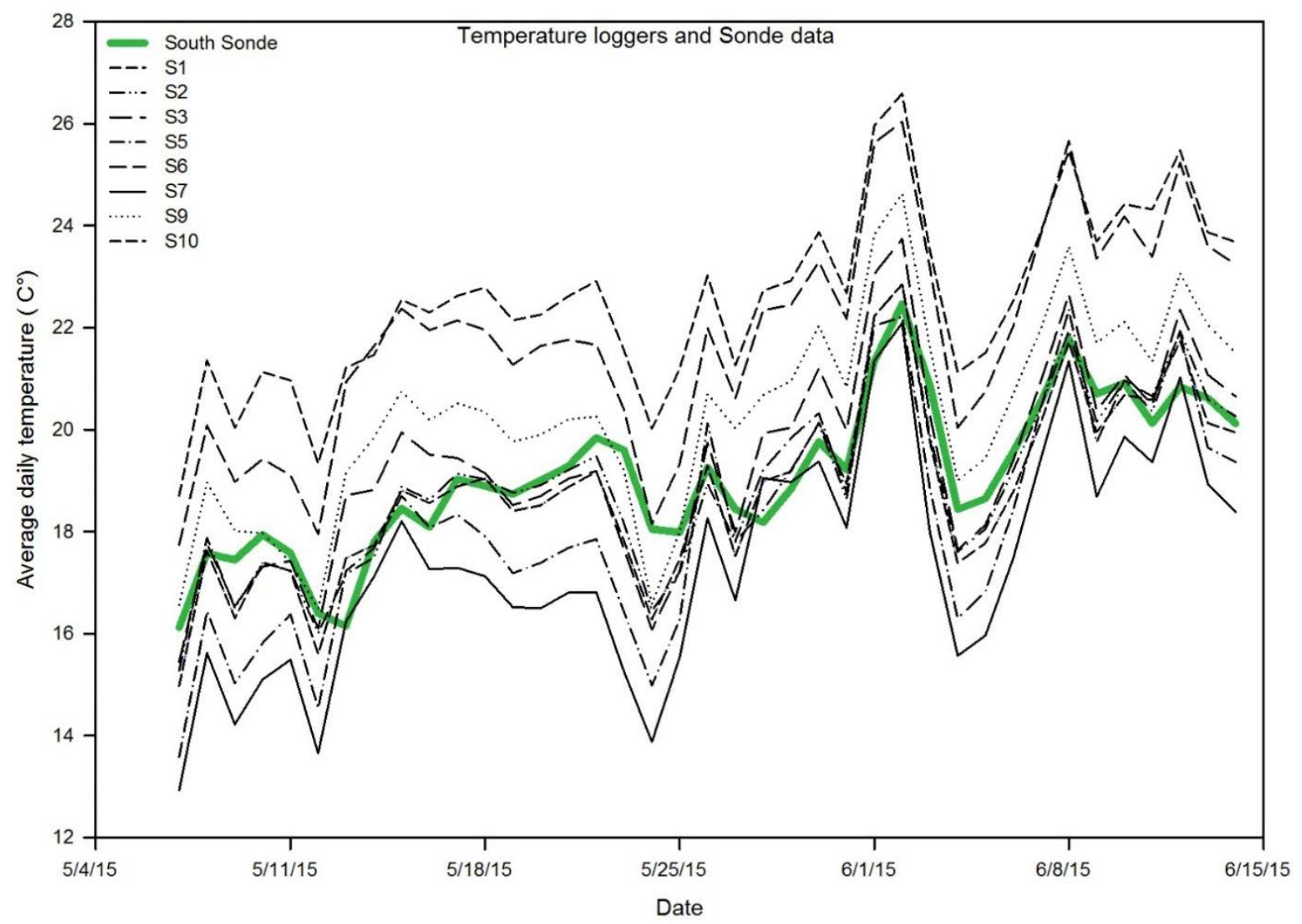

Fig. 18. Daily variations in temperature from temperature logger and South sonde only data. First deployment (5/4/15 to 6/15/2015). North sonde data was missing for this time period 


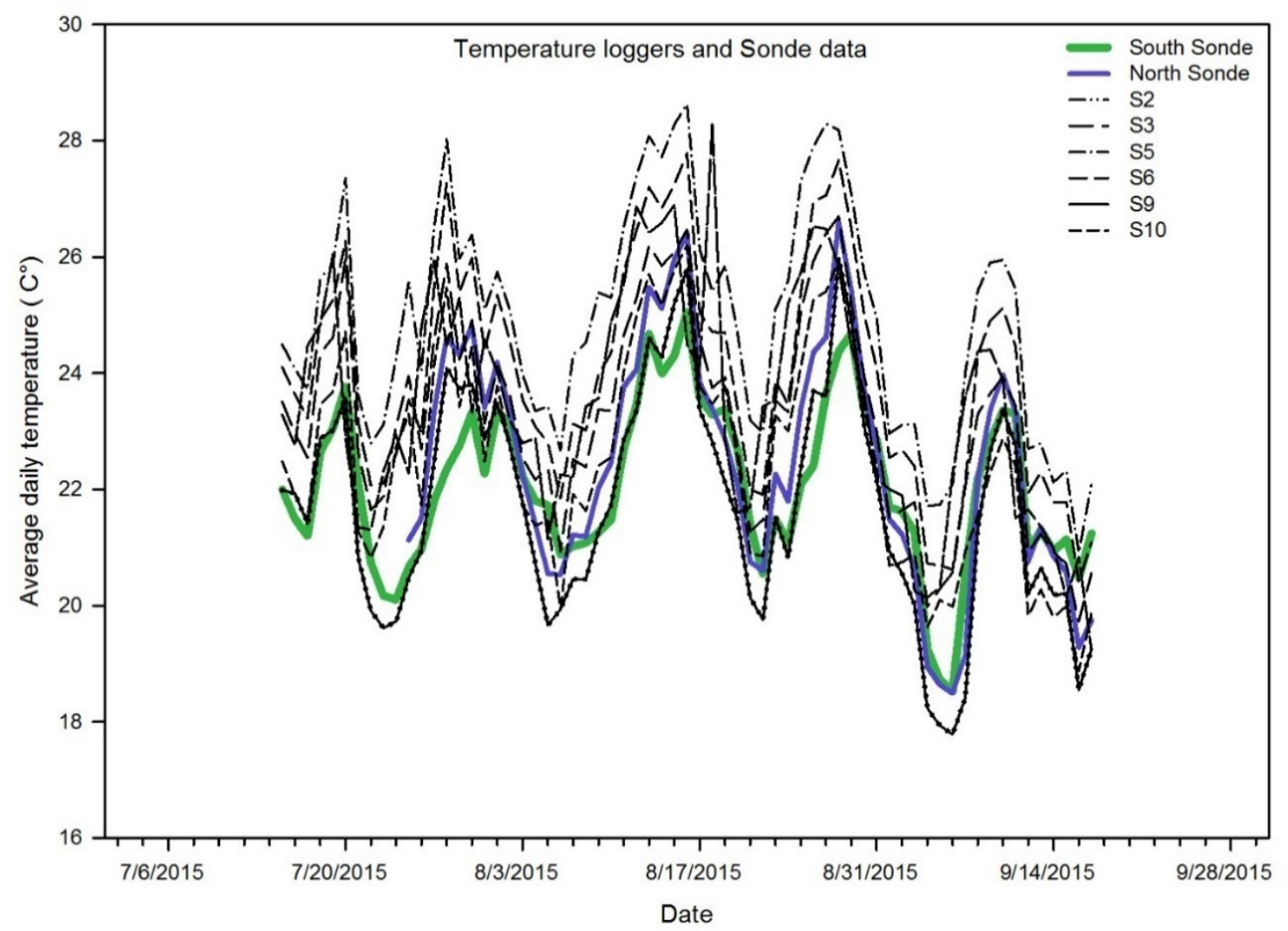

Fig. 19. Daily variations in temperature from temperature loggers, south sonde, and north sonde data. Second deployment (7/15/2015-9/17/2015) 


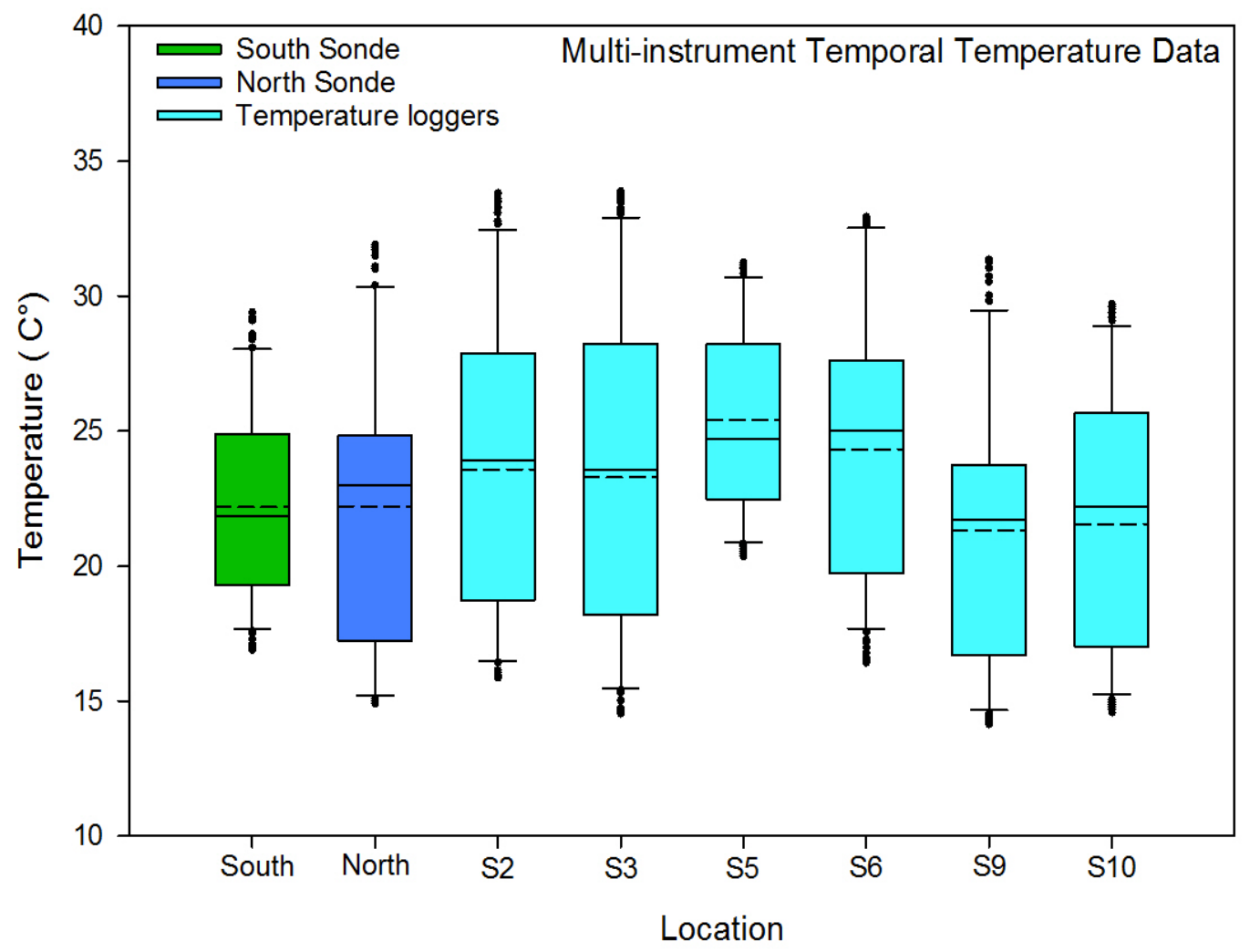

Fig. 20. Variations in temperature within a single day, 9/08/2015. Black dots represent outliers in the data. ---- = mean, $\_=$median, $\bullet=$ outliers 
YSI data. The YSI data points and temporally corresponding sondes' means and standard errors for each measurement were calculated for each field day (Table 15). Days where all three water quality instruments had data (3/15/2015 and 9/18/2015) showed significant post-hoc differences. For 9/18/2015, the south had significantly lower dissolved oxygen and higher temperatures and salinities than the north. The YSI measurements had significantly higher temperatures and lower salinities than the south sonde, and lower dissolved oxygen readings and higher salinities than the north sonde (Table 16). These differences in water quality measurements across instruments further supports that there are spatial differences in water quality within North Azevedo Pond. 
Table 18. Average YSI data points versus average temporally corresponding sondes' measurements; - indicates missing data for that time period; a) DO (dissolved oxygen),

b) temperature, c) salinity, d) $\mathrm{pH}$

a) DO $(\mu \mathrm{M})$

\begin{tabular}{cccc} 
Date & YSI & South & North \\
\hline \hline $5 / 6 / 2015$ & $12.38 \pm 1.29$ & $9.41 \pm 0.67$ & - \\
$6 / 15 / 2015$ & $9.8 \pm 0.7$ & $9.56 \pm 0.31$ & - \\
$7 / 14 / 2015$ & $9.28 \pm 1.26$ & $3.46 \pm 0.33$ & - \\
$9 / 18 / 2015$ & $7.68 \pm 0.3$ & $8.48 \pm 0.31$ & $10.05 \pm 0.25$
\end{tabular}

b) Temperature $\left(\mathrm{C}^{\circ}\right)$

\begin{tabular}{cccc} 
Date & YSI & South & North \\
\hline \hline $5 / 6 / 2015$ & $24.55 \pm 0.86$ & $19.69 \pm 0.33$ & - \\
$6 / 15 / 2015$ & $24.52 \pm 0.87$ & $22.15 \pm 0.34$ & - \\
$7 / 14 / 2015$ & $25.82 \pm 0.83$ & $22.49 \pm 0.2$ & - \\
$9 / 18 / 2015$ & $23.54 \pm 0.37$ & $22.08 \pm 0.22$ & $24.65 \pm 0.25$
\end{tabular}

c) Salinity (ppt)

\begin{tabular}{cccc} 
Date & YSI & South & North \\
\hline \hline 5/6/2015 & $48.01 \pm 0.15$ & $33.44 \pm 0.02$ & - \\
6/15/2015 & $37.95 \pm 0.44$ & $32.95 \pm 0.03$ & - \\
$7 / 14 / 2015$ & $38.47 \pm 0.55$ & $36.61 \pm 0.03$ & - \\
$9 / 18 / 2015$ & $37.23 \pm 0.15$ & $38.19 \pm 0.03$ & $33.27 \pm 0.05$ \\
& & & \\
d) $\mathbf{~}$ H & & South & North \\
Date & $8.42 \pm 0.14$ & $8.41 \pm 0.01$ & - \\
\hline \hline 5/6/2015 & $8.82 \pm 0.13$ & $7.77 \pm 0.01$ & - \\
6/15/2015 & $8.28 \pm 0.09$ & $8.01 \pm 0.02$ & - \\
7/14/2015 & $8.58 \pm 0.09$ & $8.52 \pm 0.02$ & $8.43 \pm 0.01$ \\
9/18/2015 & & & -
\end{tabular}


Table 19. One-way ANOVAs comparing three water quality instruments (north sonde, south sonde, and handheld YSI) for each water quality measurement: a) DO (dissolved oxygen), b) temperature, c) salinity, and d) $\mathrm{pH}$; Post-hoc Tukey HSD test results are included where there was significance. $\mathrm{df}=$ degrees of freedom, error; $\mathrm{MS}=$ mean square, MS error= Mean square of error; $f=f$ ratio, $p=p$-value, “*”=significant $p$-value $(\mathrm{p}<.05)$, post-hoc = significant pairwise comparisons; $\mathrm{S}=$ south sonde; $\mathrm{N}=$ north sonde; $\mathrm{Y}=$ handheld YSI; "-” = no significant pairwise comparisons.

\section{a) DO ( $\mu \mathrm{M})$}

\begin{tabular}{rcccccc}
\multicolumn{1}{c}{ Date } & df & MS & MS error & f & p & Post-hoc \\
\hline \hline $3 / 16 / 2015$ & 2,15 & 20.99 & 3.18 & 6.60 & $0.0088^{*}$ & $\mathrm{~N}>\mathrm{Y}, \mathrm{S}>\mathrm{Y}$ \\
$5 / 6 / 2015$ & 1,14 & 35.28 & 8.50 & 4.15 & 0.061 & - \\
$6 / 15 / 2015$ & 1,20 & 3.20 & 0.31 & 0.10 & 0.757 & - \\
$7 / 14 / 2015$ & 1,6 & 67.68 & 3.42 & 19.80 & $0.0043^{*}$ & - \\
$9 / 18 / 2015$ & 2,36 & 18.95 & 1.10 & 17.30 & $<.0001^{*}$ & $\mathrm{~N}>\mathrm{Y}, \mathrm{N}>\mathrm{S}$
\end{tabular}

\section{b) Temperature $\left(\mathrm{C}^{\circ}\right)$}

\begin{tabular}{rcccccc}
\multicolumn{1}{c}{ Date } & df & MS & MS error & $\mathrm{f}$ & $\mathrm{p}$ & Post-hoc \\
\hline \hline $3 / 16 / 2015$ & 2,15 & 0.61 & 1.28 & 0.48 & 0.631 & - \\
$5 / 6 / 2015$ & 1,14 & 3.41 & 94.43 & 27.66 & $0.0001^{*}$ & - \\
$6 / 15 / 2015$ & 1,20 & 30.99 & 96.42 & 6.43 & $0.0197^{*}$ & - \\
$7 / 14 / 2015$ & 1,6 & 22.14 & 1.47 & 15.06 & $0.0082^{*}$ & - \\
$9 / 18 / 2015$ & 2,36 & 42.97 & 38.46 & 20.11 & $<.0001^{*}$ & $\mathrm{~S}<\mathrm{N}, \mathrm{S}<\mathrm{Y}, \mathrm{N}>\mathrm{Y}$
\end{tabular}

c) Salinity (ppt)

\begin{tabular}{rcccccc}
\multicolumn{1}{c}{ Date } & df & MS & MS error & $\mathrm{f}$ & $\mathrm{p}$ & Post-hoc \\
\hline \hline $3 / 16 / 2015$ & 2,15 & 9.56 & 1.06 & 9.03 & $0.0027^{*}$ & $\mathrm{~S}<\mathrm{Y}, \mathrm{S} \approx \mathrm{N}$ \\
$5 / 6 / 2015$ & 1,14 & 848.85 & 0.09 & 9487.75 & $<.0001^{*}$ & - \\
$6 / 15 / 2015$ & 1,20 & 137.55 & 1.06 & 129.72 & $<.0001^{*}$ & - \\
$7 / 14 / 2015$ & 1,6 & 6.88 & 0.60 & 11.50 & $0.0146^{*}$ & - \\
$9 / 18 / 2015$ & 2,36 & 88.45 & 0.12 & 761.74 & $<.0001^{*}$ & $\mathrm{~S}>\mathrm{Y}, \mathrm{N}<\mathrm{S}, \mathrm{N}<\mathrm{Y}$
\end{tabular}




\section{d) $\mathrm{pH}$}

\begin{tabular}{rcccccc}
\multicolumn{1}{c}{ Date } & df & MS & MS error & $\mathrm{f}$ & $\mathrm{p}$ & Post-hoc \\
\hline \hline $3 / 16 / 2015$ & 2,15 & 1.31 & 2.41 & 0.55 & 0.591 & - \\
$5 / 6 / 2015$ & 1,14 & 0.00 & 0.08 & 0.00 & 0.959 & - \\
$6 / 15 / 2015$ & 1,20 & 6.04 & 0.09 & 66.04 & $<.0001^{*}$ & - \\
$7 / 14 / 2015$ & 1,6 & 0.14 & 0.02 & 7.60 & $0.033^{*}$ & - \\
$9 / 18 / 2015$ & 2,36 & 0.07 & 0.04 & 1.71 & 0.195 & -
\end{tabular}

\section{DISCUSSION}

\section{South and north system differences}

The construction of the water control structures caused substantial changes to both the south and north benthic infaunal communities within North Azevedo Pond by indirectly altering the water quality and effectively changing the ecosystem. Ecologically, it was prudent to examine more closely the dominant taxa and specifically, the individual species in these communities that were driving shifts temporally and spatially within North Azevedo Pond. There were several species of the more dominant major taxonomic groups that were highlighted in this study because of their indication of a highly stressful environment and their importance in driving the differences between communities.

\section{Abiotic differences.}

Hydrology. Prior to the ponding manipulation, North Azevedo Pond had two distinctly different communities defined by drastically different abiotic factors that fell on different points of an ecological gradient. The higher elevated north system was mostly dry with inundation occurring predominately adjacent to the culvert and relatively poor 
circulation. The north system had a smaller tidal range than the south system because of its higher elevation and farther distance from the main channel (Fig. 4). The south system had a proportionally much larger inundation area the majority of the time with better circulation than the north system. Additionally, both microsystems were hydrologically isolated from each other. The north's small inundation area had poorer water quality than the South system, in part, due to the higher algal coverage in the north (Oliver, pers. obs.).

In addition to hydrological differences, south and north had different sediment composition. South was characterized by coarser (sand) and more poorly sorted sediment, whereas the north's sediment composition was dominated by finer (silt and clay) better sorted sediment.

Infaunal community differences. The infaunal communities of the south and north regions of the wetland were significantly dissimilar from one another (Table 3), and these differences persisted after the ponding manipulation occurred. The cluster analysis and the MDS plot initially revealed these community differences by showing distinct groupings of south and north samples (see Appendix B, Figure 5). The north end of the wetland was dominated by polychaetes $\left(23,974\left(\mathrm{~m}^{2}\right)^{-1}\right)$ and oligochaetes $\left(24,487\left(\mathrm{~m}^{2}\right)^{-1}\right)($ Table 7). Mollusks $\left(19,744\left(\mathrm{~m}^{2}\right)^{-1}\right)$ and crustaceans $\left(33,333\left(\mathrm{~m}^{2}\right)^{-1}\right)$ were the dominant taxa groups in the south end (Table 6).

These two microsystems fell on different points of a hydrographic and stress gradient that distinguished them from one another. In Barros et al. 2014, the Elkhorn Slough was described as showing a gradient of overall diversity ( $\beta$ - diversity) from marine to 
freshwater, where overall diversity decreased from the mouth to the back of the Slough. With an overall higher influx of marine water in the south end of Azevedo pond, relative to the north end, due to having a higher tidal range; the south system was a more marine dominated community. The South end exhibited a similar trend to the large-scale system ß-diversity pattern, where there was a higher benthic infaunal diversity in more marine water systems. Similarly, if this system was placed in the context of a marine tidal setting, where the North was considered an exposed high intertidal and the South was deemed more of a subtidal setting, the North would be on the more stressful end of the gradient relative to the south (Ricketts et al. 1985).

After the ponding experiment took place, the inundation time and area increased for both the south and north regions. For the north, this created a benthic community in areas where there was none prior, given the majority of it was frequently dry. With more water in the system, the water quality improved simply because there was water where there was none before. It also altered the circulation, where prior to the manipulation the south and north were hydrologically isolated, and post-manipulation, the north's water flowed down to the south. This mixing between the south and north is also evidenced by the observed increase in short episodic extreme events in the south system (Table 17). The increase in these events is thought to occur as a result of higher north water levels pushing poorer quality water from the north system into the south system.

\section{North community}

The north system was a high intertidal mudflat-a unique habitat and setting to carry out a manipulation on. Although there were no Before North water quality data, it can be 
assumed that water quality did improve for this system given there was a persistence of water where there was little to none before. Despite this improvement, this now more aquatic system still remained a stressful one characterized by frequent extreme water quality events.

Before North and After North communities were not significantly different from each other given a few After sites were vastly different than the others and at times clustered more with Before samples. Several 2009 sample sites had a unique pulse in more stress sensitive taxa that were not present prior to manipulation or in the 2014 After sampling. For instance, Edwardsiids increased from a mean of 5,385 (SE=34.04) in October 2008 to 14,231 individuals $\left(\mathrm{m}^{2}\right)^{-1}(\mathrm{SE}=61.11)$ in September 2009, and then dropped to 1,795 $\left(\mathrm{m}^{2}\right)^{-}$ ${ }^{1}$ (SE=9.16). Edwardsiids are the one of the most common burrowing cnidarians found in estuarine and marine systems. Interestingly, the Oliver et al. 2009 report found Edwardsiidae individuals in only two Elkhorn Slough Wetlands-Pick n’ Pull and Rookery Lagoon. Both of these locations were classified as well-flushed systems. This may be an indicator that the increase in edwarsiids in the north was probably due to the hydrological manipulation.

Mollusk richness and abundance has been shown to increase in tidally restored systems (Thelen and Thiet 2009, Thiet et al. 2014). Mollusk species Gemma, Nutricola, and Tryonia were only present in the sample S6 2009 ( Fig. 4, see Appendix D). This sampling site was the deepest and closest site to the north water control structure and experienced the most tidal input and inundation out of all of the northern infaunal sampling sites, allowing for more sensitive taxa to establish populations. The absence of 
these mollusks in 2014 sampling may be in part due to temperature and oxygen fluctuations after the initial establishment of tidal restoration which followed patterns of similar long term monitoring tidal restoration studies (Dauer 1993; Hyland et al. 2004, Thelen and Thiet 2009). At the beginning of the ponding manipulation, water quality improved enough to allow for more sensitive taxa to establish a presence. However, consistent good water quality conditions did not sustain in the North (23.8\% hypoxia), and the frequency of stressful water quality events is thought to have wiped out these more stress sensitive species.

The crustacean Monocorophium decreased from a mean of 6,923 to 3,974 individuals $\left(\mathrm{m}^{2}\right)^{-1}$ in 2009 and then further decreased in 2014 samples to a mean of 641 individuals $\left(m^{2}\right)^{-1}$. The aforementioned species specific differences between sampling years created the intermixed clustering between Before and After North samples, and also the isolation of After 2009 samples from the After 2014 samples.

Interestingly, podocopids (an ostracod), appeared in the After North July 2014 samples only and not the 2009 samples, and it was the only dominant crustacean for this sampling year. Most brackish ostracods are known to be fairly tolerant of low oxygen conditions. Their distribution and abundance are affected more by changes to salinity where they are known to have higher abundances at higher salinities at more heavily tidally influenced areas (Frenzel \& Boomer 2005, Hussain et al. 2007). Given the North’s hypersalinity conditions, podocopids may have positively responded to these high salinity conditions concurrent with increased tidal flushing and consequent marine water input to the system. 


\section{Infaunal patterns.}

Polychaetes. According to Pearson and Rosenberg 1978, those benthic invertebrates that are opportunistic and short-lived oftentimes are most prevalent in disturbed stressful systems. Usually, benthic communities dominated by opportunistic annelids are likely to be too stressful a habitat for longer living organisms such as mollusks and crustaceans to inhabit (Reise 1982, Warwick and Clarke 1993, Wildsmith et al. 2009). The north region of the wetland had high mean abundances of several annelids. Two in particular, both tube-dwelling annelids, Pseudopolydora kempi (Pseudopolydora), and Capitella teleta (Capitella) were important in driving species specific differences between the North and the South communities.

Capitella teleta. Capitella is a well-known indicator of high disturbance to an aquatic environment. It's an opportunistic species with a short life span, and it is able to tolerate extremely stressful water quality conditions, in part due to it being a deposit feeder. Its feeding strategy does not depend on the steady presence of water for a food supply. Due to the inconsistent presence of water in the north end prior to the ponding manipulation, with some areas experiencing a fluctuation of dry and wet spells, Capitella teleta was able to establish and sustain a population (5,256 average individuals (m2)-1, SE=64.42), where other stress sensitive taxa could not survive. Despite high capitellid presence before the ponding experiment, it declined dramatically to 1,615 average individuals (m2)-1 (SE=6.21) in the After sampling period. This may be due in part to a mass die off which then was followed by an improvement in water quality conditions from the ponding manipulation, allowing other less stress tolerant taxa to colonize and establish 
populations. South community did show a slight spike in Capitella in the After sampling to 1,667 average individuals $\left(\mathrm{m}^{2}\right)^{-1}(\mathrm{SE}=6.21)$ further supporting the observed shift to a slightly more stressful environment in the south due to the ability of north's poorer water quality to interact with the south.

Pseudopolydora. Pseudopolydora abundance increased from a mean of mean of 7,436 to 38,077 individuals $\left(\mathrm{m}^{2}\right)^{-1}$, whereas Capitella abundance decreased. Pseudopolydora is primarily a deposit feeder and secondarily a suspension feeder, whereas Capitella is only a deposit feeder. Pseudopolydora falls lower on the stress tolerant spectrum than Capitella, which may be why it had less of a presence in the Before North sampling when water quality was at its worst (Oliver, pers. comm.). Conversely, in the After North, Pseudopolydora presence characterized the north community with dense tube mats that were clearly visible from the marsh vegetation and water edge. When water quality improved post ponding manipulation, Pseudopolydora's population thrived and its tube mats may have outcompeted capitellids for space and feeding due to their similar ecological role.

Oligochaetes. Oligochaetes were the other annelid taxa group that defined the north's infaunal community. Weedy oligochaetes species found most commonly in the north were indicative of organic rich finer sediment habitat.

Paranais litoralis cf (Paranais) and Tubificoides spp. were two oligochaetes in the top ten most abundant taxa from the north end and both their mean abundances decreased from before to after the ponding experiment (Table 7). Paranais exhibited in other studies a seasonal fluctuation of being highly dense in either the spring, early summer, or 
autumn, but with low abundance or absence in the late summer due to high temperatures and lower nutritional quality in the sediment (Giere and Pfannkuche 1982, Cheng et al. 1993, Gamenick et al. 1996, Gillet et al. 2007, Johnson et al. 2007). The Before North sampling was in the fall (October 2008) and not in the late summer when both the After North sampling years were; so, this seasonal sampling difference may be the reason for the decrease in abundance in the After North samples. Ecologically, Paranais is known to be an early succession species, with a high abundance in the early development of a benthic community, but decreasing and making way for other oligochaetes such as tubificids later (Oliver, pers. comm.). Similarly, Paranais was most abundant in almost all of the "Very-Restricted Tidal Wetlands" in the Oliver et al 2009 report making it a potential indicator of stagnant restricted flow habitat. Thus, this decrease in abundance may indicate an increase in tidal flow to the habitat.

Tubificoides spp. are a well-known weedy oligochaete group; but other studies have observed this group, like most tubificid oligochaetes, to have relatively low fecundity and less tolerance of poor water quality conditions than other pollutant tolerant oligochaetes (Gillet et al. 2007). Tubificids in previous studies have been found to have lower densities during times when water flow was high due to being dragged away by the highwater velocity (Bispo et al. 2001). However, aggregation and density are high during times when water levels are low due to limited habitat covered by water. This decrease in tubificids may be indicative of an increase in water flow and in habitat availability for other infauna taxa besides oligochaetes.

Thus, a decrease in both tubificids and naidids may be indicative of a decrease in 
organic input to the sediment as well as a shift in hydrological regime of the North. With a higher tidal flow, habitat availability increased and paved the way for other taxa to settle and establish populations in the intertidal mudflats. Conversely, the south increased in oligochaetes over time from mean of 11,282 to 15,462 individuals $\left(\mathrm{m}^{2}\right)^{-1}$, another indicator that north’s water quality influenced the south's after the ponding manipulation, creating more stressful water quality conditions and allowing for opportunistic taxa like weedy oligochaete populations to persist and thrive.

\section{Environmental drivers for community shifts.}

Water quality. Prior to water control structure construction, the north region experienced shorter and less frequent inundation periods over a larger area of the system. Despite there being no benchmark for what the water quality was prior to water control structure, it is reasonable to infer that any increased tidal flushing to the system would improve it from its pre-existing conditions. These pre-existing conditions associated with muted systems were more hypoxic events and greater temperature fluctuations (Burdick et al. 1997, Ritter et al. 2008, Oliver et al. 2009), all of which create stressful habitat conditions for benthic infaunal communities.

The water quality for the post-water control structure indicated a relatively stressful environment for infauna, despite presumed water quality improvement associated with increased inundation. The north end experienced extreme dissolved oxygen conditions: $23.86 \%$ of the time it was hypoxic and $25.75 \%$ of the time DO was between the critical threshold range of $94-188 \mu \mathrm{M}$ (this range is an observed inflection where most organisms' populations are adversely affected). Not only was hypoxia prevalent in the 
north part, but also hypersalinity (25.99\%) and extreme temperatures (34.08\%) both occurred at a higher frequency than the south. These readings came from a sonde that was adjacent to the north water control structure where optimal water flow was and therefore the best water quality conditions for that region. Therefore, the sampled peripheral north infaunal sites were probably experiencing even more extreme water quality conditions than what the north sonde was capturing.

\section{South community}

Infaunal patterns. Before South and After South infaunal communities were significantly different from one another (PERMANOVA pairwise, $\mathrm{t}=1.912, \mathrm{p}=.001$ ). The community’s abundance increased from a mean of 68,974 to 87,051 individuals $\left(\mathrm{m}^{2}\right)^{-1}$. Species density remained the same. Both of these community descriptors were higher than the north community.

Mollusks and crustaceans remained dominant in the south infaunal community (Table 6). Both of these taxa are highly sensitive to changes in water quality, and their decline or absence in a community is an indicator of habitat disturbance (Wildsmith et al. 2011). The lack of substantial taxa shifts over time indicated that relative to the north, the south fell along the same stress gradient as it did prior to the ponding manipulation.

Bivalve shift. Gemma decreased from average of 19,103 to 385 individuals $\left(\mathrm{m}^{2}\right)^{-1}$ whereas the native clam, Nutricola, increased from an average of 128 to 26,154 individuals $\left(\mathrm{m}^{2}\right)^{-1}$. This bivalve shift from Gemma to Nutricola was a main driver in the significant difference between Before South and After South communities. Nutricola was 
consistently found to be linked to better tidally flushed systems in Elkhorn Slough, whereas Gemma was only found in protected tidally restricted wetlands (Oliver et al. 2009). This is partially due to its habitat preference and distribution. Nutricola is a marine coastal bivalve and thrives in marine dominant waters that are protected from the tidal energy and stress of an exposed marine environment. On the other hand, Gemma is an indicator of a less tidally disturbed estuarine muddy habitat. The replacement pattern of Gemma to Nutricola has similarly been observed in the Elkhorn Slough main channel, where a rapid shift in habitat by increased tidal prism is causing soft sediment erosion and being converted into a marine coastal embayment with a strong tidal influence. This shift pattern from estuarine to marine organisms has been observed all throughout Elkhorn Slough (Oliver, unpublished data).

The most dominant crustacean, Monocorophium insidiosum, was consistently high in tube mats for both Before South and After South sampling periods. In Oliver et al. 2009, a trend was noted between the presence of this species and tidally restricted systems. This indicated that while flushing may have increased in the system, it still remained tidally restricted, overall. However, the system never experienced stressful enough water quality conditions to cause this crustacean population crash.

Polychaetes. The presence of polychaetes increased temporally in the South. Capitella, Streblospio benedicti (Streblospio), and Pseudopolydora all increased in abundance. All of these polychaetes are known pollutant tolerant opportunistic species (Pearson and Rosenberg 1978), especially Capitella. This spike in capitellids was an indicator of disturbance to the environment. It's also important to keep in mind that the 
After South samples were only taken in 2014 and not in 2009 like the After North samples were. From looking at the North 2014 community, it appears that the water quality conditions were probably much more stressful than in 2009. However, there were no water quality data in the north from 2009 to prove this for certain. This pattern of shift in stressful water quality may also have been the case for the south end, in that initially the ponding manipulation improved water quality but due to several more adjustments and changes, the water quality worsened over time. With an increase in circulation between south and north, the north's poorer water quality influenced the south, which is evident in the increase of short term episodic events of hypoxia, hypersalinity, and extremely high temperatures (Table 17). These spikes in stress-tolerant and disturbance indicator polychaetes further supports that the south's water quality worsened, and north’s influence was substantial enough to affect its water quality.

Batillaria refuge. The non-native snail, Batillaria, increased in abundance from Before South to After South (see Appendix C). This non-native gastropod was not found in such high numbers in the north end of the pond. Batillaria's spiked presence was indicative of a shift in habitat type in the south end. In the Oliver et al. 2009 report, it was noted that prior to hydrographic manipulations, North Azevedo Pond had dense patches of Batillaria, but only in the high mudflats which were historically vegetated but at the time of that study, were fringed by pickleweed. These high intertidal mudflats were specifically avoided for sampling given their known poor infaunal community. This increase in Batillaria suggests an increase in their preferred habitat: high mudflat (Yamada 1982). Prior to the ponding manipulation, the south's water only ponded at the 
deeper areas of the pond, similar to a bowl. Between the pickleweed and the ponded bowl, there was a large unvegetated marsh plain that only experienced inundation episodically at extremely high tides. With the increase in ponding to the system, the unvegetated high marsh plain transformed to an intertidal marsh plain that experienced more tidal influence than what it did prior to the ponding manipulation. This new intertidal high mudflat created the perfect habitat for Batillaria; abundance increased from 526 to 16,436 individuals $\left(\mathrm{m}^{2}\right)^{-1}$.

However, where there was an increase in Batillaria in North Azevedo Pond, its decline has been observed most everywhere else in Elkhorn Slough. This is in part due to the fact that Elkhorn Slough is a highly eroding system (Oliver et al. 2013), and with salt marsh subsidence occurring rapidly the high marsh plain is the most susceptible to erosion. These high marsh plain areas were vegetated at one time but are now quickly eroding on the outer areas of the marsh and sometimes in the inner marsh where it converts to lower intertidal pannes covered by algae (Oliver et al. 2013). The unvegetated marsh plain is where the Batillaria are most abundant and so their widespread decrease in population is correlated with this decline in their habitat.

Likewise, with an increase in exposed mudflat, surface water macroalgal mats could not survive due to desiccation. Therefore, with an increase in mudflat, there was a linked decline in algae although this is only inferred and not shown through any formal data set. Batillaria's abundance in the After South sampling largely contributed to driving the significant differences between in the community structure between before and after the ponding manipulation. 
Oligochaetes. The tubificid oligochaetes were more prevalent in the south than naidid oligochaetes. Tubificids are longer living and have lower fecundity than naidids which might indicate that this habitat is low enough in stress that these populations have time to grow and persist without crashing from extremely stressful conditions (Gillet et al. 2007). Some seasonal differences in the life history of naidids and tubificids that were not captured in the sampling scope of this study may further explain oligochaete taxa specific differences (Gillet et al. 2007).

\section{Environmental drivers.}

Water quality. The south region of North Azevedo Pond worsened temporally in water quality conditions with an increase in duration for all water quality events. This may have caused an increase in more stress tolerant polychaetes. Despite these negative changes in water quality, the south maintained relatively tolerable water quality for the existing benthic communities.

\section{North Azevedo versus other Elkhorn Slough wetlands}

In the Oliver et al. 2009 (the preliminary data for this study), North Azevedo was categorized as a tidally restricted wetland system in addition to two other systems, Whistlestop Lagoon and West Bennett Slough. As a follow up, data were compared to the peripheral data to see where North Azevedo fell relative to the other tidal regimes including restricted. The After Impact North Azevedo data clearly clustered away from all other tidal flow regime data and were more closely linked to Before Impact North Azevedo infaunal communities than any other system (see Appendix H). So, North 
Azevedo system's community did not vastly change relative to other tidal systems, and was isolated from all other tidal regime wetlands in the study. It remains a unique system from other Elkhorn Slough wetlands given it is a high intertidal mudflat with ponding, unlike all other wetland systems in the Slough.

Estuarine habitat loss indicators. Elkhorn Slough has historically experienced many non-native species invasions (Wasson et al. 2005). These shifts to introduced species can be indicators of changes to marsh habitat and marsh loss. North Azevedo Pond had two non-native species' populations that substantially changed between before and after the ponding manipulation and are indicative of habitat changes to the system. However, there was no shift from native to non-native or vice versa patterns overall (Table 5) The estuarine non-native clam, Gemma gemma, thrives in soft sediment muds. The spike in the native marine Nutricola indicated a habitat shift to a more marine dominant system and a loss of estuarine habitat. This shift from introduced to native species is an ambivalent signal, while it’s a positive signal of a loss in an introduced species it also indicates a loss in marsh habitat. There was also a shift to an introduced species, Batillaria which also signaled change in habitat from a high and dry unvegetated marsh plain to a high intertidal mudflat.

\section{Globally similar tidally restored wetland systems}

Other tidally restricted systems that have experienced an input in flushing have had varying success in restoring the system as a whole. In Rhode Island, a completely impounded system was tidally opened by reinstating pre-existing culverts. The system transitioned from a stagnant pond to a dynamic tidally influenced system with newly 
exposed tidal mudflats and salt marsh vegetation (Raposa 2008). The south region of North Azevedo Pond similarly formed higher mudflats post-hydrographic manipulation which were biologically defined in the spike in abundance of Batillaria. Similar to North Azevedo, several other tidal restoration studies found that water table levels increased after tidal changes were made (Burdick et al. 1997), but not always (Rozsa 1988, Sinicrope et al. 1990).

One study that created open tidal exchange to a restricted marsh found short-term adverse effects to the system. Mollusks and crustaceans, both taxa commonly found in better flushed healthier systems, decreased in abundance, whereas polychaetes increased in abundance and dominated the community (Wildsmith 2009). The north region of North Azevedo Pond experienced mollusk and crustacean population fluctuations but it remained dominated by polychaetes. However, the south region maintained high numbers of mollusks and crustaceans. Another tidal restoration study in a New England estuary paralleled patterns seen in North Azevedo Pond. With an increase in tidal flushing, benthic species density increased (similar to the north region of North Azevedo) and pollutant indicator species such as Capitella decreased (Zajac and Whitlach 2001). This study also found recruitment of certain species in parts of the marsh where they had not been previously. This parallels the pattern of mollusks appearing in the north region of North Azevedo in the After Impact 2009 sampling year where they had not been found previously.

\section{Adaptive management implications}

This experimental restoration at North Azevedo Pond had a positive impact on the 
infauna, in that it increased tidal inundation to the system and in some areas created a benthos where there was not one prior. However, given that the system is a high tidally restricted marsh, the extent to which the infaunal community can improve is limited, even with further hydrological manipulations to the system. If anything, ponding should be reduced in the south in order to control for the Batillaria colonization that has occurred due to the creation of a new habitat, high intertidal mudflat. Long term monitoring of the Batillaria is recommended. Simultaneous monitoring of other habitats where Batillaria is present should be compared to this monitoring in order to identify any differences in environmental patterns.

For environmental monitoring, a sonde should permanently be placed in the north region of the wetland. It is evident from the descriptive spatial water quality data recorded for this study that the sonde in the south cannot solely be used to represent the water quality for the whole system. The north had considerably poorer water quality with higher occurrences of hypoxia, high temperatures, and hypersalinity. All of these critical events would have been overlooked if the south sonde was the only instrument used. Additionally, further sediment analysis is recommended in order to measure organic content, a parameter not measured in this study but is necessary in understanding infaunal patterns (Baustian and Rabalais 2004, Carvalho et al. 2005, Hampel et al. 2009, Caffrey et al. 2010, Kodama et al. 2012, Rakocinski 2012). Sediment transport is another parameter necessary to document, because considerable sediment movement can alter habitats such as the new higher mudflats present in the south of North Azevedo Pond (Rosenberg 2001, Bouman et al. 2002). Algal blooms and percent coverage would ideally 
have been documented to further describe the community trends in this study's data, however, future monitoring could assess seasonal changes in macroalgal mats.

\section{CONCLUSIONS}

Although these hydrographic manipulations clearly created significant shifts spatially and temporally in benthic infaunal communities, it's difficult to conclude whether they actually improved the system. North water quality was critically poor, and the south water quality was temporally more influenced by the north region’s water quality conditions. However, the community shifts in both spatial communities were telling of changes to hydrology. Tidal influence was much higher after the construction, creating a more marine dominant habitat in the “After” regime.

This project was limited by previous sampling. The south end had more "Before Impact” samples, and the north end had more "After Impact” samples. This made it difficult to compare the differences spatially given that both locations were not necessarily sampled during the same sampling period. In fact, the only sampling period where both south and north were sampled was July 2014.

It is also unclear how much the water control structures were adjusted postconstruction. According to ESNERR's documentation of the project, very little if any adjustments were made in the north end in order to prevent any bank erosion and instability of the railroad tracks adjacent to the structure. However, multiple adjustments were made continuously in the south end of the pond and very little documentation exists as to the details of these tidal flashboard adjustments.

It appears that the current state of the wetland is different than the initial hydrological 
changes created by the two water control structures. For instance, where record numbers of Batillaria are declining everywhere else in the slough, they have spiked in population in the south end of the wetland. It would be worth following up with benthic sampling for both the south and north sites as well as collecting water quality and sediment data and observations.

While it is difficult to conclude that this wetland has been successfully restored to a healthier system, it would be fair to state that the structures did alter the water quality of North Azevedo Pond and these changes are reflected in individual species shifts in the benthic infaunal communities. This change to a more tidally influenced regime has implications for how sea level rise could potentially affect other peripheral wetlands in Elkhorn Slough. It also could prove useful in understanding the health of tidally impounded systems in order to understand how to protect tidally open systems from further marine intrusion. Lastly, the water quality for North Azevedo Pond differs spatially and thus in order to be better informed about water quality changes, it would make the most sense to have a sonde stationed in the north region of the wetland as well as the south part of the wetland. 


\section{REFERENCES}

Aldridge DW, Payne BS, Miller AC (1987) The effects of intermittent exposure to suspended solids and turbulence on three species of freshwater mussels. Environ Pollut 45:17-28

Anderson D, Glibert P, Burkholder J (2002) Harmful algal blooms and eutrophication: nutrient sources, compositions, and consequences. Estuaries 25:704-726

Barros F, Blanchet H, Hammerstrom K, Sauriau PG, Oliver J (2014) A framework for investigating general patterns of benthic ß-diversity along estuaries. Estuar Coast Shelf Sci 149:223-231

Baustian MM, Rabalais NN (2009) Seasonal composition of benthic macroinfauna exposed to hypoxia in the northern Gulf of Mexico. Estuar Coasts 32:975-983

Beck NG, Bruland KW (2000) Diel biogeochemical cycling in a hyperventilating shallow estuarine environment. Estuaries 23:177

Beck NG, Fisher AT, Bruland KW (2001) Modeling water, heat, and oxygen budgets in a tidally dominated estuarine pond. Mar Ecol Prog Ser 217:43-58

Bilyard GR (1987) The value of benthic infauna in marine pollution monitoring studies. Mar Pollut Bull 18:581-585

Boumans RMJ, Burdick DM, Dionne M (2002) Modeling habitat change in salt marshes after tidal restoration. Restor Ecol 10:543-555

Bryant V, Newbery DM, McLusky DS, Campbell R (1985) Effect of temperature and salinity on the toxicity of arsenic to three estuarine invertebrates (Corophium volutator, Macoma balthica, Tubifex costatus). Mar Ecol Prog Ser 24:139-153

Caffrey JM, Chapin TP, Jannasch HW, Haskins JC (2007) High nutrient pulses, tidal mixing and biological response in a small California estuary: Variability in nutrient concentrations from decadal to hourly time scales. Estuar Coast Shelf Sci 71:368380

Callaway J (2001) Hydrology and substrate. In: Zedler J (ed) Handbook for Restoring Tidal Wetlands, 1st edn. CRC Press, Boca Raton, FL p 89-117

Carvalho S, Moura A, Gaspar MB, Pereira P, Cancela Da Fonseca L, Falcão M, Drago T, Leitão F, Regala J (2005) Spatial and inter-annual variability of the macrobenthic 
communities within a coastal lagoon (Óbidos lagoon) and its relationship with environmental parameters. Acta Oecologica 27:143-159

Chapin T, Caffrey J, Jannasch H, Coletti L (2004) Nitrate sources and sinks in Elkhorn Slough, California: results from long-term continuous in situ nitrate analyzers. Estuaries

Cheng IJ, Levinton LS, McCartney M, Martinez D, Weissburg MJ (1993) A bioassay approach to seasonal variation in the nutritional value of sediment. Mar Ecol Prog Ser 94:275-285

Copeland B (1974) Impoundment systems. In: Odum H, Copeland B, McMahan E (eds) Coastal Ecological Systems of the United States. Conservation Foundation, Washington D.C., p 168-179

Coulter Corporation (1992) Coulter LS, User Manual

Diaz DJ, Rosenberg R (1995) Marine benthic hypoxia: A review of its ecological effects and the behavioural responses of benthic macrofauna. Oceanogr Mar Biol Annu Rev 33:245-303

Diaz RJ, Solan M, Valente RM (2004) A review of approaches for classifying benthic habitats and evaluating habitat quality. J Environ Manage 73:165-181

Dutch M, Aasen S, Welch K, Long E, Grantham B, Shull D (2005) Relationships between benthic infaunal community structure and dissolved oxygen levels in bottom waters of Hood Canal. 2005 Puget Sound Georgia Basin Research Conference In: Seattle, WA.

Eertman RHM, Kornman BA, Stikvoort E, Verbeek H (2002) Restoration of the sieperda tidal marsh in the Scheldt estuary, The Netherlands. Restor Ecol 10:438-449

Eriksen CH (1968) Ecological significance of respiration and substrate for burrowing Ephemeroptera. Can J Zool 46:93-103

Erman DC, Ligon FK (1988) Effects of discharge fluctuation and the addition of fine sediment on stream fish and macroinvertebrates below a water-filtration facility. Environ Manage 12:85-97

Gamenick I, Jahn A, Vopel K, Giere O (1996) Hypoxia and sulphide as structuring factors in a macrozoobenthic community on the Baltic Sea shore: Colonisation studies and tolerance experiments. Mar Ecol Prog Ser 144:73-85 
Gee AK, Wasson K, Shaw SL, Haskins J (2010) Signatures of restoration and management changes in the water quality of a central California estuary. Estuar Coasts 33:1004-1024

Giere O, Pfannkuche O (1982) Biology and ecology of marine Oligochaeta: a review. Oceanogr Mar Biol Annu Rev 43:173-308

Gillett DJ, Holland AF, Sanger DM (2007) On the ecology of oligochaetes: Monthly variation of community composition and environmental characteristics in two South Carolina tidal creeks. Estuar Coasts 30:238-252

Gilmore R, Cooke D, Donohoe C (1982) A comparison of the fish populations and habitat in open and closed salt marsh impoundments in east-central Florida. Northeast Gulf Sci 5:25-37

Hampel H, Elliott M, Cattrijsse A (2009) Macrofaunal communities in the habitats of intertidal marshes along the salinity gradient of the Schelde estuary. Estuar Coast Shelf Sci 84:45-53

Hastie BF, Smith SDA (2006) Benthic macrofaunal communities in intermittent estuaries during a drought: Comparisons with permanently open estuaries. J Exp Mar Bio Ecol 330:356-367

Hawkins CP, Norris RH, Hogue JN, Feminella JW (2000) Development and evaluation of predictive models for measuring the biological integrity of streams. Ecol Appl 10:1456

Hughes BB, Haskins JC, Wasson K, Watson E (2011) Identifying factors that influence expression of eutrophication in a central California estuary. :1-11

Hussain SM, Ganesan P, Ravi G, Mohan SP, Sridhar SGD (2007) Distribution of Ostracoda in marine and marginal marine habitats off Tamil Nadu and adjoining areas, southern east coast of India and Andaman Islands: Environmental implications. Indian J Mar Sci 36:369-377

Jewell W, McCarty P (1971) Aerobic decomposition of algae. Environ Sci Technol 5:1023-1031

Johnson D, Fleeger J, Galvan K, Moser E (2007) Worm holes and their space-time continuum: spatial and temporal variability of macroinfaunal annelids in a northern New England salt marsh. Estuar Coasts 30:226-237 
Kennish MJ (2002) Environmental threats and environmental future of estuaries. Environ Conserv 29:78-107

Kneib RT (1984) Patterns of invertebrate distribution salt marsh : abundance in the intertidal causes and questions. Estuaries 7:392-412

Kodama K, Lee JH, Oyama M, Shiraishi H, Horiguchi T (2012) Disturbance of benthic macrofauna in relation to hypoxia and organic enrichment in a eutrophic coastal bay. Mar Environ Res 76:80-89

Long ER, Dutch ME, Aasen S, Welch KI, Partridge VA, and Shull DH (2007) Relationships between the composition of the benthos and sediment and water quality parameters in Hood Canal: Task IV - Hood Canal Dissolved Oxygen Program. Washington State Department of Ecology Publication. Olympia, WA

Nezlin N, Kamer K, Stein ED, Carr A, Hyde J (2006) Relationships between dissolved oxygen and macroalgal distribution in upper Newport Bay. Southern California Coastal Water Research Project. Technical Report \#494

Odum EP (1980) The status of three ecosystem-level hypothesis regarding salt marsh estuaries: tidal subsidy, outwelling, and detritus-based food chains. In: Kennedy VS (ed) Estuarine Perspectives. Academic Press, New York, p 485-495

Odum WE, Odum EP, Odum HT (1995) Nature’s pulsing paradigm. Estuaries 18:547555

Oliver JS, Hammerstrom KK, Aiello IW, Oakden JA, Slattery PN, Kim SL (2009) Benthic invertebrate communities in the peripheral wetlands of elkhorn slough ranging from very restricted to well flushed by tides. Moss Landing, CA. Monterey Bay National Marine Sanctuary Report

Oliver JS, Lopez HL, Hammerstrom KK (2013) Geomorphology and ecology of extreme tidal erosion of elkhorn slough. Central Coast Water Resources Center, Moss Landing, CA. CCWater Reports

Paerl H (1997) Coastal eutrophication and harmful algal blooms: Importance of atmospheric deposition and groundwater as "new" nitrogen and other nutrient sources. Limnol Oceanogr 42.5:1154-1165

Pearson T, Rosenberg R (1978) Macrobenthic succession in relation to organic enrichment and pollution of the marine environment. Oceanogr Mar Biol Annu Rev 16:229-311 
Pennings SC, Bertness MD (2001) Salt marsh communities. In: Bertness MD, Gaines SD, Hay ME (eds) Marine Community Ecology. Sinauer Associates, Sunderland, MA, p 289-316

Portnoy JW (1991) Summer oxygen depletion in a diked New England estuary. Estuar Coasts 14:122-129

Portnoy JW, Giblin AE (1997) Effects of historic tidal restrictions on salt marsh sediment chemistry. Biogeochemistry 36:275-303

Portnoy JW (1999) Salt marsh diking and restoration: biogeochemical implications of altered wetland hydrology. Environ Manage 1:111-120

Rabalais NN, Turner RE, Justic D, Dortch Q, Wiseman, Jr. WJ (1999) Characterization of hypoxia: Topic I report for the integrated assessment on hypoxia in the gulf of mexico. NOAA/National Centers for Coastal Ocean Science, Silver Spring

Reise K (1982) Long-term changes in the macrobenthic invertebrate fauna of the Wadden Sea: Are polychaetes about to take over? Netherlands J Sea Res 16:29-36

Rey J, Kain T, Crossman R, Peterson M, Shaffer J (1991) Zooplankton of impounded marshes and shallow areas of a subtropical lagoon. Florida Sci 54:191-203

Richards C, Bacon K (1994) Influence of fine sediment on macroinvertebrate colonization of surface and hyporheic stream substrates. Gt Basin Nat 54:106-113

Richards D (1996) The use of aquatic macroinvertebrates as water quality indicators in mountain streams in Montana. PhD dissertation. Montana State UniversityBozeman, Bozeman, MT

Ricketts EF, Calvin J (1985) Between Pacific Tides (JW Hedgpeth and DW Phillips, Eds.), 5th edn. Stanford University Press, Stanford, CA

Ritter AF, Wasson K, Lonhart SI, Preisler RK, Woolfolk A, Griffith K a., Connors S, Heiman KW (2008) Ecological signatures of anthropogenically altered tidal exchange in estuarine ecosystems. Estuar Coasts 31:554-571

Roman C, Garvine R, Portnoy JW (1995) Hydrologic modeling as a predictive basis for ecological restoration of salt marshes. Environ Manage 10:559-566

Roman CT, Raposa KB, Adamowicz SC, James-Pirri MJ, Catena JG (2002) Quantifying vegetation and nekton response to tidal restoration of a New England salt marsh. Restor Ecol 10:450-460 
Rozsa, R. 1988. An overview of wetland restoration projects in Connecticut, pp. 1-11. In: M.W. Lefor and W.C. Kennard, (eds.), Proceedings of the Fourth Wetlands Conference: Wetlands Creation and Restoration, November 15, 1986. Report No. 34, Connecticut Institute of Water Resources. University of Connecticut, Storrs, Connecticut

Schaadt T (2005) Patterns and causes of variability in the cover, biomass, and total abundance of Ulva spp. in Elkhorn Slough, California. MS dissertation. Moss Landing Marine Laboratories, Moss Landing, CA

Schelske C, Odum E (1962) Mechanisms maintaining high productivity in Georgia estuaries. In: Gulf and Caribbean Fisheries Institute. p 75-80

Sinicrope T, Hine P, Warren R, Niering W (1990) Restoration of an impounded salt marsh in New England. Estuar Coasts 13:25-30

Steever E, Warren R, Niering W (1976) Tidal energy subsidy and standing crop production of Spartina alterniflora. Estuar Coast Mar 4:473-478

Stocks KI, Grassle JF (2003) Benthic macrofaunal communities in partially impounded salt marshes in Delaware: Comparisons with natural marshes and responses to sediment exposure. Estuaries 26:777-789

Teske PR, Wooldridge TH (2003) What limits the distribution of subtidal macrobenthos in permanently open and temporarily open/closed South African estuaries? Salinity vs. sediment particle size. Estuar Coast Shelf Sci 57:225-238

Thelen BA, Thiet RK (2009) Molluscan community recovery following partial tidal restoration of a New England estuary, U.S.A. Restor Ecol 17:695-703

Thiet RK, Kidd E, Wennemer JM, Smith SM (2014) Molluscan community recovery in a new england back-barrier salt marsh lagoon 10 years after partial restoration. Restor Ecol 22:447-455

Vaquer-Sunyer R, Duarte C (2008) Thresholds of hypoxia for marine biodiversity. Proc Natl Acad Sci 105:15452-15457

Vose FE, Bell SS (1994) Coastal and estuarine research federation resident fishes and macrobenthos in mangrove-rimmed habitats: evaluation of habitat restoration by hydrologic modification mangrove-rimmed habitats. Estuaries 17:585-596 
Ward CJ, Steinke TD, Ward MC (1986) Mangroves of the Kosi System, South Africa: their re-establishment since a mass mortality in 1965/66. South African J Bot 52:501-512

Warwick RM, Clarke KR (1993) Comparing the severity of disturbance: a meta- analysis of marine macrobenthic community data. Mar Ecol Prog Ser 92:221-231

Wasson K, Fenn K, Pearse JS (2005) Habitat differences in marine invasions of central California. Biol Invasions 7:935-948

Weaver JE, Holloway LF (1974) Community structure of fishes and macrocrustaceans in ponds of a Louisiana tidal marsh influenced by weirs. Contributions in Marine Science. 18:57-69

Wenner AEL, Beatty HR (1988) Wetland communities macrobenthic and adjacent open marsh impoundments habitats in South Carolina. Estuaries 11:29-44

Wildsmith MD, Rose TH, Potter IC, Warwick RM, Clarke KR, Valesini FJ (2009) Changes in the benthic macroinvertebrate fauna of a large microtidal estuary following extreme modifications aimed at reducing eutrophication. Mar Pollut Bull 58:1250-1262

Wildsmith MD, Rose TH, Potter IC, Warwick RM, Clarke KR (2011) Benthic macroinvertebrates as indicators of environmental deterioration in a large microtidal estuary. Mar Pollut Bull 62:525-538

Yamada SB (1982) Growth and longevity of the mud snail Batillaria attramentaria. Mar Biol 67:187-192

Zajac RN, Whitlatch RB (2001) Response of macrobenthic communities to restoration efforts in a New England estuary. Estuaries 24:167-183 


\section{APPENDICES}

\begin{tabular}{|c|c|}
\hline Date & Event \\
\hline 1872 & $\begin{array}{l}\text { Southern Railroad built railroad curtailing many peripheral wetlands } \\
\text { including NAP from main channel }\end{array}$ \\
\hline 1920 & $\begin{array}{l}\text { North Azevedo higher marsh areas were diked to increase pasture for } \\
\text { surrounding dairy farms }\end{array}$ \\
\hline 1947 & Moss Landing Harbor was built and altered the hydrology of the slough \\
\hline 1997 & $\begin{array}{l}\text { The culvert in the southern end of NAP broke open, increasing tidal } \\
\text { exchange }\end{array}$ \\
\hline $\begin{array}{c}\text { August } \\
2007 \\
\text { April } 2008 \\
\end{array}$ & $\begin{array}{l}\text { Baseline preliminary benthic sampling in Southern end ( Oliver et al. } \\
\text { 2009) }\end{array}$ \\
\hline $\begin{array}{c}\text { October } \\
2008\end{array}$ & Benthic sampling in northern end of North Azevedo Pond \\
\hline $\begin{array}{c}\text { December } \\
2008 \\
\end{array}$ & Northern water control structure completed \\
\hline $\begin{array}{c}\text { December } \\
2009 \\
\end{array}$ & Southern water control structure completed \\
\hline $\begin{array}{l}\text { September } \\
2009\end{array}$ & North sampled \\
\hline July 2014 & South and North sampled \\
\hline
\end{tabular}

Appendix A: Timeline of relevant historical and ecological events for North Azevedo Pond. 




Appendix B: Dendrogram of cluster analysis of benthic infaunal communities 


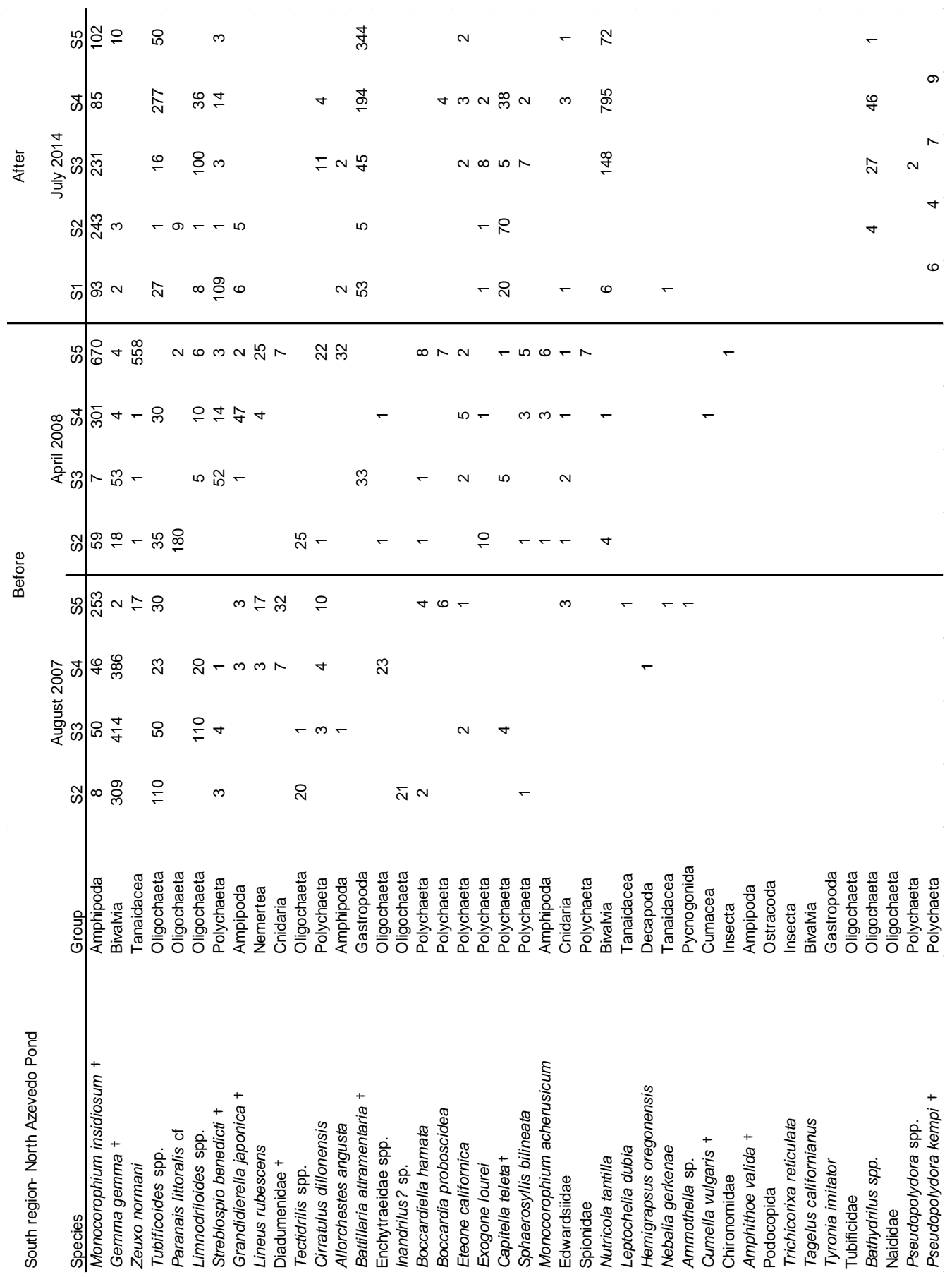

Appendix C: Benthic invertebrates per $.0078 \mathrm{~m}^{2}$ in the south region of North

Azevedo Pond; † denotes non-native taxa 


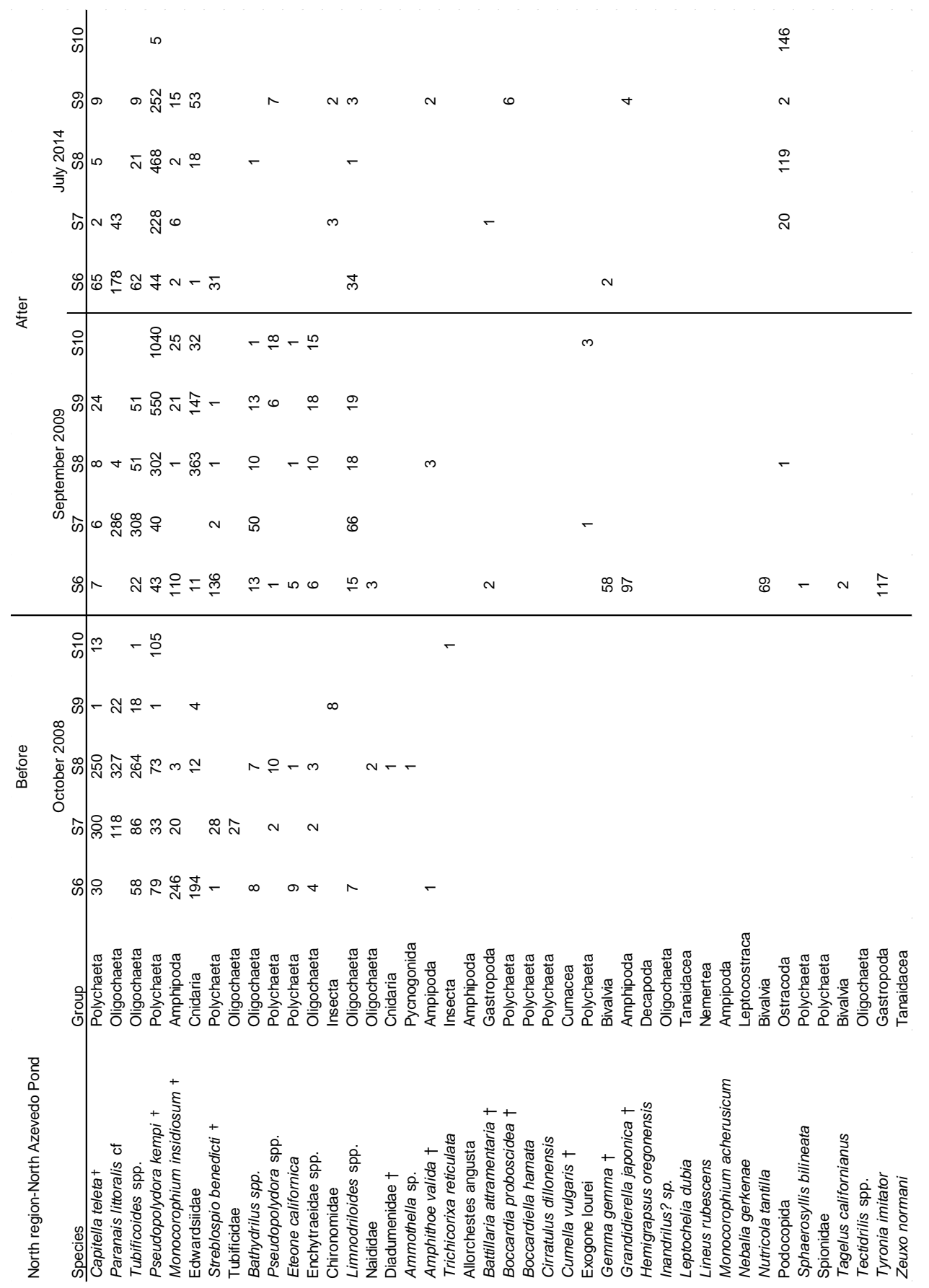

Appendix D: Benthic invertebrates per $.0078 \mathrm{~m}^{2}$ in north region of North Azevedo Pond; † denotes non-native taxa 


\begin{tabular}{l|l|l} 
Site ID & Latitude & Longitude \\
\hline S1 & 36.84609 & -121.75354 \\
S2 & 36.84576 & -121.75358 \\
S3 & 36.84591 & -121.75352 \\
S4 & 36.84605 & -121.75355 \\
S5 & 36.84619 & -121.75370 \\
S6 & 36.84906 & -121.75561 \\
S7 & 36.84850 & -121.75544 \\
S8 & 36.84945 & -121.75545 \\
S9 & 36.84907 & -121.75494 \\
S10 & 36.84948 & -121.75519
\end{tabular}

Appendix E: Site names with corresponding latitude and longitude 


\begin{tabular}{|c|c|c|c|c|}
\hline \multirow[b]{2}{*}{ Grain size factors } & \multicolumn{2}{|c|}{ South } & \multicolumn{2}{|c|}{ North } \\
\hline & $\begin{array}{c}\text { Before } \\
\text { B (n=0) }\end{array}$ & $\begin{array}{c}\text { After } \\
\text { B }(n=5)\end{array}$ & $\begin{array}{c}\text { Before } \\
B(n=3)\end{array}$ & $\begin{array}{c}\text { After } \\
\mathrm{B}(\mathrm{n}=8)\end{array}$ \\
\hline Mean & - & $21.35(4.54)$ & $22.5(3.96)$ & $16.18(3.34)$ \\
\hline SD & - & 13.77 (34.98) & 3.87 (30.12) & $3.63(16)$ \\
\hline Mode & - & $99.34(0.08)$ & $147.37(0.21)$ & $49.81(0.12)$ \\
\hline Clay \% & - & 13.77 (3.43) & 11.22 (2.27) & $19.31(3.78)$ \\
\hline Silt \% & - & $63.87(3.01)$ & $64.68(2.91)$ & $65(1.95)$ \\
\hline Sand \% & - & $22.36(6.31)$ & $24.1(4.88)$ & $15.69(4.53)$ \\
\hline
\end{tabular}

Appendix F: Basal grain size data for sediment core samples 

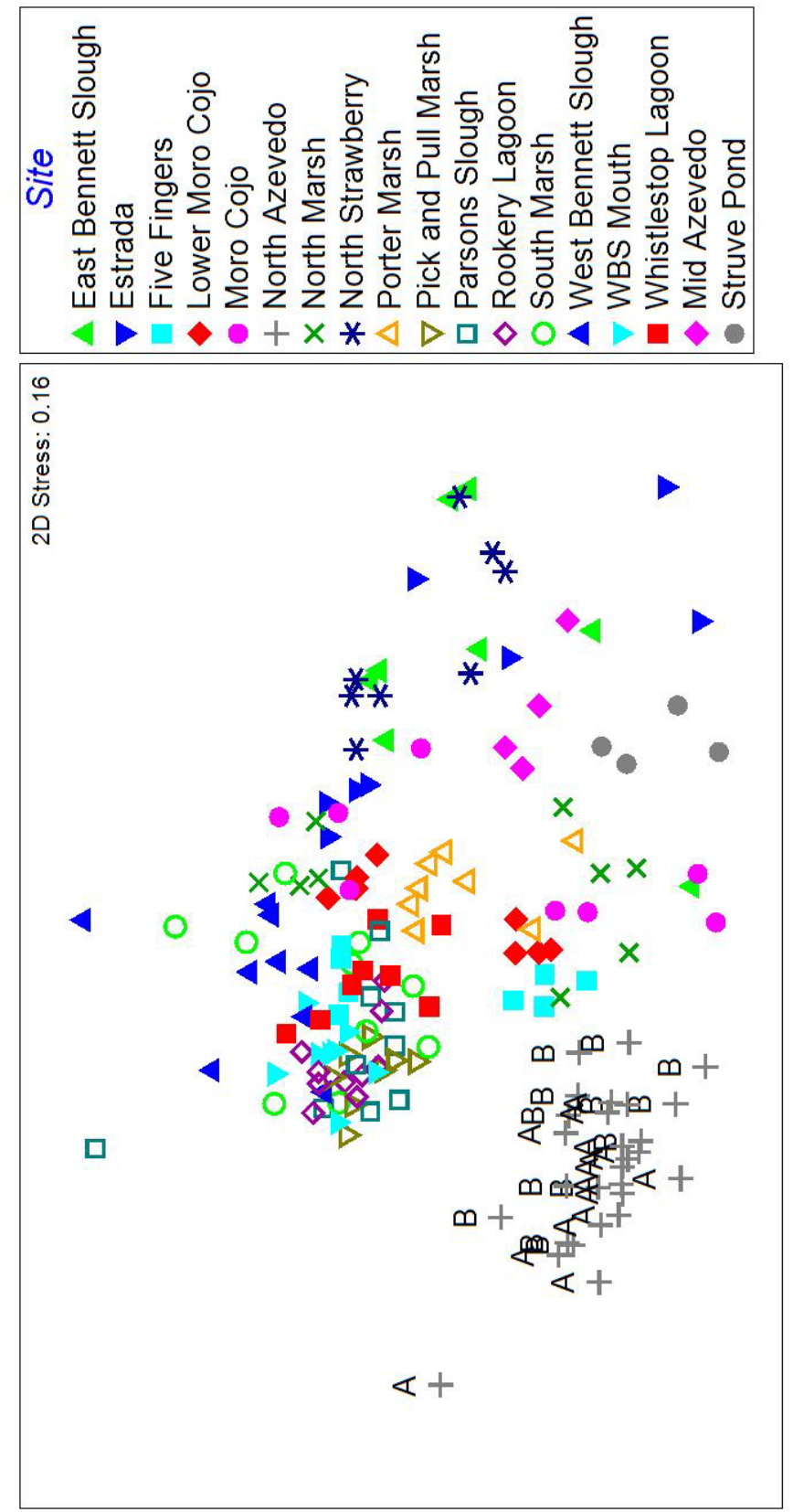

Appendix G: MDS plot of peripheral wetland report data and North Azevedo data; A= After Impact, B=Before Impact 